\title{
AVALIAÇÃO DOS EFEITOS DE DUAS METODOLOGIAS DE FORMAÇÃO ESPORTIVA EM DISTINTOS NÍVEIS DE MATURAÇÃO BIOLÓGICA SOBRE AS QUALIDADES FÍSICAS DE PRATICANTES DE GINÁSTICA RÍTMICA DE 8 E 9 ANOS
}

Doutoramento em Ciências do Desporto

Orientador: Professor Doutor Estélio Henrique Martin Dantas 
MARIA FRANCISCA DE SOUZA BORDALO

\section{AVALIAÇÃO DOS EFEITOS DE DUAS METODOLOGIAS DE FORMAÇÃO ESPORTIVA EM DISTINTOS NÍVEIS DE MATURAÇÃO BIOLÓGICA SOBRE AS QUALIDADES FÍSICAS DE PRATICANTES DE GINÁSTICA RÍTMICA DE 8 E 9 ANOS}


Tese submetida ao Programa de Pós-Graduação Stricto Sensu em Ciências do Desporto da Universidade de Trás-os-Montes e Alto Douro (UTAD), como parte dos requisitos para obtenção do título de Doutor em Ciências do Desporto de acordo com o disposto no Decreto-Lei 107/2008 de 25 Junho. 
Bordalo, Maria Francisca de Souza.

AVALIAÇÃO DOS EFEITOS DE DUAS METODOLOGIAS DE FORMAÇÃO ESPORTIVA EM DISTINTOS NÍVEIS DE MATURAÇÃO BIOLÓGICA SOBRE AS QUALIDADES FÍSICAS DE PRATICANTES DE GINÁSTICA RÍTMICA DE 8 E 9 ANOS. Maria Francisca de Souza Bordalo. Vila Real: [s.n], 2012.

Orientador: Professor Doutor Estélio Henrique Martin Dantas Dissertação (Doutoramento) Universidade de Trás-osMontes e Alto Douro.

PALAVRAS-CHAVE: Ginástica Rítmica. Flexibilidade. Coordenação. Força Explosiva. Crianças. 


\section{DEDICATÓRIA}

Aos meus pais, Lauro e Rosalina, ao esposo Alberto Bordalo e queridos filhos amados, minha princesa Tayana e ao meu príncipe Alberto Henrique, que sempre incentivaram para o meu crescimento profissional, apoiando e compreendendo minhas transformações como educadora. 


\section{AGRADECIMENTO}

À DEUS, obrigado por tudo, pelos anos de estudo cansativos, pelos momentos de desânimo, pela insegurança. Obrigado pelos nossos pais e amigos nestes momentos. Obrigado pelos nossos professores doutores e mestres que souberam mostrar para nós os verdadeiros valores da vida. Obrigado pela sabedoria, pelo desejo de progresso pelas decisões cheias de entusiasmos. Obrigado Senhor!

Ao professor Doutor Estélio Henrique Martin Dantas, meus sinceros agradecimentos, não apenas pela orientação firme e segura demonstrada na elaboração deste trabalho, mas também pelo incentivo, confiança e amizade nesses anos de convivência;

A todos os doutores do curso de Doutoramento em Ciências do Desporto, pelos conhecimentos transmitidos e pela confiança depositada; em especial aos meus queridos amigos Antônio José e Victor Reis.

A amiga Nazaré Portal, pelos momentos de alegria, incentivo, compreensão, e apoio, a traves de nossa amizade durante esses anos de convivência;

A Universidade do Estado do Pará, pela concessão da bolsa de estudo que possibilitou a realização deste trabalho.

A Secretaria de Educação do Estado do Pará, pela liberação para o estudo do curso de doutoramento.

Por fim, agradeço em especial aqueles que sempre me apoiaram incondicionalmente, que apostaram em mim mais do que ninguém e que seguramente são os que mais compartilham da minha alegria: minha amada família. 
ÍNDICE GERAL 
ÍNDICE DE TABELAS 
ÍNDICE DE FIGURAS 
ÍNDICE DE QUADROS 


\section{RESUMO}

Este trabalho teve por objetivo avaliar os efeitos de duas distintas metodologias de formação esportiva, a Tradicional e a Maturacional, sobre as qualidades físicas de meninas praticantes de ginástica rítmica na faixa etária de 8 a 9 anos em diferentes níveis de maturação biológica. Para tal, teve sua amostra de 120 crianças divididas, randomicamente (por sorteio), em seis grupos de 20 crianças, sendo 3 com a idade de 8 anos e 3 grupos com a idade de 9 anos: Grupo de treinamento tradicional (GT); Grupo de treinamento maturacional (GM) e Grupo controle (GC). Estes grupos foram subdivididos em precoce, normal e tardio pela avaliação da maturação biológica por Raio-X de mão e punho, com o aparelho modelo Villa Sistem Medical (Italian) $630 \mathrm{ma}$, utilizando o Protocolo de Greulich-Pyle. Para a avaliação da flexibilidade, da força explosiva e da coordenação foram utilizados os protocolos de LABIFIE (abdução da articulação do ombro e flexão da coluna lombar), o teste de Burpee e o teste de Impulsão Vertical Sargent Jump Test, respectivamente. Os grupos GT e GM realizaram aulas de Educação Física, durante o período de 16 semanas, com frequência de 02 (duas) vezes por semana e com a duração de 45 cada aula, sendo 10 minutos de aquecimento, 30 minutos de parte principal e 5 minutos de volta à calma. O grupo GT, realizou a metodologia de formação esportiva tradicional, que preconiza a aplicação de exercícios de acordo com os elementos técnicos básicos da Ginástica Rítmica, os quais abordam os pivôs, os equilíbrios, as flexibilidades, os saltos e as atividades rítmicas e expressivas, levando em consideração a idade cronológica. O grupo GM, realizou atividades esportivas com ênfase no treinamento da coordenação (psicomotricidade), da resistência muscular localizada e da flexibilidade, em que regras são adaptadas, as competições e os treinos devem ter caráter lúdico, sendo considerada a maturação 
biológica. O GC não recebeu qualquer tratamento especial, a fim de servir como referência padrão às variáveis a que se submeteram os grupos experimentais. $\mathrm{Na}$ análise de dados, além da estatística descritiva foram utilizados os testes de Shapiro Wilk (normalidade), Levene (homogeneidade) e ANOVA seguido do Post Hoc de Tukey (comparações intra e inter-grupos). O nível de significância foi de $p<0,05$. Os resultados revelaram melhora significativa a favor dos grupos experimentais, em ambas faixas etárias, tendo o GM alcançado resultados mais satisfatórios. Além disso, observou-se, também, em relação à divisão pela maturação biológica, a superioridade dos resultados nos subgrupos precoce. O poder do experimento foi de $99 \%$ em todas as variáveis. Desta forma, infere-se que, por causa das mudanças em importantes parâmetros físicos, pela maturação, a seleção de crianças para a prática da Ginástica Rítmica não deve se fundamentar apenas na idade cronológica, mas, sobretudo, na maturação biológica. Esses dados são fundamentados na melhora significativa no GM, quando comparado seus valores no pós-teste e com os demais grupos, levando a recusar a hipótese nula $\left(\mathrm{H}_{0}\right)$ levantada no vigente estudo.

Palavras-chave: Ginástica Rítmica. Flexibilidade. Coordenação. Força Explosiva. Crianças. 


\begin{abstract}
Effects of two methods of sports training at different levels of biological maturation on the physical qualities of practicing rhythmic gymnastics of 08 and 09 years This study aimed to evaluate the effects of two different sports training methodologies, the traditional and maturity on the physical qualities of practicing rhythmic gymnastics girls aged 8-9 years in different levels of biological maturity. To this end, had their sample of 120 children divided randomly (by lottery), in six groups of 20 children, three at the age of eight years and three groups at the age of nine years: traditional training group (TG); Group training maturity (GM) and control group (CG). These groups were subdivided into early and late normal for the assessment of biological maturation by X-ray of hand and wrist, with the device model Sistem Medical Villa (Italian) $630 \mathrm{~m}$, using the Greulich-Pyle Protocol. For the assessment of flexibility, explosive strength and coordination protocols were used LABIFIE (abduction of the shoulder joint and flexion of the lumbar spine), the test and the test Burpee Impulse Sargent Vertical Jump Test, respectively. The groups GT and GM performed rhythmic gymnastics education classes during the period of 16 (sixteen) weeks, with a frequency of 02 (two) times a week and with a duration of 45 (forty five) minutes each lesson, 10 minutes heating, the main part of 30 minutes and 5 minutes cool-down. The TG performed the traditional sports training methodology, which recommends the implementation of exercises according to the National Curriculum, which address sports, games, fights, gymnastics and rhythmic and expressive activities, taking into account chronological age. The GM group, conducted sports activities with emphasis on training of coordination (psychomotor), the muscular endurance and flexibility, where the rules are adapted, competitions and drills should be playful, considering the biological maturation. GC did not receive any
\end{abstract}


special treatment in order to serve as the standard reference to variables that have undergone the experimental groups. In data analysis, and descriptive statistics were used for testing the Shapiro Wilk (normality), Levene (homogeneity) and ANOVA followed by post hoc Tukey's test (comparisons within and between groups). The significance level was $\mathrm{p}<0.05$. The results revealed significant improvement in favor of the experimental groups in both age groups, with the GM achieved more satisfactory results. The experimental power was $99 \%$ in all variables. Moreover, it was observed also in relation to the division by sexual maturation, the superiority of the subgroups early results. Thus, it is inferred that, because of changes in important physical parameters, the maturation, selection of children for physical education should not be based only on chronological age, but especially on biological maturation. These data are based on the significant improvement in GM compared their values in the post-test and the other groups, leading to refuse hipóstese null (H0) raised in the current study.

Keywords: rhythmic gymnastics; flexibility; coordination; explosive strength; children. 
AVALIAÇÃO DOS EFEITOS DE DUAS METODOLOGIAS DE FORMAÇÃO ESPORTIVA EM DISTINTOS NÍVEIS DE MATURAÇÃO BIOLÓGICA SOBRE AS QUALIDADES FÍSICAS DE PRATICANTES DE GINÁSTICA RÍTMICA DE 8 E 9 ANOS

\section{CAPÍTULO I - INTRODUÇÃO}




\section{CAPÍTULO I - INTRODUÇÃO}

A Ginástica Rítmica (GR) é uma modalidade exclusivamente feminina talvez por destacar a leveza e a graciosidade da mulher, que iniciou ainda no começo do século XIX com influências das artes cênicas, dança, música e pedagogia, passou por períodos de estruturação e refinamento até chegar às características na qual possui hoje ${ }^{(1)}$.

Velardi ${ }^{(2)}$ mostra ainda que essa modalidade surgiu a partir das necessidades e capacidades de se educar o corpo como um todo, indo além do aprimorar as habilidades e capacidades físicas.

A Ginástica Rítmica, ou como é reconhecida pela sigla GR, é um esporte que apresenta uma associação entre a técnica do movimento e a arte do movimento ${ }^{(3)}$.

A Arte do movimento na GR pode ser apreciada porque nesse esporte a perfeição dos gestos técnicos se associa à criação artística das composições coreográficas $^{(4)}$, isto é, quando a técnica perfeita e eficiente denota não apenas o virtuosismo, a maestria e a originalidade do movimento da ginasta mas também expressa e comunica ao expectador alguma ideia, mensagem ou emoções.

Assim, a GR, pode ser considerada tanto uma técnica quanto uma arte do movimento. Na GR a técnica e a arte do movimento constituem a unidade que espelha o fenômeno da expressão; expressão que é considerada como fenômeno porque, além de ser percebida pelos sentidos ou pela consciência humana, abrange pela sua melhor compreensão, inúmeras dimensões, dentre estas se destacam a histório-evolutiva e a esportiva.

A GR começou a ser praticada desde o final da Primeira Guerra Mundial, mais não possuía a regras específicas sem nem um nome determinado. Várias escolas inovaram os exercícios tradicionais da Ginástica Artística, misturando-os com as música. Em 1946, na Rússia, surge o termo "rítmica", devido a utilização da música e da dança durante a execução dos movimentos ${ }^{(5)}$.

Segundo Rossete ${ }^{(6)}$, desde a sua sistematização, a GR valoriza um conceito de beleza sustentada pelas características próprias do europeu, principalmente na Alemanha, Bulgária, Rússia e Tcheslováquia, porém com a esportivazação da modalidade, as competições internacionais cada vez mais valorizam também o padrão da beleza e do biotipo longelíneo e ectomorfo. 
$\mathrm{Na}$ atualidade, a GR é uma das manifestações gímnicas com destaque no cenário nacional e mundial, considerando que é uma das três ginásticas que compõem o programa dos Jogos Olímpicos. No Brasil, o Paraná é o local no cenário competitivo nacional e internacional. Assim, é preciso que novos estudos aconteçam, haja vista a necessidade de referencias teóricos que venham subsidiar o treinamento em GR. Para tanto, o estudo priorizou uma das habilidades exigidas na ginástica rítmica que é a flexibilidade, por ser essencial para realização de todos os elementos corporais.

A GR é uma modalidade desportiva essencialmente feminina que se fundamenta na expressividade artística. É conceituada como a busca do belo, uma explosão de talento e criatividade, em que a expressão corporal e o virtuosismo técnico se desenvolvem juntos, formando um conjunto harmonioso de movimento ${ }^{(7)}$.

Essa modalidade possui dimensão expressiva e requer criatividade. Como expressão gímnica, é atividade gímnico-artística que exige da ginasta demonstração de suas qualidades de coordenação e destreza, aliadas à estreita inter-relação entre dinamismo, amplitude e rítmo de movimentos.

A GR é sustentada por uma estrutura trifásica: a execução de elementos corporais, manejo de aparelhos e acompanhamento musical. Pode ser apresentada em coreografias individuais com duração de $1^{\prime} 15^{\prime \prime}$ até 1 ' $30^{\prime \prime}$ ou conjunto com 2 ' $15^{\prime \prime}$ até 2` 30 ”, em uma da área delimitada em 13x13 metros. Os elememtos corporais (pivot, saltos, equilíbrios e flexibilidades) são sempre acompanhados por músicas em sequências apresentados individualmente ou em conjunto de cinco ginastas. Essa modalidade, em caráter competitivo deve obrigatoriedade seguir o Código de Pontuação. As regras para a realização de competições de GR, em qualquer nível, estão definidas no codigo de pontuação de Federação Internacional de Ginástica.

Considerando esse aspecto, conclui-se que a criança deve iniciar na GR por volta de seis anos. Segundo Alonso ${ }^{(8)}$, a GR é um dos esportes privilegiados, que por possui habilidades motoras bem próximas da cultura corporal encontra nas brincadeiras e nos jogos infantis, favorecendo desde os cinco anos de idade possibilitar vivências motoras na GR sem que estejamos iniciando precocemente na habilidade.

O processo pedagógico da GR deve privilegiar os aspectos individuais de exploração da criatividade, de expressividade, de compreensão das estruturas musicais, das formas de manifestação do rítmo de movimento e da compreensão das diversas 
possibilidades de movimentação determinadas pela cultura corporal, que influenciam o meio social e que é parte dele[....] a GR e determinada internamente pelas capacidades fisicas básicas e externamente pelas influencias culturais e sociais.

De acordo com Pallarés ${ }^{(9)}$, na escola, a GR, permite para os alunos de todos os níveis de ensino, por intermédio de programas com conteúdos e lógicos, conduzi-los a uma espontaneidade e flexibilidade de execução e criatividade de movimentos, beneficiando-os com a aquisição de comportamentos e atitudes interiores e exteriores que contribuem para a conquista de um equilíbrio psicomotor, em que pela solicitação efetiva e permanente de uma coordenação sensório-motriz, pela execução de movimentos apoiados em ritmos musicais adequados, há uma grande oportunidade de aperfeiçoar os movimentos rítmicos, o que redundaria em maior rendimento nas tarefas escolares.

Com formação de atitudes internas, a GR oportuniza a aquisição do domínio próprio, na conquista da realização de formas de coordenação rítmica, oportuniza a alegria quando atinge a automatização do movimento pelas repetições, a confiança e segurança no domínio de formas mais complexas, as vivências sociais de cooperação, de companheirismo, de integração de tarefas de grupo, o entrosamento da música e o ritmo origina o desenvolvimento da acuidade auditiva, sensibilidade e gosto pela música, concentração e atenção na utilização temas musicais propostos e prontos reflexo na presteza em realizar coordenações de movimentos rítmicos.

A GR na escola é uma contribuição para o processo educativo, oportunizando o crescimento do educando em suas possibilidades físicas, espirituais, intelectuais e sociais ${ }^{(9)}$.

Ao pensarmos na GR como atividade, reportamos ao trabalho de ${ }^{(1)}$ que desmistifica o esporte buscando torná-los mais próximo da realidade do praticante, oferecendo aos indivíduos possibilidades de vencerem seus próprios limites corporais, imbuídos de prazer, num ambiente de liberdade e movimentos corporais são criados, construídos a parte das crianças, com incentivo e orientação do professor. Proporcionar oportunidades à criança, identificar diferentes formas de colocar o corpo no solo, produzindo assim os conhecidos movimentos acrobáticos e pré-acrobáticos.

A GR trabalhada como atividade tem caráter formativo com a finalidade de desenvolver as habilidades motoras por meio de seus movimentos. Há maior 
preocupação com o processo de aprendizagem do que com o produto e a perfeição do movimento final; as atividades são realizadas se forma lúdica e espontânea; uma forma de ginástica voltada para todo tipo de praticante, em que a individualidade é valorizada e o próprio ritmo de desenvolvimento é respeitado, em que não existe movimento errado, na qual objetivo é experimentar, explorar, criar e desafiar as leis da física, desenvolver um domínio do corpo para torná-lo funcional e eficiente nas diferentes situações do dia-a-dia ${ }^{(10,11)}$.

A essa proposta a autora atribui o nome de "GR popular", que tem como permitir que o lúdico apodere-se das atividades propostas e o ritmo deve ser constantemente explorado e cultivado em atividades motoras diversas.

Trabalhando a GR como esporte, há inevitavelmente o caráter competitivo e a finalidade é desenvolver as habilidades específicas com alta precisão técnica e que atenda ao grau de exigência do código de pontuação, ou seja, as regras da modalidade. A expectativa é de um movimento tecnicamente perfeito e ao contrário da GR como atividade a ênfase está no produto final. Dessa forma, percebemos que ela não está ao alcance de todos, pois se torna uma forma de ginástica extremamente elitista, cabendo aos mais talentosos e para aqueles que este desejo de dedicarem inúmeras horas de treinamento para atingirem o máximo de perfeição e precisão nas complexas habilidades da modalidade ${ }^{(11)}$.

O crescimento do esporte é um fenômeno mundial ${ }^{(12)}$ que vem repercutindo em todas as esferas da sociedade. Devido à diversidade de opções de práticas esportivas, pais e filhos podem ficar indecisos sobre o que praticar, quando iniciar e quando competir.

A GR pode contribuir para a formação esportiva geral, pois estimula as capacidades físicas e motoras, que também são importantes para a prática de outras modalidades esportivas.

A iniciação esportiva acontece quando a criança passa a praticar regularmente uma determinada modalidade, aprendendo sobre suas regras e técnicas de movimento orientada por um profissional, na qual irá desenvolver suas habilidades básicas sem que com isso tenha-se o objetivo de visar o rendimento da criança em competições. Oliveira e Paes ${ }^{(13)}$, relatam por meio de suas pesquisas que a iniciação esportiva tem plena contribuição para a formação de cidadãos ocasionando diversos benefícios para a 
criança, e reforça o conceito de que o objetivo não é de forma alguma a revelação de campeões.

Sabemos que essa iniciação na prática de exercícios físicos tem extrema importância no processo de maturação de cada indivíduo, porém saber dosar a quantidade correta quando há o envolvimento de crianças dentro de um esquema de treinamento periodizado é uma tarefa bastante trabalhosa. Assim, quando ocorre essa mudança de conceito da iniciação para o aprimoramento de movimentos específicos, entra em cena a especialização esportiva precoce. Especialização precoce no esporte inicia-se quando a criança é introduzida a um treinamento planejado e de longo prazo, aumentando a carga de atividades para um aumento de rendimento antes da fase pubertária, além de participações periódicas em competições" (14).

Dessa maneira, a especialização acaba tomando frente de um plano de ensino que a princípio visaria apenas à introdução da criança em uma nova modalidade deixando para trás uma aquisição de novas habilidades motoras, passando a enfatizar o aprimoramento de habilidades específicas da modalidade que essa criança pratica, correndo o risco de submetê-la a um treinamento não condizente à sua faixa etária ${ }^{(15)}$.

Com isso, deixamos claro que o futuro da criança dentro da GR depende principalmente de uma iniciação esportiva aplicada e vivenciada de forma correta, sem a transposição das etapas de ensino-aprendizagem, na qual a criança possa se sentir a vontade, sem sofrer pressões vindas dos técnicos, pais ou até mesmo da mídia, no momento errado.

A GR como desporto é uma pratica que exige muito de seus atletas deixando subtendido aos espectadores a necessidade do treinamento elevado para a obtenção de resultados expressivos. Assim, é muito fácil que quem esteja de fora considere os treinamentos como sendo algo desumano ou exagerado, fora dos conceitos e padrões considerados adequados, deixando clara a necessidade do técnico de respeitar os limites da faixa etária de cada atleta, sabendo trabalhar de modo a evitar todos os riscos decorrentes da especialização precoce.

Porém pode haver uma inversão dessa situação quando a cobrança pela a excelência das crianças se dá por parte dos pais, que exige dos técnicos que transformem seu, filhos em campeões, refletindo essa ideia para a criança que cobra-se de forma não saudável. A dedicação exagerada do atleta no esporte de alto nível pode 
afeta negativamente o desenvolvimento da personalidade das crianças, como por exemplo: auto valorização exagerada, fixação a motivação do rendimento, medo do fracasso, estresse psíquico, instabilidade emocional e isolamento social ${ }^{(16)}$.

Devemos levar em conta que um profissional de educação física lida com vidas humanas, e atitudes equivocadas nos treinamentos pode gerar danos catastróficos na vida da criança tanto no contexto físico com quanto no psicológico. A responsabilidade sobre a criança não pode recair somente sobre o treinador, mas também sobre todas as pessoas do seu círculo social que incentivam ou influenciam em sua vida.

Todas as atitudes que a criança venha a tomar na sua carreira esportivo de certa forma, são um reflexo do que ela passou ao se iniciar no esporte, e no apoio que teve de seus familiares e treinadores. Se a iniciação aconteceu muito cedo e acabou transformando a especialização precoce, a probabilidade de ela desenvolver problemas de ordem física e psicológica é eminente, tendo como uma das consequências o abandono da prática esportiva.

A prática inadequada da modalidade, as cobranças vindas de modo exagerado e intenso e o medo do fracasso ocasionado pela pressão decorrente da busca do êxito, pode fazer com que a criança se desestimule, perdendo o interesse pela prática (tanto da GR quanto de qualquer outra modalidade, pois os aspectos citados que se referem aos riscos relacionados à especialização precoce podem ser direcionados a esse tema de uma forma geral).

Com uma iniciação correta e cargas de treino apropriadas para cada faixa etária a criança pode obter sucesso no contexto esportivo sem que isso esteja vinculado a consequências desastrosas em seu desenvolvimento que podem acompanhá-la durante toda sua trajetória dentro e fora do esporte. 
AVALIAÇÃO DOS EFEITOS DE DUAS METODOLOGIAS DE FORMAÇÃO ESPORTIVA EM DISTINTOS NÍVEIS DE MATURAÇÃO BIOLÓGICA SOBRE AS QUALIDADES FÍSICAS DE PRATICANTES DE GINÁSTICA RÍTMICA DE 8 E 9 ANOS

\section{CAPÍTULO II - OBJETIVOS}




\section{CAPÍTULO II - OBJETIVOS}

\subsection{OBJETIVOS DO ESTUDO}

Devido às características do presente estudo tornou-se possível o estabelecimento de um objetivo geral e dois objetivos específicos.

\subsubsection{OBJETIVO GERAL}

O objetivo do presente estudo foi avaliar os efeitos de duas distintas metodologias de formação esportiva: a tradicional e a maturacional, sobre as qualidades físicas de meninas praticantes de GR na faixa etária de 8 a 9 anos em diferentes níveis de maturação biológica.

\subsubsection{OBJETIVOS ESPECÍFICOS}

Os objetivos específicos, tal como concebidos no presente estudo, serviram de base para a elaboração das hipóteses que foram testadas. Constituem-se em:

1. Avaliar o efeito de duas distintas metodologias de formação esportiva, a tradicional e a maturacional, sobre a força explosiva e a coordenação motora de meninas praticantes de GR na faixa etária de 8 a 9 anos em diferentes níveis de maturação biológica.

2. Avaliar o efeito de duas distintas metodologias de formação esportiva: a tradicional e a maturacional sobre a Flexibilidade de meninas praticantes de GR na faixa etária de 8 a 9 anos em diferentes níveis de maturação biológica. 


\subsection{HIPÓTESES}

As hipóteses serão apresentadas em forma de substantiva e serão explicitadas nas suas formas nula e derivadas.

\subsubsection{HIPÓTESE SUBSTANTIVA}

Hs - O presente estudo antecipa que distintas metodologias de formação esportiva, a tradicional e a maturacional, acarretarão efeitos diferenciados sobre as qualidades físicas de meninas praticantes de GR a na faixa etária de 8 a 9 anos em diferentes níveis de maturação.

\subsubsection{HIPÓTESE NULA}

H0 - Não ocorreria diferença significativas, para $p<0,05$, no desenvolvimento de qualidades físicas em meninas praticantes de GR na faixa etária de 8 a 9 anos, em diferentes níveis de maturação, quando submetidos a duas metodologias de formação esportiva: a tradicional e a maturacional.

\subsubsection{HIPÓTESES DERIVADAS}

$\mathrm{H}^{1}$ - Ocorreria diferença significativa, para $\mathrm{p}<0,05$, no desenvolvimento da força explosiva e da coordenação motora em meninas praticantes de GR na faixa etária de 8 a 9 anos, em diferentes níveis de maturação,quando submetidasa duas distintas metodologias de formação esportiva: a tradicional e a maturacional.

H2 -Ocorreria diferença significativa, para $\mathrm{p}<0,05$, no desenvolvimento da flexibilidade em meninas praticantes de GR na faixa etária de 8 a 9 anos, em diferentes níveis de formação esportivs: a tradicional e a maturacional 
AVALIAÇÃO DOS EFEITOS DE DUAS METODOLOGIAS DE FORMAÇÃO ESPORTIVA EM DISTINTOS NÍVEIS DE MATURAÇÃO BIOLÓGICA SOBRE AS QUALIDADES FÍSICAS DE PRATICANTES DE GINÁSTICA RÍTMICA DE 8 E 9 ANOS

\section{CAPÍTULO III - REVISÃO BIBLIOGRÁFICA}




\section{CAPÍTULO III - REVISÃO BIBLIOGRÁFICA}

Para uma melhor compreensão e esclarecimento, a metodologia adotada nesta pesquisa será apresentada nos subitens, a seguir: 3.1) Histórico da Ginástica Rítmica 3.2) A Ginástica Rítmica 3.3) Maturação Biológica e 3.4) Qualidades Físicas.

\subsection{HISTÓRICO DA GINÁSTICA RÍTMICA}

A Técnica do movimento que caracteriza a GR como esporte é uma combinação harmoniosa coordenada entre elementos corporais e manejo de aparelhos corda, arco, bola, maças e fita. Essas combinações devem ser encadeadas em uma sequência coreográfica denominada série, individual ou de conjunto, e que espelha o nível de qualidade de execução e o grau de dificuldade praticada por quem a executa, a ou as ginastas, e constitui um critério de apreciação tanto para os árbitros quanto para os expectadores dessa modalidade esportiva ${ }^{(1)}$.

Segundo o Código de Pontuação da FIG ${ }^{(17)}$, a coreografia está caracterizada por uma ideia guia realizada por um discurso motor unitário, do início ao fim, com a utilização de todos os possíveis movimentos do corpo e do aparelho. As ginastas são as intérpretes dessa unidade indivisível: elementos corporais-aparelhos-música que caracterizam a GR.

Esta unidade também denominada de triologia da $\mathrm{GR}^{(18)}$ quando unida ao belo e ao estético, possibilita a GR transcender o seu status de esporte e ser também considerada com arte: arte do movimento.

A dimensão histórico-evolutiva diz respeito à origem e à evolução do esporte $\mathrm{e}$ da expressão do esporte e, a dimensão esportiva permite analisar no esporte, nas normas e na literatura específica da GR o que é tratado como expressão nessa modalidade. Essas dimensões serão abordadas, a seguir, para desvelar os interessados, estudiosos e praticantes desta modalidade esportiva o fenômeno da expressão na GR, a partir dessas perspectivas.

O fenômeno da expressão na GR será analisado por meio da expressividade dos seus movimentos desde a sua origem, com sistematização de Rudolf Bode, até a atualidade. 
A GR é fruto de um movimento renovador ginástico, que se processou em fases de lenta evolução, desde o início do século XIX, e que recebeu significativas contribuições das ideias humanísticas, que estavam presentes nas diferentes áreas do conhecimento humano e na evolução dos movimentos artísticos ${ }^{(19)}$.

As ideias renovadoras humanísticas, que permeavam o pensar ocidental moderno, foram decorrentes da época da renascença e compreendeu historicamente o período entre os fins do século XIV e o final do século XVI. O Humanismo é um momento de transição que se inicia na cultura medieval e se solidifica no renascimento. Durante a cultura humanista, o ser humano passa a ser considerado o centro do universo, procura a felicidade e a perfeição para si e seu semelhante e restabelece a sua totalidade corpo e espírito; está nova posição do homem diante a realidade vai determinar uma nova visão do mundo e as grandes mudanças sociais, políticas e culturais que caracterizaram o período do Renascimento ${ }^{(20)}$.

Dessa forma, as grandes transformações sociais, políticas e culturais, que ocorreram no período do Renascimento, devido à cultura humanística, vão eclodir nas ideias renovadoras do início do século XIX e determinar, assim, as mudanças radicais que levaram ao mundo moderno ${ }^{(20)}$.

O movimento renovador ginástico, na Educação Física, é caracterizado pela valorização dos movimentos naturais e globais que eram desenvolvidos, objetivando a totalidade do homem - corpo e espírito, em oposição aos movimentos construídos e segmentares que visam apenas à parte física ${ }^{(21)}$.

A GR faz parte desse movimento renovador ginástico, sendo que inúmeros foram os precursores e sucessores que a influenciaram e modificaram, contribuindo, assim, para a sua sistematização e desenvolvimento que levaram e atuaram em distintos momentos históricos, suas obras serão apresentadas procurando-se estabelecer, nas suas contribuições à GR e à Ginástica Moderna, a relação com o caráter expressivo da GR.

Jean Basedow (1723-1790), alemão, foi professor e em 1711 fundou em Dessau, o "Filantropinum" . No programa educativo dessa escola, colocou em prática a filosofia naturalista do filósofo francês Jean Jacques Rosseau (1723-1778) e os exercícios físicos, naturais passaram a contribuir parte essencial de um plano harmônico, integral: corpo e espírito. 
Nascia, assim, o movimento renovador Ginástico: a ginástica natural, e com ela a expressividade espontânea e natural dos gestos gímmicos ${ }^{(22-24)}$. Essa ginástica foi sofrendo, paulatinamente, modificações da própria área da Educação bem como contribuições de outros movimentos renovadores que ocorreram nas artes da dança, teatro e da música. As influências mais importantes serão apresentadas, a partir dos seus contribuidores.

Jean George Noverre (1727-1809/1810) foi um revolucionário da dança, que procura devolver no bailarino sua condição de meio expressivo e diminuir, na dança, a sua artificialidade aproximando-a da natureza. Foi influenciado também pelas ideias de Rosseau, publicou, em 1759, cartas sobre a dança e o ballet, definindo o ballet de ação como:

Portando, para Noverre, a dança não era simplesmente uma técnica virtuosa, mas também um meio de comunicação. Noverre influencia, mais tarde seus sucessores Duncan e Laban, na dança, que permitiram a dança clássica ultrapassar o limite da técnica pura e ao bailarino usar o seu virtuosismo, como meio para expressar as experiências humanas, suas idéias e suas emoções ${ }^{(24)}$. Esse caráter expressivo dos movimentos poderá ser notado, posteriormente já na Ginástica Moderna, no século XX, influenciada, principalmente, pelas obras de Laban.

Heiarilld Pestalozzi (1746-1827), suíço, pedagogo, afirmava que caberia à Educação Física o desenvolvimento do indivíduo, na sua totalidade corpo e espírito, por intermédio de exercícios naturais, pois a criança tem necessidade instintiva e natural do movimento, sendo que a própria natureza lhe dá as condições para que possa se mover, não apenas como o seu corpo, mas também com seu espírito ${ }^{(23,24)}$. As ideias de Pestalozzi dão mais força ao desenvolvimento da ginastica natural e ao caráter expressivo espontâneo dos movimentos, mais tarde observados no método da Ginástica Rítmica de Ruldolf Bode.

François Delsarte (1811-1871), francês, atuou brevemente como ator no teatro Ópera Cônica, após, sentindo-se com vocação e capacitado para ensinar, ministrou aulas de eloquência e arte dramática. Os objetivos de Delsarte, nessa função de docente, aspecto relacionado a arte dramática, era lavar o ator a usar todo o seu corpo e não apenas o seu corpo e não apenas o seu rosto e sua fala, para poder comunicar com mais intensidade ao público os estados de espírito e as situações que estavam representando. 
O estudo feito por Delsarte surgiu da paixão que possuía pelos gestos corporais como forma de linguagem expressiva. Ele criou uma série de gestos, em relação à exteriorização das emoções. O seu sistema de exercícios não tinha a pretensão de se tornar um método ginástico, mais mesmo assim, ficou conhecido como ginástica expressiva, que apresentava duas qualidades novas ao movimento: a beleza e o caráter expressivo e interpretativo dos movimentos ${ }^{(23)}$.

As ideias de Delsarte foram levadas aos Estados Unidos pela a americana Genevieve Stebbins, sua aluna, que modificou seu sistema de exercícios, dando uma nova interpretação às suas ideias: a ginástica respiratória. Hedwing Kalmeyer, aluna de Stebbins, se estabeleceu na Alemanha em 1908 e por intermédio do seu Instituto de Cultura Expressiva e corporal, fundado em 1909, propagou os movimentos naturais de sua professora, como meio expressivo das aspirações estéticas e da vida emocional ${ }^{(22,}$ 24, 25).

A obra de Delsarte vai influenciar, indiretamente, a Ginástica Rítmica, através de Kalmeyer que, além de suas contribuições pessoais, trazia as interpretações norteamericanas: o sistema de Delsarte, ou seja, um método eficaz para uma expressão artística graciosa. O trabalho de Delsarte teve grande influência na Europa, tanto para o desenvolvimento da dança moderna, quanto para o da Ginástica Moderna ${ }^{(22-24)}$.

Isadora Duncan (1878-1920), americana, a bailarina dos pés descalços, legou à dança não uma técnica nova, mas sim um caminho para o futuro: a dança moderna. A dança, para Isadora, era uma arte de libertação corporal e social, pois, por meio dela, poderiam ser expressas não apenas as idéias e as emoções pessoais, como também o pulsar de uma sociedade. A libertação pessoal, para Duncan, é voltar à natureza, aos fenômenos naturais, é buscar nestes os seus movimentos e ritmos, para poder dançá-los com corpo e alma. A obra de Ducan, na qual os movimentos livres e naturais eram utilizados também como meio de expressão pessoal, teve repercussão na dança e nas experiências pedagógicas-musicais de Jacques Dalcrose, que influenciou, diretamente, Ruldolf Bode ${ }^{(22-24)}$.

Emile Jacques Dalcroze (1865-1950) austríaco, músico, professor de solfejo e harmonia no conservatório de Genebra, elaborou um sistema de GR, denominado de eurritmia, um sistema educativo para ensinar a música por intermédio do movimento ${ }^{(22,}$ 24, 26). Esse método era uma espécie de solfejo corporal e musical, que possibilitava 
analisar e corrigir essas dificuldades musicais apresentadas por seus alunos, por meio das manifestações psicofísicas dos movimentos corporais ${ }^{(22,24,27)}$.

A música era a base da rítmica; o aluno deveria primeiro sentir e marcar a música, com movimentos simples, para que, depois de a ter estudado e incorporado, a devolvesse ao espaço, de acordo com o seu temperamento, por meio de gestos naturais, convencionais ou improvisados, dessa maneira, Dalcroze uniu os conhecimentos científicos de ordem fisiológica e psicológica aos da arte da música e a do movimento, sendo que é nesta última, que Langlade \& Langlade ${ }^{(22,24)}$ relacionam as influências de Duncan na obra de Dalcroze.

As repercussões da obra de Dalcroze foram diretas na GR, pois Rudolf Bode, seu aluno, foi influenciado pelo valor das atividades rítmicas de suas possibilidades educativas. O comportamento motor expressivo recebeu por intermédio de Dalcroze, duas contribuições: o movimento expressivo e natural, possivelmente de influência de Isadora Ducan e a música, que foi utilizada por Bode, como meio para a evocação eo domínio dos movimentos ${ }^{(22,24,26)}$.

A GR de Bode e Medau, dessa forma, foi influenciada por essas contribuições que imprimiram ao caráter expressivo de seus movimentos dois aspectos distintos: o aspecto expressivo natural, espontâneo dos movimentos do ser humano e o aspecto expressivo-artístico, interpretativo da arte do movimento.

A GR de Bode era um método ginástico constituído de movimentos naturais, denominados a mãos livres; esses exercícios eram executados com acompanhamento musical que tinha por objetivo sensibilizar o aluno para a execução, o domínio e a criação de novos movimentos. Os aparelhos bastão, bola, medicine-ball e tamborim foram utilizados, bem posteriormente, apenas como complemento do trabalho a mãos livres.

Henrich Medau, aluno de Bode, desvincula-se de seu professor, após alguns anos de trabalho e cria sua própria escola. Medau ofereceu novas contribuições à GR de seu mestre, dentre as quais se destaca-se a utilização de aparelhos manuais como a bola, a maças, e o Arco que se constituíram em um novo procedimento, para a obtenção dos movimentos rítmicos fluentes e totais ${ }^{(22,24)}$.

A GR, sistematizada por Ruldof Bode em 1911 e modificado por um Medau a partir de 1939, recebeu da Educação Física, da pedagogia e das artes da música, da 
dança e do teatro o seu caráter rítmico, estético e expressivo. Essas formas ginásticas tiveram repercussão na Alemanha e no cenário internacional, com a difusão em diversos países, escolas de ginástica e institutos de Educação Física começaram a desenvolvê-la, porém, cada um com sua própria interpretação dos métodos ${ }^{(19,24)}$.

Segundo Langlade \& Langlade ${ }^{(24)}$, essa ginástica, que antes era desenvolvida apenas como caráter educativo, passa a ser executada também com um outro objetivo, o de demonstrações; essas evoluíram para uma forma competitiva que, segundo Jacquot (1980), teve início em 1948 na União Soviética, que organizou uma competição interna de Ginástica Artística, como era chamada dessa forma pelos países do leste europeu, pois a consideravam como uma arte de expressão pessoal por meio do movimento ${ }^{(21)}$.

Em 1952, foi fundada em Viena a liga Internacional de Ginástica Moderna (LIGIM) que, de acordo com um critério rítmico, estético e expressivo, denominou de Ginástica Feminina Moderna, todas essas interpretações ginásticas originadas da escola de Bode e Medau. A LIGIM tinha por objetivo estudar e difundir as bases da Ginástica Feminina Moderna, assim como promover demonstrações e organizar competições entre as suas escolas filiadas ${ }^{(12,24,28)}$. Diversas foram as apresentações e competições ocorridas a partir 1948, tanto em nível nacional com apresentações e competições internas em cada país, e com apresentações internacional, organizadas pela LIGIM e pela FIG, que reconheceu a GR como atividade esportiva, todavia associada a provas de Ginástica Artística e a denominou, em 1960, de Ginástica Moderna. Em 1962, a FIG, que reconhece, finalmente reconhece, a Ginástica Moderna como uma modalidade esportiva independente, aprovando o I Campeonato Mundial de Ginástica Rítmica Moderna que foi realizado em 1963 na Hungria, na cidade de Budabeste. A partir dessa data até hoje, esse Campeonato Mundial é organizado de dois em dois anos ${ }^{(5,17)}$.

De acordo com Crause (1984), a GR sofreu, desde seu reconhecimento até a década de 80, diversas modificações referente à definição e caracterização do trabalho a mãos livres, inclusão e determinação dos aparelhos oficiais, determinação dos tipos de provas, especificação de normas para a elaboração, acompanhamento musical e julgamento das séries; até mesmo quanto à sua denominação, houve modificações, tendo sido reconhecido oficialmente, a partir de 1975, como Ginástica Rítmica Desportiva. Segundo Santos (2004) a atual Ginástica Rítmica Desportiva (GRD); atualmente é denominada somente como Ginástica Rítmica. 
Dessa maneira, por intermédio da retrospectiva histórica da antiga GRD, o que se pode constatar até este momento é que o caráter expressivos dos movimentos desse esporte, sua expressão, apresenta distintas características.

No período de sistematização da Ginástica Rítmica (1911) até a evolução desse movimento ginástico para uma forma de movimentos técnicos, objetivando demonstrações e competições (1948) bem como no período que antecede o seu reconhecimento como esporte pela FIG (1963) a expressão na GR é mais detonada através de movimentos naturais e auto-expressivos (espontâneos) do que por um caráter interpretativo e artístico por meio de movimentos criativos e estilizados.

No período de 1963 até o final da década de 80, a expressão na GR vai aos poucos perdendo seus movimentos mais naturais e auto-expressivos (espontâneos) e acentuando, nos movimentos, um caráter mais interpretativo e artístico, tendendo a exteriorizar estados internos mentais ou emocionais devido à forte influência da Escola Búlgara mas, ao mesmo tempo, espelhando também o virtuosismo da clássica Escola Russa.

A partir da década de 90 até a atualidade (2005), essa união entre a técnica e a arte do movimento é simultaneamente associada e detonada no discurso motor unitário das composições coreográficas, ou seja, o virtuosismo, a maestria, a originalidade evidenciam não apenas uma plasticidade estética como também comunicam estados subjetivos mentais e/ou emocionais por meio da utilização dos inúmeros recursos que as composições podem apresentar: corpo, movimento, aparelhos, música e ocupação espacial - deslocamentos, planos e formações( séries de conjunto) e mesmo a própria vestimenta das ginastas porque este todo compõe o esporte e o espetáculo da GR.

No entanto, segundo Santos ${ }^{(18)}$, esta associação entre a técnica e a arte do movimento vem sendo progressivamente, desde o final do milênio até a atualidade, limitada ou delimitada pela tendência que caracteriza a GR, aumento das exigências e níveis das dificuldades dos elementos corporais e dos aparelhos nas composições coreográficas devido às modificações das normas do Código de Pontuação da FIG.

A GR é um esporte, na área de competição para a equipe de arbitragem; para o público é o esporte-espetáculo, ultrapassa a dimensão esportiva é a Arte do movimento que encanta e comove. 
Róbeva e Rankévola ${ }^{(29)}$ duas especialistas do mundo na GR, afirmam em sua obra, o que já dizia a elas Juliet Somânova "ouvi o público, ninguém pode ser melhor avaliador". As autoras relatam que na elaboração de suas composições para o esporte, para o julgamento das séries, elas também se preocupavam com os pormenores porque “chega-se àquele ponto que comoverá o público e permanecerá na memória"; preparavam as suas ginastas para mostrar o sentimento de aproximação com o aparelho e ao mesmo tempo, executar os movimentos mais difíceis com leveza e satisfação, pois, o público não deseja ver a tensão e sim precisa sentir a alegria da ginasta alheia aos seus esforços porque como Róbeva e Rankélova (29) “exibimos, não exercitamos”.

A GR desde sua origem teve como essência os movimentos expressivos, a estética e o belo, isto é, a arte do movimento. Segundo Barbosa ${ }^{(30)}$, a mesma plasticidade dos movimentos rítmicos da ginástica que data no início do século XIX, atualmente, ainda se encontra presente de forma mais ampla e diversificada, ou seja, a técnica e a beleza destes movimentos estão um pouco mais evidenciados.

A tendência natural de qualquer esporte, em sua evolução, é alterar as regras de acordo com nível técnico apresentado por seus praticantes mas, no caso da GR como em outros esportes (nado sincronizado e a patinação artística) em que a arte do movimento também se faz presente e caracteriza o belo e o estético destas modalidades ${ }^{(3)}$.

Em 1961, alguns países do leste Europeu organizaram o primeiro campeonato internacional da modalidade. No ano seguinte, a Federação Internacional de Ginástica (FIG) reconheceu a Ginástica Rítmica (GR) como um esporte. A partir de 1963, começaram a ser realizados os primeiros campeonatos mundiais promovidos pela FIG. A maior parte dos aparelhos utilizados atualmente foram introduzidos nessa competição,com a execução da fita e das maças. Em 1984, a GR foi reconhecida pelo Comitê Olímpico Internacional e introduzida nos Jogos Olímpicos daquele ano. No entanto, as melhores ginastas do mundo, provenientes dos países do Leste Europeu, não participaram da competição devido ao boicote liderado pela antiga União Soviética ${ }^{(5)}$.

\subsection{A GINÁSTICA RÍTMICA}

A GR, segundo Lafranchi ${ }^{(7)}$, é uma modalidade esportiva essencialmente feminina que requerer um alto nível de desenvolvimento das qualidades físicas, 
objetivando, a perfeição técnica da execução de movimentos corporais complexos associados a um controle exímio de aparelhos. Para se alcançar resultados expressivos na GR, seu treinamento requer um árduo empenho desde as categorias de base. Como em todos os esportes, prognosticar e diagnosticar de forma mais precisa possível, as possibilidades de alto desempenho das iniciantes na GR poupará tanto para os técnicos quanto para as próprias ginastas, investimentos desnecesários e frustações futura. $\mathrm{O}$ prognóstico de desempenho de ginastas iniciantes realizado sem critérios científicos aumenta significativamente as chances de erro.

A GR é uma modalidade esportiva exclusivamente feminina, cuja disputa é realizada por meio da apresentação de uma composição coréografica acompanhada de música, na qual se combinam movimentos ginásticos, rítmicos e artísticos que exigem elevada coordenação motora, alto grau de percepção espacial, grande capacidade rítmica, níveis excelentes de flexibilidade, força, impulso, agilidade e ótima postura ${ }^{(31)}$.

A GR, como toda a modalidade esportiva, possui valências físicas específicas que devem ser trabalhadas durante todo o período de treinamento.

A flexibilidade é uma das principais qualidades físicas da GR. Segundo Weineck (32), é conhecida como a capacidade de um atleta executar movimentos de grande amplitude ou sob forças externas ou ainda que requeiram a movimentação de muitas articulações.

A coordenação representa a capacidade de resolver de maneira rápida e econômica as tarefas motoras em situações previsíveis ou não, que estão ligadas principalmente às ações esportivas e no caso da GR, torna-se fundamental para a execução de praticamente todos os movimentos.

Para Laffranchi ${ }^{(7)}$, o ritmo é explicado por um encadeamento de tempo das execuções dos movimentos e está diretamente ligado ao sistema nervoso e sua relação com a GR perpassa para além do próprio nome.

O equilíbrio é definido por Gallahue ${ }^{(33)}$,como uma habilidade de um indivíduo manter a postura de seu corpo inalterada, mesmo quando este é colocado em vários posições.A agilidade representa a capacidade de executar movimentos rápidos e como mudanças de direção ${ }^{(34)}$. 
A força explosiva ou potência, segundo Shimiditbleicher ${ }^{(35)}$, refere-se à possibilidade do sistema neuromuscular produzidir o maior impulso possível num determinado período de tempo.

Ressistência é a capacidadede manter a atividade física de maneira eficiente e prolongamento chegando até o estado de fadiga ${ }^{(7)}$.

Assim, as qualidades físicas bem desenvolvidas e treinadas as ginastas, também devem possuir um padrão estético que a modalidade também exige.

Meninas longilíneas, com baixo peso e com pernas e braços longos são padrões exigidos na modalidade. Essa seleção se dá não apenas pelo fato de que, aquelas com maior massa corporal tenham maior dificuldade em executar os elementos corporais e com aparelhos da GR, mas também por uma questão de estética nas apresentações. Meninas magras e altas são visualmente mais belas apresentando que brevilíneas e com um maior acúmulo de gordura corporal.

Pode-se afirmar então, a ginástica teve sua origem na expressividade e harmonia entre o corpo, rítmo e técnica. Resultado dessa integração é o que vemos no dia de hoje estampados nos movimentos de beleza e plasticidade da GR.

Nos elementos corporais ou habilidades motoras específicas de GR chamadas de dificuldades corporais estão envolvidos: os saltos, os equilíbrios, os pivôs e a flexibilidades e ondas, sendo que abordaremos neste estudo o salto suas variações, para que se possa, através de uma análise de força explosiva e salto vertical, conseguir transportar parâmetros para a GR.

A criança deve iniciar na GR por volta dos seis anos de idade e pode iniciar quando se trabalha o lado da aprendizagem motora, no âmbito da descoberta de movimentos, a exploração dos movimentos ginásticos. Também para Gallahue e Ozmun (33), as crianças possuem um potencial desenvolvimentista para está no estágio maduro da maior parte das habilidades motoras fundamentais.

O trabalho da GR baseia em seis formas básicas de movimento: molejar,impulsionar, andar, correr, saltitar e saltar. Estas apresentam característica dinâmicas com lançar, aparar, quicar, saltitar, beter, andar, balancear, rolar, correr etc. (7). 
Segundo Tibeau (36) a GR possui três característica básicas marcantes: movimentos corporais, manuseio de aparelhos e acompanhamento musical apropriado. Esses elementos, então, formam uma unidade que fundamenta a própria existência da GR.

A Ginástica Rítmica procura unir as habilidades de um esporte, aliando-se às características femininas. "A prática da Ginástica Rítmica permite ao praticante desenvolver suas capacidades e habilidades, que contribuim de maneira significativa para a formação de sua personalidade" ${ }^{(9)}$.

Para se tornar uma ginasta de bom nível técnico e chegar a participar de competições internacionais, uma atleta leva em média oito anos se preparando, pois nesse estágio, a mesma deverá dominar todos os aparelhos e as dificuldades corporais exigidas na categoria adulto com uma boa execução, ou seja, o mínimo de falhas. A partir daí, a têndencia é que a ginastas eleve gradualmente o nível de dificuldade de suas sèries, aperfeiçoando cada vez mais seus movimentos criando um estilo próprio e definitivo.

Em geral da música é feita pela ginasta com o auxílio da técnica, devendo respeitar a faixa etária, o aparelho e as característica de cada uma. A música pode ser escolhida anteriormente à escolha dos elementos corporais. Conforme Vieira (3) “ A música valoriza o movimento através de maior expressão, emoção e capacidade de transmitir beleza e técnica, proporcionando segurança e amplitude de movimentos". O trabalho com música não deve se restringir apenas ao periodo de elaboração das séries, mas sim estar presente em todas as aulas. Ao colocar diferentes estilos musicais, a técnica começará a observar o estilo de cada ginasta, po meio de suas preferências e afinidades.

$\mathrm{Na}$ prova de conjunto, cinco atletas trabalham juntas como uma só unidade, como se contassem uma história. O conjunto é julgado na habilidades da atletas para demonstrar domínio do corpo e habilidades do aparelho de maneira sincronozada e harmoniosa. Um exercício de conjunto tem que incluir dificuldades dasmesmas característicos do aparelho. Além disso, as atletas de conjunto têm de executar elementos que envolvem trocas grandes e pequenas de materiais. Quanto mais interação houver entre as ginastas, melhor será o exercício. 
A GR tem como requisito um alto nível de desenvolvimento de certas capacidades físicas, visando uma perfeita execução de movimento com o corpo e aparelhos, formando um conjunto harmonioso entre movimento e rítmo ${ }^{(7)}$. A modalidade envolve sincronia perfeita entre corpo e assim, para das qualidades físicas bem desenvolvidas e treinadas, as ginastas também devem possuir um padrão estético que a modalidade também exige.

\subsection{MATURAÇÃO}

O crescimento, o estado de nutrição e a maturação estão intrinsecamente conectados e reciprocamente influenciados por uma panóplia de fatores, tornando-se cada vez mais, alvo de preocupação da comunidade científica.

É crença comum que a prática de atividade física moderada é benéfica para a criança em crescimento. No entanto, quando praticada de forma intensa, durante longos períodos e em períodos de crescimento críticos, levanta alguns questionamentos. Efetivamente, a intensidade, a frequência e o tipo de metabolismo muscular envolvido são fatores determinantes das possíveis implicações do exercício no padrão de crescimento e maturação.

A vida é um processo dinâmico de mudanças iniciado na concepção e finalizado com a morte ${ }^{(33)}$. Os indivíduos passam por diferentes etapas manifestadas por meio de alteração de características biológicas e psico-sociais, até alcançarem um estado maduro.

A maturação se caracteriza como a busca pela estabilidade por meio de mudanças qualitativas que se processam em dois contextos distintos: o biológico e o comportamental ${ }^{(33)}$. Em se tratando de um processo, a maturação ocorre continuamente, existindo apenas variações em relação à intensidade das mudanças nos diferentes períodos. $\mathrm{Na}$ adolescência, por exemplo, em decorrência de diversos fatores como variações nos níveis de produção e liberação de secreção hormonal e os fatores genéticos e ambientais, as alterações biológicas se fazem extremamente presentes e notadas, trazendo também consequências para os aspectos psicológicos, sociais e motores. 
Porém, o envolvimento precoce de crianças e adolescentes em atividades esportivas de alto rendimento traz preocupações para os profissionais da área de Educação Física e do Esporte, assim como para os da área médica. Essas preocupações surgem, pois, motivados por fatores extrínsecos e intrínsecos, os indivíduos os referidos períodos etários estão se dedicando precocemente a treinamentos intensos com o intuito de alcançar um alto nível competitivo ${ }^{(37)}$, o que poderia acarretar em alterações no processo maturacional.

É difícil fazer qualquer afirmação referente à idade ideal para o início da especialização e da competição formal, uma vez que esta varia de acordo com a modalidade. Portanto torna-se importante conhecer os efeitos do treinamento rigoroso e sistemático sobre o crescimento e os aspectos maturacionais dos jovens atletas, mais especificamente sobre os aspectos somáticos e alguns aspectos motores ${ }^{(38)}$.

A GR é uma modalidade apontada, com grande frequência, como a responsável pelas alterações nos aspectos maturacionais de suas atletas. Segundo dados de Caçola (39) a iniciação nessa modalidade, sendo do sexo feminino, ocorre entre os cinco e sete anos e a competição formal a partir dos dez anos de idade. Iniciando a prática e a competição com tão pouca idade, uma série de fatores maturacionais, possivelmente sofreriam influências.

Um exemplo da possível alteração maturacional em atletas de GR, sexo feminino é o somatotipo, que desperta discussão a respeito da participação de fatores genéticos e de seleção natural, poucas vezes levados em consideração ${ }^{(40-42)}$.É importante ressaltar que o início precoce da prática e competição da GR não é infundado, quando são consideradas as exigências técnicas dessa modalidade. Porém, nos períodos iniciais da prática de qual quer esporte é preciso ter atenção no volume e na intensidade das cargas as quais as crianças serão submetidas, para que não ocorram excessos.

A maturação é um processo que ocorre durante toda a vida, sendo que para cada fase, espera-se que ocorra a aquisição de algum comportamento ou função característico de determinada idade. De acordo com ${ }^{(33)}$, o processo maturacional manifesta-se por meio de mudanças qualitativas que permitem o progresso em direção a níveis elevados de funcionamento; do ponto de vista biológico, é determinado geneticamente. O 
caminho para alcançar o estado maduro apresenta variações de velocidade de indivíduo para indivíduo e uma sequência de eventos que parece ser constante ${ }^{(38,43)}$.

O estirão do crescimento é um momento do intensivo aumento das dimensões dos indivíduos, traduzidas pelo incremento dos valores de estrutura e quantidade de tecido adiposo e muscular. As meninas iniciam esse processo, em média, dois anos antes que os meninos, justificando as diferenças estaturais entre os sexos por volta dos dez aos doze anos de idade.

Há diferença também no aumento relativo de massa magra e tecido adiposo: as meninas ganham menor quantidade de massa magra e mais adipócitos enquanto ocorre o contrário com os meninos. Porém, em ambos os casos, o ganho de massa muscular é acompanhado naturalmente pelo crescimento da força.

Em relação à estrutura, segundo o dado estatístico, o coeficiente de correlação entre a estatura adulta e a estatura imediatamente anterior ao início do estirão é de 0.8 . Isso significa que perto de $30 \%$ da variabilidade da estatura adulta ocorre em virtude da diferença magnitude do pico do crescimento na adolescência ${ }^{(44)}$.

A velocidade com que essas mudanças ocorrem também varia de acordo com os diversos fatores, e pode ser maior ou menor que a média, as mudanças precoces ou tardias podem influenciar temporariamente o aspecto emocional dos adolescentes ${ }^{(44)}$. Os estudos mostram que os lideres são geralmente aqueles que amadurecem mais cedo. Aqueles que apresentam as mudanças tardiamente tendem a se sentirem socialmente deslocados e são mais ansiosos.

Em relação aos aspectos sociais, podemos verificar que durante o período da adolescência, os indivíduos necessitam de intensa sociabilização, o que corresponde à modificação de um comportamento conforme a expectativa de um determinado grupo, formado por indivíduos unidos por um interesse comum, por exemplo uma atividade esportiva $^{(45)}$.

Segundo Guedes \& Guedes ( 1997), a maturação é o termo utilizado para descrever as mudanças biológicas, ocorridas de forma ordenada, objetivando atingir o estado adulto, sem a influência direta de estímulos externos conhecidos mas que são, pelo menos em parte, resultados da interação do organismo e seu meio.

A maturação é um processo direcional que se inicia no momento da concepção e que termina com o atingir do "alvo" - o estado biológico maduro (Malina et at, 2004). 
Segundo Malina et al.(2004),a maturação biológica da criança apresenta uma grande variabilidade individual, nem sempre em consonância com a sua idade cronológica. Este conceito implica um progresso por um estado Maturacional. Cada individuo tem dentro de si um relógio que regula a sua progressão pelos estados maturacionais. A maturação biológica está relacionada com o calendário cronológico.O crescimento e a maturação biológica não procedem concertadamente com o calendário e com a idade cronológica da criança (Malina et al, 2004).Por isso num grupo de crianças da mesma idade e do mesmo sexo, vai haver variação na idade biológica, ou nos estádios de maturação. No ponto de vista maturacional podem haver indivíduos retardados e outros avançados, comparando com a idade cronológica. Isto significa que duas crianças podem ter a mesma idade cronológica mas situarem em estádios de maturação diferentes.

A maturação biológica é responsável pela introdução de uma considerável força de variância na morfologia e na aptidão desportiva motora (sobral, 1984; Beunen, 1993; Malina et al,2004)

Para Vieira et al. (2006) os indicadores mais utilizados para identificar o nível Maturacional são; a idade gestacional, a idade morfológica ( maturação somática), a idade dentária (maturação dentária), a idade óssea(maturação esquelética) e a idade de aparecimento das características sexuais secundárias ( maturação sexual).

A maturação motora, os meninos e as meninas de sete anos vivem temporariamente uma etapa de reflexão. Os momentos em que permanecem quietos, colocando em ordem suas impressões e alheios à realidade exterior, são provavelmente tão necessários e proveitosos como o período de ação. Vão demorar pelo menos um ano para iniciar uma nova etapa expansiva, porém sua capacidade para analisar as reações dos demais, sua curiosidade, a atenção que dão ás conversas dos adultos e outras condutas típicas dos oito anos mostrarão os valiosos e importantes avanços acumulados nas últimas etapas de sua maturidade.

A maturação física, três de cada quatro meninos, nesta faixa etária, podem saltar sobre um pé só, mantendo o outro encolhido, e alternar este salto com outros usando os pés. Esta combinação de saltos já é possível graças ao fortalecimento da musculatura.

As meninas alcançam alturas inferiores às registradas pelos meninos. As diferenças podem ser pouco notáveis ainda aos sete anos, porém, a partir dos oito, as medidas 
superadas por elas equivalem praticamente às atingidas pelos meninos um ano antes. Esta defesagem será constante, sempre que for preciso esforço muscular. Os ligamentos, tendões e músculo se fortificarem, porem não podem suportar cargas extremas.

As meninas começam sua maturidade por volta dos nove anos e este período dura de dois a três anos.

Maturação perseptiva, em sua conduta motora terá perdido grande parte da impulsividade dos anos anteriores. Pouco a pouco aprenderá a utilizar a percepção para estabelecer o contato mais positivo com tudo a sua volta.

Os progressos esperados na compreensão do esquema corporal, por outro lado, vão permitir que, aos oito anos, a criança saiba distinguir sem dificuldade a direita e a esquerda de outra pessoa, assim como reconhecer e descrever a posição relativa de três objetos.Com igual facilidade, saberá executar as ordens que indiquem um movimento à direita ou a esquerda, e imitar as posições adotadas pelo professor ou professora.

Maturação cognitiva, melhora a memória a partir dos oito anos, a criança tem a sua disposição uma alta capacidade e motivação pessoal para aprender e guardar a maior quantidade possível de informação.

Maturação psicossocial, no final deste período, ou seja, pouco antes ou depois de fazer oito anos, alterna entre a atividade mental e a expansividade. Assim como aos sete anos deve ser destacada sua prudência, aos oito é ressaltado o seu afã por participar e desfrutar da vida, porém com um nível superior de maturidade.

O êxito é importante para construir sua alto estima baseada na habilidade e no estímulo às suas condutas positivas. Interessa-se por conhecer informação sobre o seu rendimento acadêmico. Confia em resultados como ganhar ou perder. Desenvolver estreitas amizades com colegas da mesma idade e sexo.

\subsection{QUALIDADES FÍSICAS}

A GR é uma modalidade esportiva praticada exclusivamente por mulheres que consiste na expressividade artística, elegância e plasticidade de movimentos acompanhados pelo ritmo, música e pela técnica corporal. As habilidades técnicas que 
compõem a GR denominam-se também como elementos corporais obrigatórios dentro de uma coreografia, que são eles: os saltos, os equilíbrios, os pivôs e as flexibilidades. Para que haja o desenvolvimento de um bom trabalho e o treinamento dos elementos corporais, têm-se as principais capacidades físicas, sendo elas: a flexibilidade, a coordenação, ritmo, o equilíbrio a resistência (aeróbica, anaeróbica e muscular localizada), a agilidade e a força explosiva.

Em função da modalidade, as ginastas precisam de níveis motores elevados referentes a flexibilidade, potência de menbros inferiores e forças de menbros superiores, velocidade e agilidade ${ }^{(29)}$. Com isso, a força de um salto é um dos elementos fundamentais no treinamento espacífico de força rápida ou explosiva.

Pode-se afirmar então, a ginástica teve sua origem na expressividade e harmonia entre o corpo, ritmo e técnica. Resultado dessa integração é o que vemos no dia de hoje estampados nos movimentos de beleza e plasticidade da GR.

Róbeva e Rankélova ${ }^{(29)}$, afirmam que as atletas de GR, de acordo com as características próprias da modalidade, precisam de altos níveis motores referentes à flexibilidade, potência de membros inferiores, forças de membros superiores, velocidade e agilidade.

Nos elementos corporais ou habilidades motoras específicas de GR chamadas de dificuldades corporais, estão envolvidos: os saltos, os equilíbrios, os pivôs e a flexibilidades, sendo que abordaremos neste estudo o salto suas variações, para que se possa, através de uma análise de força explosiva e salto vertical, conseguir transportar parâmetros para a GR.

Para que esses movimentos específicos da modalidade sejam realizados de forma satisfatória, é necessário ser feito um trabalho com foco nas qualidades essenciais a modalidade, tais como a força, a resistência muscular, a flexibilidade, o equilíbrio, o ritmo, a coordenação e a agilidade. Os aparelhos a serem utilizados por essa modalidade são a corda, o arco, a bola, a fita e as maças. E importante salientar que essa modalidade pode ser praticada também a mãos livres (ausência de aparelhos).

Em relação às qualidades físicas necessárias para à pratica da GR, segundo Laffranchi ${ }^{(7)}$ tem-se, como principais valências para o desenvolvimento do trabalho: a flexibilidade, a coordenação, o ritmo, o equilíbrio, a agilidade e a força explosiva, sendo a flexibilidade uma das principais qualidades físicas na prática da GR, pois esta valência 
é caracterizada pela a amplitude dos movimentos das diferentes partes do corpo. A flexibilidade é essencial para a execução de todos os elementos corporais e a amplitude dos movimentos é uma das principais características deste esporte.

A GR é uma manifestação gímnica que une os movimentos corporais a técnica do manejo dos aparelhos corda, bola, arco, maças e fita em harmonia com a música. Além disso, é uma modalidade olímpica com alto nível de complexidade que encanta os expectadores pela graciosidade e beleza que as ginastas transmitem por meio dos movimentos criativos e expressivos demonstrados nas coreografias.

Por trabalhar com a combinação corpo-música-aparelho, torna-se uma manifestação com amplas possibilidades de dinâmica, criatividade, ludicidade com características próprias, diferentes de outras escolas de expressão corporal. Dessa forma, poderá propiciar o desenvolvimento integral do aluno por meio da experimentação das inúmeras vivências corporais ${ }^{(30) \text {. }}$

A formação esportiva é um processo longo e, assim, o imediatismo ou a supressão de qualquer uma das fases terá consequências, seja em médio ou longo prazo. Certamente, as crianças e os jovens serão aqueles que mais sofrerão as consequências da especialização precoce, caso esta seja a opção dos técnicos, pois geralmente serão acompanhadas por altas demandas, pressões por rendimento e resultados imediatos. E mais, provavelmente, essas crianças e jovens encerrarão a carreira esportiva levarão para o futuro experiências pouco encorajadoras para se manterem fisicamente ativos. E, provavelmente, esses estarão pouco motivados a incentivar as gerações futuras à participação esportiva poderão se tornar técnicos e acreditar que a especialização precoce seja inevitável e, consequentemente, procederão da mesma forma.

É possível aproximarmos do ideal de formação esportiva, mas, as mudanças devem ser graduais para que o sistema atual não entre em colapso. É fato que os técnicos precisam manter suas posições e para justificá-las, devem competir e obter que satisfaçam as instituições, os pais e, se for o caso, os patrocinadores.

A alternativa seria esclarecê-los sobre as particularidades da GR. Reportar progressos individuais dos atletas, seu grau de satisfação no esporte, suas conquistas e superações individuais pode amenizar a ênfase sobre a competição e os resultados. Os técnicos e os demais envolvidos no esporte não devem poupar esforços para proteger os 
atletas, para prolongar sua participação e, principalmente, para lhes proporcionar experiências positivas no esporte.

Mesmo que o atleta não seja um destaque, se bem orientado, ele poderá incentivar gerações futuras. E, eventualmente, poderá surgir um campeão, ainda que não seja este o principal objetivo da participação esportiva.

A iniciação esportiva acontece quando a criança passa a praticar regularmente uma determinada modalidade, aprendendo sobre suas regras e técnicas dos movimentos orientados por um profissional, na qual irá desenvolver suas habilidades básicas sem que com isso tenha-se o objetivo de visar ao rendimento da criança em competições. Oliveira e Paes ${ }^{(13)}$, relatam por meio de suas pesquisas que a iniciação esportiva tem plena contribuição para a formação de cidadãos ocasionando diversos benefícios para a criança e reforçam o conceito de que o objetivo não é de forma alguma a revelação de campeões.

\subsubsection{COORDENAÇÃO}

Juntamente com a força, velocidade e resistência, a coordenação é uma das principais capacidades motoras. Se as primeiras representam o alicerces da condição física que sustentam os desempenhos desportivos, a coordenação deve ser vista como o pré-requisito para a aprendizagem a e aperfeiçoamento das habilidades motoras (Bompa, 1995; Manno, 1994).

David et al. (2000) definem coordenação como os movimentos observados entre segmentos do mesmo membro ( coordenação intra-segmentar), entre segmentos de diferentes membros( coordenação inter-segmentar), ou entre um segmento de membro e um objeto

O desenvolvimento da coordenação tem como período mais marcante a fase prépurbetária, pois é aqui que a criança revela um maior contato com uma grande diversidade de estimúlos motores. $\mathrm{Na}$ fase pubertária, o tempo necessário para se realizarem os reajustamentos provocados pelo crescimento alométrico, leva a uma diminuição da capacidade coodenativa ( Reilly et al, 2000). Este período de reajustamento coordenativo tem implicações até ao nível dos escalões de formação, 
onde os elementos mais EM devem ser mais solicitados em atividades de caráter coordenativo de forma a fazer face à desarmonia segmentar ( Bompa, 1995).

O nível de coordenação do movimento é especialmente importante para a obtenção de resultados nos jogos esportivos, nas lutas, nos esportes de coordenação completa, ou seja, naquelas modalidades em que se faz necessários variar as ações motoras, sem deixar de manter suas inter-relações e seu ordenamento adequado ${ }^{(46)}$.

Platonov ${ }^{(47)}$ fundamenta a importância do nível da coordenação motora na parte técnica dos atletas com grande variedade de exercícios na fase geral, especifica e complementa, e também da capacidade de regular os parâmetros dinâmicos e espaçotemporais dos movimentos.

$\mathrm{O}$ curso do desenvolvimento motor da criança, a emergência do andar marca o início da interação do ser humano com o meio, dando independência na exploração dos objetos e no convívio com as pessoas. Para que possa explorar esses objetos a sua volta, ela adquire uma série de habilidades manipulativas que vão ser adicionadas ao seu repertório motor, permitindo o seu uso para determinados fins, e que exijam maiores níveis de coordenação motora ${ }^{(48)}$.

A coordenação é a interação harmoniosa e econômica do sistema músculoesquelético, do sistema nervoso com o fim de produzir ações motoras precisas e equilibradas e reações rápidas adaptadas ${ }^{(49)}$.

A coordenação é a qualidade física que serve como mediadora das demais, pois a associação entre suas manifestações é que forma suas caracterizações ${ }^{(50)}$.

Dessa forma, a coordenação é uma habilidade motora complexa necessária para o alto desempenho ${ }^{(51)}$, que melhora com a lentificação do crescimento, ou seja, dos 7 aos $12 \operatorname{anos}{ }^{(33,52)}$.

A coordenação pode ser geral com grandes movimentos do corpo ou fina, com movimentos mais precisos e que exijam movimentos mais detalhados. É importante ressaltar que a coordenação motora é formada por vários tipos de capacidades, que incluem a capacidade para avaliar e regular os parâmetros dinâmicos e espaços temporais dos movimentos e a capacidade para manter o equilíbrio, para o sentido de ritmo, para se orienta no espaço, para relaxar voluntariamente os músculos, para manifestar racionalmente e transformar as ações motoras em condições específicas ${ }^{(47)}$. 
Segundo Silva Dantas ${ }^{(53)}$, a caracterização das qualidades físicas básicas evidencia-se por sua associação entre suas manifestações, e torna-se bastante evidente a coordenação como grande mediadora das demais qualidades físicas.

Essa qualidade física é considerada de suma importância para qualquer atividade física, pois proporciona o desempenho de movimentos de forma excelente, com alta eficiência e grande economia de esforços, possibilitando o individuo a alcançar seu maior nível. Assim, a coordenação é uma habilidade motora complexa necessária para o alto desempenho ${ }^{(51)}$.

Segundo Lopes ${ }^{(49)}$ o estudo da coordenação motora representa grande importância nas disciplinas científicas que estudam o movimento humano. A aprendizagem motora, o controle motor e o desenvolvimento motor, são exemplos focando seus esforços no sentido de entender como as ações motoras se processam em diferentes níveis, desde a forma como são reguladas até ao seu resultado.

Existem três formas decisivas no estabelecimento da coordenação motora em restrições particulares dos sistemas dinâmicos, facilitando a fazer de controle por parte de um programa motor: a) Restrições organísmicas, referentes a aspectos morfológicos, como por exemplo, dimensões corporais; B) Restrições do ambiente, referentes a agentes externos associados a execução motora de alguma forma, como força de gravidade, quantidade de luz no ambiente, e outros; c) Restrições na tarefa, referentes a características do objetivo e complexidade da tarefa ${ }^{(18)}$.

Pesquisas na motricidade infantil, geralmente são utilizadas para avaliar, analisar e estudar o desenvolvimento de crianças em diferentes estágios de evolução. Neste contexto, Caetano ${ }^{(54)}$ propõe uma escola de desenvolvimento motor (EDM) composta por uma bateria de testes para avaliar o desenvolvimento motor de crianças dos 2 aos 11 anos de idade. Os testes motores compreendem os seguintes componentes: 1) Motricidade fina, ou seja, a coordenação viso manual, com o mínimo de força, com a precisão exata da tarefa; 2) Motricidade Global que envolve grandes grupos musculares; 3) Equilíbrio, que corresponde a incapacidade do organismo de compensar e anular todas as forças que agem sobre o corpo; 4) Esquema corporal, que é considerada a capacidade de discriminar as partes corporais e organizar as partes do corpo na execução de uma tarefa; 5) Organização espacial, que é a noção do espaço do corpo que o rodeia, ou seja, a avaliação com precisão a relação entre o indivíduo e o meio 
ambiente; 6) Organização temporal, cuja percepção do tempo envolve a ordem e a duração dos acontecimentos.

Classifica-se a coordenação motora em dois grupos.

Coordenação Motora Grossa, capacidade de usar de forma mais eficiente os músculos esqueléticos (grandes músculos), resultando em uma ação global mais eficiente, plástia e econômica. Esse tipo de coordenação permite a criança ou adulto dominar o corpo no espaço, controlando os movimentos mais rudes. Ex: andar, pular, rastejar, etc.

E coordenação Motora Fina, capacidade de usar de forma eficiente e precisa os pequenos músculos, produzindo assim movimentos delicados e específicos. Esse tipo de coordenação permite dominar o ambiente, propriciando manuseio dos objetos. Ex: recortar, lançar em um alvo, costurar, etc.

Uma criança bem coordenada sempre adquire determinada habilidade com rapidez e consegue desempenhá-la sem problemas. Comparado à criança que pode desempenhar determinado movimento com rigidez e dificuldade, o jovem atleta bem coordenado, utilizará menos energia na mesma situação ${ }^{(51)}$.

Para Bompa ${ }^{(51)}$, nessa habilidade motora complexa, necessária para um excelente desempenho, há aquisição de rapidez, utilizando o infante menos energia quando comparado com outro que executa um movimento com rigidez e dificuldade.

Em jovens do sexo masculino, ela é mais acentuada do que nas meninas, possibilitando um treinamento ilimitado de suas habilidades ${ }^{(32)}$.

Essas habilidades são adquiridas rapidamente à medida que a criança torna-se mais coordenada, desempenhando-a com mais facilidade e sem maiores problemas. Consequentemente, crianças que têm melhor coordenação motora, desenvolverão suas tarefas com menos gasto de energia do que aquelas que ainda não desenvolveram tal habilidade ${ }^{(51)}$.

A coordenação apresenta vários tipos de capacidades, a capacidade para avaliar e regular os paralelos dinâmicos e espaços-temporais dos movimentos, capacidade para manter o equilíbrio, para o sentido de ritmo, para orientar-se no espaço, para relaxar voluntariamente os músculos, para manifestar racionalmente e transformar as ações motoras em condições especificas ${ }^{(55)}$. 
A coordenação motora tem uma expressão multifacetada relevante no desenvolvimento do processo educativo da criança, não-somente em termos psicomotores, mas também no domínio do desempenho cognitivo. Estudar a coordenação motora de crianças em idade escolar é também importante pela sua associação íntima a aspectos da aprendizagem motora e controle motor nas mais diversas tarefas do seu quotidiano e rotinas de vida (primeiramente com a coordenação grosseira, refinando-a posteriormente), bem como pelas implicações pedagógicas e educativas que decorrem das aulas de Educação Física ${ }^{(56,57)}$.

Juntamente com a força, velocidade e resistência, a coordenação é uma das principais capacidades motoras. Se as primeiras representam o alicerces da condição física que sustentam os desempenhos desportivos, a coordenação deve ser vista como o pré-requisito para a aprendizagem a e aperfeiçoamento das habilidades motoras (Bompa, 1995; Manno, 1994).

David et al. (2000) definem coordenação como os movimentos observados entre segmentos do mesmo membro ( coordenação intra-segmentar), entre segmentos de diferentes membros( coordenação inter-segmentar), ou entre um segmento de membro e um objeto

O desenvolvimento da coordenação tem como período mais marcante a fase prépurbetária, pois é aqui que a criança revela um maior contato com uma grande diversidade de estimúlos motores. $\mathrm{Na}$ fase pubertária, o tempo necessário para se realizarem os reajustamentos provocados pelo crescimento alométrico, leva a uma diminuição da capacidade coodenativa ( Reilly et al, 2000).

\subsubsection{FORÇA}

Um dos tipos da capacidade física de força muscular que é tratada é a força explosiva ou potência que segundo, Laffranchi ${ }^{(7)}$,consiste na capacidade do corpo de realizar o máximo de energia num ato de explosão em que os movimentos de força são exercidos com maior velocidade. $\mathrm{Na} \mathrm{GR}$, os saltos (membros inferiores) e os lançamentos (membros superiores) são exemplos de força explosiva e exigências de dificuldades corporais realizadas nas coreografias, tanto de conjunto como individuais. 
A capacidade física força explosiva, que é um dos elementos principais para o desenvolvimento potencial da ginasta, e pelo qual é analisado o salto vertical, tendo em vista que para se alcançar padrões elevados na GR, é necessário ter as capacidades físicas bem desenvolvidas de acordo com os movimentos da modalidade.

Força é uma qualidade física na qual um músculo ou grupo muscular produz uma tensão, para vencer uma resistência ${ }^{(58)}$.

Barbanti ${ }^{(34)}$, no entanto, afirma que é necessário diferenciar a força como grandeza física, que é o produto da massa pela aceleração (lei de Newton)e a força de execução de movimentos esportivos que se classifica em força interna e força externa. A força interna é aquela que é realizada por músculos, ligamentos, tendões; já a força externa é realizada por agentes externos, como a gravidade, a resistência do ar, a oposição exercida por um adversário ou um peso a ser levantado.

Fleck e Kramer ${ }^{(59)}$ definem a força como a quantidade máxima de força de um músculo ou grupo muscular pode gerar em um padrão específico de movimento em determinada velocidade específica.

A melhor capacidade de força é um fator determinantemente importante em todas as atividades esportivas. Contudo, a força por si mesma, trabalhada sem levar em consideração a especificidade do esporte, pode influir negativamente no rendimento. A força então influencia na execução da técnica, e muitas vezes, a falta técnica é causada pela falta de força nos grupos musculares e não somente por falta de coordenação ou habilidade ${ }^{(60)}$.

Para que se possa fazer uma classificação, é necessário considerar que a força pode se manifestar e se caracterizar pelos aspectos de força geral e força específica ${ }^{(32)}$. O mesmo autor define que a força geral, indepententemente da moBdalidade esportiva,é a força utilizada de todos os grupos musculares. E a força específica é entedida como força desenvolvida por um determinado grupo muscular para desenvolver certo movimento em uma modalidade específica.

Barbanti ${ }^{(34)}$ diferencia numa terminologia esportiva os tipos de força em : capacidade de força máxima, capacidade de resistência de força e capacidade de força rápida (capacidade de força explosiva).

Weineck ${ }^{(32)}$ força máxima e a maior força que o sistema muscular pode dar movimento, por meio de uma contração muscular que se opõe a uma determinada 
resistência. Ainda o mesmo autor revela que a força máxima dinâmica é a força que o sistema neuromuscular pode desenvolver uma contração muscular rápida dentro de determinada sequência de movimentos. Já a força máxima estática é sempre maior que a dinâmica.

De acordo com Badillo e Ayestarán ${ }^{(60)}$, a capacidade de manifestar a força explosiva está relacionada com a composição muscular, com a porcentagem do tipo de fibra, a frequência do impulso, a sincronização, a coordenação intermuscular, a capacidade de força máxima, a aceleração e a velocidade de encurtamento do músculo.

A força explosiva específica em cada esporte, vista do ponto anatômicofisiológico-psicológico, depende essencialmente de fatores como: tamanho do corte transversal das fibras musculares em ação, do número de fibras musculares, da estrutura do músculo, da velocidade de construção da musculatura, da coordenação neuromuscular, das condições psicológicas como a motivação, descanso, ânimo, vontade, entre outros ${ }^{(61)}$.

Concordando com a definição e levando em conta a psicomotricidade, o autor Hernandes Jr. (1998) caracteriza a força potência com a capacidade psicomotora, em que as alavancas ósseas e seus respectivos músculos executam o maior número possivel de contrações mantendo uma velocidade média em máximo de tempo.

Badillo e Ayestarán ${ }^{(60)}$ classificam a força rápida (explosiva) como: a força explosiva máxima seria definida como a melhor referencia entre a força aplicada e o tempo empregado para tanto na manifestação da força máxima contra qualquer resistência. Equivale ao máximo gradiente de força $(\mathrm{N} / \mathrm{s})$ obtido em uma contração voluntária máxima diante de qualquer resistência.

Contudo a força por si mesma, trabalhada sem levar em consideração a especificidade do esporte, pode influir nagativamente no rendimento. A força então influência na execução da técnica e muitas vezes a falta técnica é causada pela força nos grupos musculares, e não somente por falta de ccordenação ou habilidade ${ }^{(60)}$. Estes autores explicam que a força explosiva está presente em todas as manifestações de força. Sem o pré-alongamento, a força explosiva fica dependente da capacidade contrátil, ou seja, a força máxima isométrica ou dinâmica (força pura) e é necessário desenvolver uma grande força pelo recrutamento e sincronização imediatamente do maior numero de unidades motoras. Para medir a força explosiva usa-se o salto vertical 
sem contramovimento, pois vai depender da capacidade do indivíduo de aplicar força o mais rápido possível (força explosiva), enquanto a altura de saltos vai depender da velocidade decolagem.

Dentro das características mecânicas fisiológicas do salto vertical, a força e um salto é um dos elsmentos fundamentais no treinamento específico de força rápida ou explosiva. Para a realização do salto vertical, com o intuito de alcançar maior altura, é necessário imprimir a aceleração ao próprio corpo superar o seu peso. Para compor a força de salto são necessárias três qualidades: a força, a velocidade e a coordenação ${ }^{(34)}$. Este autor afirma que os saltos verticais, como exercícios, são voltados para obter impulsões, tendo como objetivo elevar o centro de cavidade do corpo no máximo de alturaque se pode alcançar podendo ser realizados com uma ou duas pernas.

Quanto à sua atividade mecânica, o salto caracteriza-se por duas fases, o amortecimento ou contra movimento e a impulsão. Na fase de amortecimento ou contramovimento a contração é do tipo excêntrica(fase dinâmica negativa), que objetiva uma ação de frear o movimento, sendo que a energia elástica armazena-se e restitui-se em energia mecânica. Nesta fase, ocorre um alongamento (pré-estiramento) dos musculos extensores das pernas, e na fase de impulsão, ocorre uma contração concêntrica e explosiva (fase dinâmica positiva), que começa no momento da tragetória final descendente do centro de gravidade, finalizado com a extensão de toda a perna, tronco, e balanceamento da cabeça e braços.

\subsubsection{FLEXIBILIDADE}

A definição de flexibilidade de acordo com Araújo ${ }^{(62)}$ é de uma máxima amplitude fisiológica passiva em um determinado movimento articular. Esta característica varia de uma pessoa para a outra e, nesse estudo, verificou-se essas diferenças nas articulações do quadril, a hiperextensão da coluna vertebral e a influência desta para um melhor desempenho dos movimentos na GR.

Outro aspesto importante na GR, é que entre habilidades, a flexibilidade, é essencial para a execução dos elementos corporais, pois esta valência permite a amplitude de movimento das diferentes partes do corpo, uma das características 
principais deste esporte ${ }^{(7)}$. Devido este fator que é importante o início da prática da modalidade durante a infância.

Em relação a flexibilidade, ela pode ser definida, para os autores como, Alter ${ }^{(63)}$ como a amplitude de movimento disponível em uma articulação ou grupo de articulações. De acordo com Hamil (64) a flexibilidade como qualidade física responsável pela execução voluntária de movimento de amplitude angular máxima, por uma articulação ou conjunto de articulações, dentro dos limites morfológicos sem riscos de provocar lesão.

A flexibilidade desenvolve-se quando os tecidos conjuntivos e os músculos são alongados por meio de exercícios regulares e adequados de alongamento, e, caso esses tecidos não sejam alongados ou exercitados, a flexibilidade diminui. Pode-se ter em mente que o componente mais importante relacionado com a flexibilidade é o tecido conjuntivo que envolve e circunda o músculo em seus vários níveis de organização.

A execução de movimento coordenativa e tecnicamente correta com a dinâmica espacial e temporal correta é impossível sem que haja uma boa capacidade de relaxamento e alongamento da musculatura.

Segundo Weineck ${ }^{(32)}$, a leveza e a graciosidade de uma ginasta ou de uma bailarina devem-se em grande parte a uma boa flexibilidade, essa afirmação do autor justifica o trabalho com a flexibilidade na base de escolinha de GR, uma vez que a flexibilidade de algumas articulações fará esses movimentos amplos como à abertura, os saltos, a ponte entre outros. Uma flexibilidade adequadamente desenvolvida aumenta o aspecto de possíveis movimentos técnicos específicos para diversas modalidades esportivas e acelera o processo do aprendizado motor.

O mesmo autor indica que com o aumento da flexibilidade, os movimentos podem ser executados com maior força e com maior velocidade, uma vez que o percurso de aceleração é maior; a resistência menor; e um maior número de fibras musculares sofre alongamento neste tipo de movimento. Ele sugere também que o trabalho criado pelo contato da criança com a flexibilidade na Educação Física Escolar, pode fazer bem, pois os músculos quando não são alongados e com pequena capacidade de alongamento têm menor força, como exemplo, exercícios em âmbitos não relacionados diretamente com a ginástica, como a corrida, o ciclismo entre outros, pois 
é um pré-requisito necessário ou que auxilia em qualquer esporte que a criança venha participar futuramente.

Dantas ${ }^{(65)}$, a flexibilidade, e principalmente os itens maleabilidade da pele e elasticidade muscular, são influenciados por alguns fatores como a idade: Quanto menor idade tiver o indivíduo, supõe-se uma maior flexibilidade pela alta quantidade de tecido cartilaginoso na região articular. Assim, quanto mais cedo iniciar o treinamento da flexibilidade maior serão as possibilidades de se atingir maiores arcos de mobilidade articular.

A criança, segundo Dantas ${ }^{(65)}$ possui uma maior capacidade de adquirir e manter alto grau de flexibilidade do que o adulto. A partir da terceira infância, fase que vai de 6 à 7 anos até o início da puberdade, normalmente ocorre o início dos surtos pubertório, havendo inúmeras alterações hormonais, fisiológicas e morfológicos, provocando modificações nos movimentos e na capacidade de estiramento dos músculos fazendo que se observem drásticas influências sobre a flexibilidade.

Segundo Laffranchi ${ }^{(7)}$, a GR apresenta uma grande complexidade de movimentos, configura suas técnicas por elementos de dança, ginástica e artes $\mathrm{d}$ manípulos, além de ser um esporte que exige um alto grau de flexibilidade, coordenação e equilíbrio para proporcionar um grande componente estético e beleza, sendo esses elementos aparecem nos últimos códigos de pontuação, sendo considerados elementos técnicos da Ginástica Rítmica.

Todo movimento da GR requer certo alto nível de condicionamento físico para ser um esporte que exige um alto grau de flexibilidade, coordenação e equilíbrio para proporcionar um grande componente estético e beleza, sendo esses elementos aparecem nos últimos códigos de pontuação, sendo considerados elementos técnicos da Ginástica Rítmica.

Segundo Silva et.al ${ }^{(66)}$ a flexibilidade é importante para o sucesso na modalidade e para uma perfeita realização nos gestos acrobáticos, como saltos, equilíbrio, pivô entre outros.

De acordo com Antualpa ${ }^{(67)}$, a flexibilidade é uma qualidade do movimento que vai além de uma capacidade específica da Ginástica Rítmica, sendo caracterizada como um elemento técnico que traz certa diferença entre as ginastas. 
AVALIAÇÃO DOS EFEITOS DE DUAS METODOLOGIAS DE FORMAÇÃO ESPORTIVA EM DISTINTOS NÍVEIS DE MATURAÇÃO BIOLÓGICA SOBRE AS QUALIDADES FÍSICAS DE PRATICANTES DE GINÁSTICA RÍTMICA DE 8 E 9 ANOS

\section{CAPÍTULO IV - METODOLOGIA}




\section{CAPÍTULO IV - METODOLOGIA}

Para uma melhor compreensão e esclarecimento, a metodologia adotada nesta pesquisa será apresentada em sub-itens a seguir: delineamento, universo, amostragem e amostra, ética da pesquisa, materiais e métodos, procedimento de análise dos dados.

\subsection{DELINEAMENTO}

O modelo de estudo foi apresentado sob a forma de tipologia da pesquisa, considerado do tipo experimental em que as variáveis independentes foram manipuladas para medir seus efeitos sobre as variáveis dependentes com o propósito maior de determinar o grau de mudança produzido pelo tratamento, estabelecendo uma relação de causa e efeito ${ }^{(68)}$.

\subsection{UNIVERSO, AMOSTRAGEM E AMOSTRA}

\subsubsection{UNIVERSO}

O universo foi constituído de 334 praticantes de GR, do gênero feminino, participantes do projeto esportivo Papo Cabeça, localizada no bairro de Val- de-Cans, na cidade Belém, Estado do Pará, com perfil econômico médio composto por trabalhadores informais que moram nos arredores do projeto.

\subsubsection{AMOSTRAGEM}

Partindo do universo do presente estudo, definido anteriormente, passou-se à aplicação dos critérios de inclusão e exclusão abaixo discriminados:

Critérios de Inclusão: Ser do gênero feminino, ter a idade de 8 a 9 anos, ser saudável, não participante de competições e estar apto fisicamente para participar do tratamento experimental. 
Critérios de Exclusão: Realizar alguma atividade esportiva direcionada fora da escola.

Após a aplicação do critério de inclusão e exclusão, constituiu-se um grupo amostral de 214 alunos.

Visando a verificar se essa quantidade era adequada, realizou-se, a partir dos dados preliminares obtidos, o cálculo do " $\mathrm{n}$ " amostral ideal abaixo descrito, para alpha $<0,05$ e beta $<20 \%{ }^{(69)}$ :

$$
\mathrm{n}=(\underline{\mathrm{Z} \times \mathrm{sd}})^{2}
$$$$
d^{2}
$$

Onde:

$\mathrm{n}=$ tamanho da amostra

$\mathrm{Z}$ = nível de confiança estabelecido

sd $=$ desvio padrão estimado

$\mathrm{d}=$ margem de erro aceita pelo pesquisador

O cálculo realizado indicou um quantitativo de 20 crianças para cada grupo, totalizando 120 crianças.

\subsubsection{AMOSTRA}

Os infantes foram divididos em dois grupos de formação esportiva: um de metodologia tradicional (Grupo Tradicional - GT) e outro com metodologia maturacional (Grupo Maturacional - GM) e, em um terceiro grupo, Grupo Controle (GC) que não recebeu tratamento especial.

Foi obtida uma amostra de 120 crianças que preencheram os requisitos, divididas, randomicamente (por sorteio), em 6 grupos de 20 crianças (quadro 1). 
Quadro 1 - Distribuição da amostra

\begin{tabular}{|c|c|c|c|c|c|c|c|c|c|}
\hline \multirow{4}{*}{$\begin{array}{c}8 \\
\text { ANOS }\end{array}$} & \multicolumn{3}{|c|}{ TARDIO $n=16$} & \multicolumn{3}{|c|}{ PRECOCE $n=14$} & \multicolumn{3}{|c|}{ NORMAL $n=25$} \\
\hline & GT & GM & $\mathrm{GC}$ & GT & GM & $\mathrm{GC}$ & GT & GM & $\mathrm{GC}$ \\
\hline & 8 & 5 & 3 & 7 & 5 & 2 & 5 & 10 & 15 \\
\hline & \multicolumn{3}{|c|}{$\mathrm{GT}=20$} & \multicolumn{3}{|c|}{$\mathrm{GM}=20$} & \multicolumn{3}{|c|}{$\mathrm{GC}=20$} \\
\hline \multirow{4}{*}{$\begin{array}{c}9 \\
\text { ANOS }\end{array}$} & \multicolumn{3}{|c|}{ TARDIO $n=14$} & \multicolumn{3}{|c|}{ PRECOCE $n=18$} & \multicolumn{3}{|c|}{ NORMAL $n=27$} \\
\hline & GT & GM & $\overline{\mathrm{GC}}$ & GT & GM & $\mathrm{GC}$ & GT & GM & $\overline{\mathrm{GC}}$ \\
\hline & 7 & 5 & 2 & 5 & 8 & 6 & 8 & 7 & 12 \\
\hline & \multicolumn{3}{|c|}{$\mathrm{GT}=20$} & \multicolumn{3}{|c|}{$\mathrm{GM}=20$} & \multicolumn{3}{|c|}{$\mathrm{GC}=20$} \\
\hline
\end{tabular}

A descrição da tabela acima mostra que as meninas na idade de 8 anos foram divididas em três sub-grupo: tardio, precoce e normal. No tardio com dezesseis meninas divididas no grupo GT com oito meninas, o GM com cinco meninas e o GC com três meninas. $\mathrm{O}$ sub-grupo precoce apresenta no total quartoze meninas dividido GT sete meninas, o GM com cinco meninas e o GC com dois meninas. O sub-grupo normal com o total de vinte e cinco meninas, dividido no grupo GT com cinco meninas, o GM com dez meninas e o GC quinze meninas.

$\mathrm{Na}$ idade de nove anos foram divididos em três sub-grupo tardio, precoce e normal. No tardio com quartoze meninas divididas no grupo GT com sete meninas, GM com cinco meninas e o GC com duas meninas. No precose no grupo GT com cinco meninas, no GM com oito meninas, e o GC com seis meninas. No normal no grupo GT com oito meninas, no GM com sete meninas e o GC com doze meninas.

No total dos grupos GT, GM e GC são vinte meninas.

\section{3. ÉTICA DA PESQUISA}

Este estudo atendeu às normas para realização de pesquisa em seres humanos de acordo com a Resolução 196/96, do Conselho Nacional de Saúde, de 10 de outubro de $1996^{(70)}$ e com a declaração de Helsinki ${ }^{(71)}$.

A instituição, na qual se realizou a pesquisa, recebeu e assinou o Termo de Informação à Instituição.

Os responsáveis pelos participantes do estudo, de forma espontânea, concordaram em assinar o Termo de Consentimento Livre e Esclarecido de participação Consentida com os mesmos conteúdos do Termo de Informação à Instituição.

O presente estudo foi submetido ao Comitê de Ética em Pesquisa, envolvendo seres humanos e teve a aprovação sob o número 031/2011 da FHCGV - Fundação Pública Estadual Hospital de Clínicas Gaspar Viana. 


\subsection{MATERIAIS E MÉTODOS}

Neste item, estão descritos os procedimentos, protocolos e instrumentos utilizados.

\subsubsection{PROCEDIMENTOS PRELIMINARES}

Primeiramente, ocorreu o desenvolvimento dos procedimentos relacionados ao item 4.2; em seguida, foram realizados os procedimentos ligados à Ética da Pesquisa, demonstrados no item 4.3 .

\section{Avaliação das medidas antropométricas}

Para a tomada de massa e estatura corporal foi utilizada uma balança mecânica com estadiômetro, marca FILIZOLA - BRASIL (Fig. 1 e 2), com precisão de escala de $\operatorname{lo0g}(72)$.

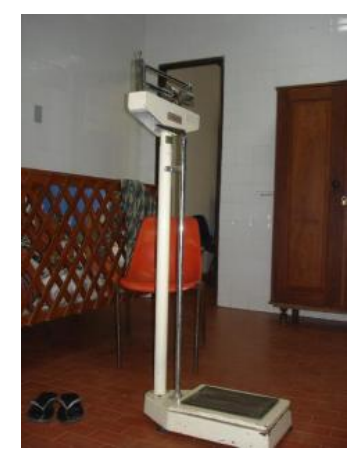

Fig. 1

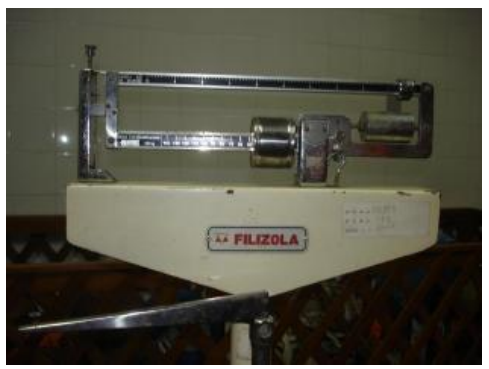

Fig 2

Figura 1 e 2 - Balança mecânica com estadiômetro FILIZOLA - BRASIL. Vistas lateral e frontal

A avaliada se posicionou na plataforma de pé, de costas para a escala da balança, com afastamento lateral dos pés, ereto e com olhar num ponto fixo à sua frente. Usou o 
mínimo de roupa possível. Realizou-se apenas uma medida ${ }^{(72)}$, que foi anotada em $\mathrm{kg}$, com aproximação de 0,1kg (FIG. 3).

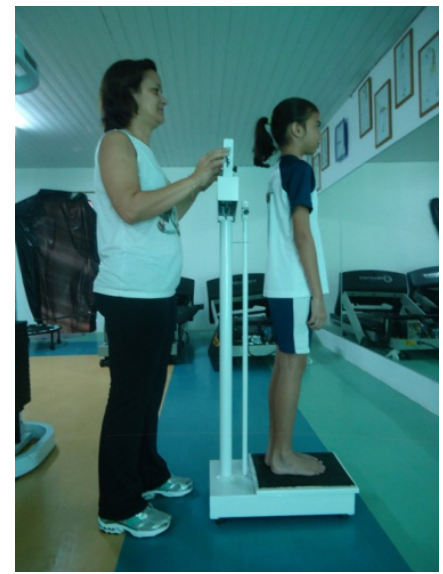

Figura 3 - Tomada de massa corporal

Foi avaliada a estatura corporal pela medida entre a distância da planta dos pés e o ponto mais alto da cabeça (vértex). A avaliada permaneceu na posição ortostática, de pé, corpo ereto, braços estendidos ao longo do corpo, pés unidos, procurando pôr em contato, com o instrumento de medida, as superfícies posteriores do calcanhar, cintura pélvica, cintura escapular e região occipital. A medida foi feita com o avaliado em apnéia inspiratória, de modo a minimizar possíveis variações sobre esta variável antropométrica. A cabeça estava orientada segundo o plano de Frankfurt, paralela ao solo. A medida foi feita com calção, exigindo que estivesse descalço ${ }^{(72)}$ (Fig. 4).

Figura 4 - Tomada de estatura

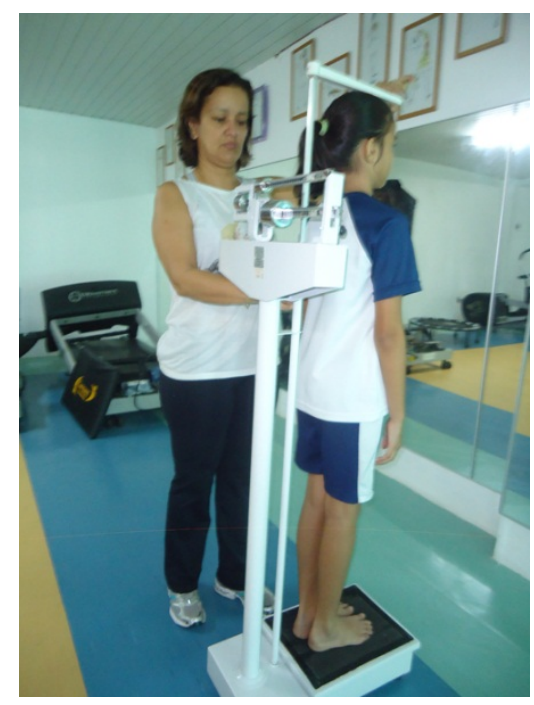




\section{Avaliação da Maturação Biológica}

Para avaliação da maturação biológica, realizou-se a avaliação radiológica de Raio-X de mão e punho, com o aparelho modelo Villa Sistem Medical (Italian) $630 \mathrm{ma}$, utilizando o Protocolo de Greulich-Pyle ${ }^{(73)}$ (FIG. 5, 6, 7 e 8).

Essa avaliação foi realizada no Hospital de Aeronáutica de Belém (HABe), com a utilização do protocolo Greulich-Pyle que, através de imagens preestabelecidas, comparou-as às obtidas com os indivíduos da pesquisa, identificando as idades maturacionais.
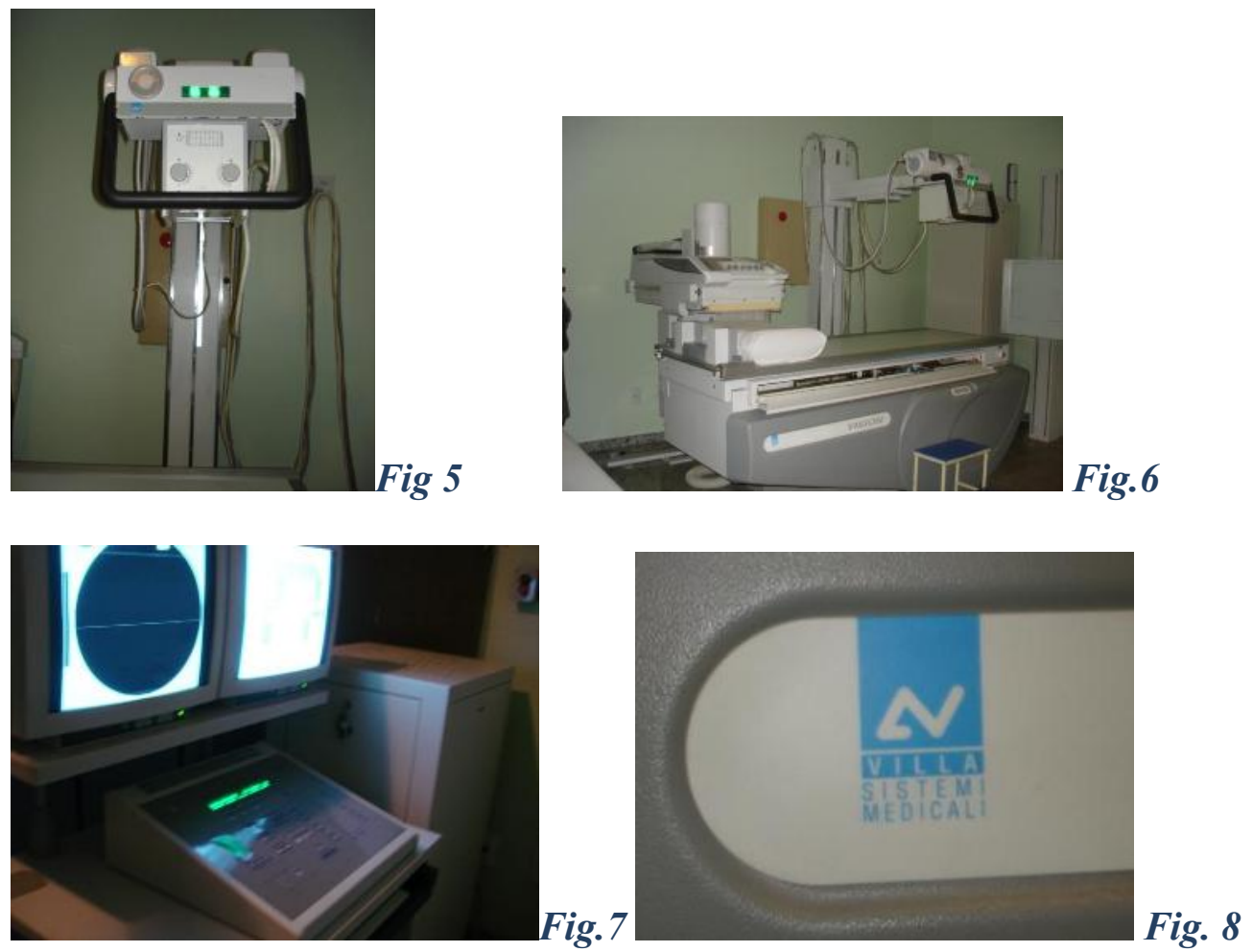

Figura 5, 6, 7 e 8 - Aparelho de raio-x. Apresentando em vista frontal, lateral, cabine de comando e marca do aparelho

Para tomada radiográfica, a criança ficou estática por três segundos, com as mãos espalmadas sobre o aparelho (Fig. 9), utilizando avental de chumbo e protetor de tireóide para proteção contra os raios $-\mathrm{x}$. 


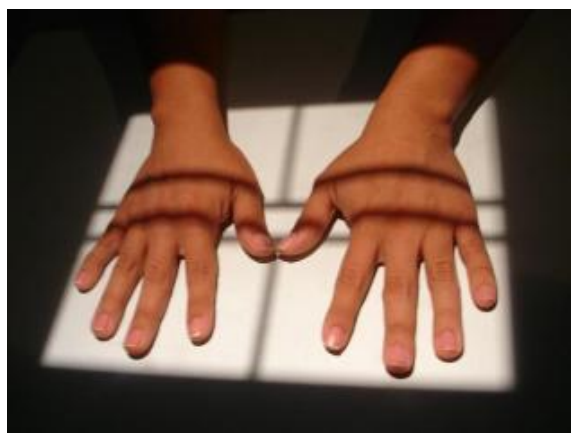

Figura 9 - Demonstração do posicionamento estático da criança com auxílio do técnico em radiologia do Hospital. Em uma vista geral e outra aproximada

\subsubsection{AVALIAÇÃO DIAGNÓSTICA}

A partir do segundo dia, foram realizadas avaliações das variáveis dependentes seguindo a ordem abaixo apresentada.

No segundo dia, pela manhã, foi realizada a avaliação da flexibilidade.

\section{Avaliação da Flexibilidade}

A avaliação da Flexibilidade foi realizada por meio dos Testes Angulares de Goniometria, do Protocolo LABIFIE de Goniometria ${ }^{(74)}$. Utilizou-se o Goniômetro da marca "Lafayette Goniometer Set" e colchonete Hoorn-Brasil, nos seguintes movimentos:

a) Abdução da Articulação do Ombro (AAO) (FIG. 11)

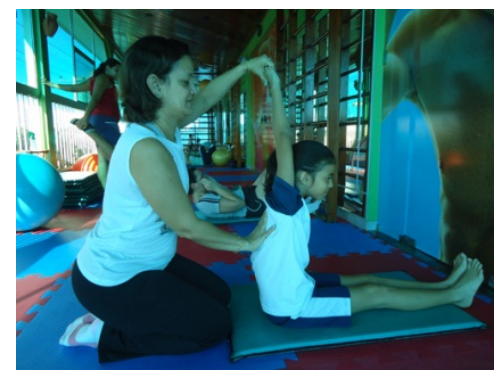

Figura 10 - Abdução da articulação do ombro 
b) Flexão da Coluna Lombar (FCL) (FIG.12)



Figura 11 - Flexão da coluna Lombar

Teste de flexibilidade

Validade: varia de acordo com a articulação, de 0.75 a 0.90.

Correlação: teste e reteste correlacionam de 0.90 a 0.98 . Entre testadores a correlação é de 0.90 .

Fidedignidade: varia de acordo com a articulação, de 0.76 a 0.98 .

Objetividade: varia de acordo com a articulação, de 0.55 a 0.93 .

Escore: a amplitude dos movimentos é diferente entre as articulações (em graus) mensuradas no fim do movimento.

No terceiro dia, pela manhã e à tarde, foi realizada a avaliação da coordenação e da força explosiva.

\section{Avaliação da Coordenação}

A avaliação da Coordenação realizou-se por meio do Teste de Burpee (75) (Fig. 12 a 16).
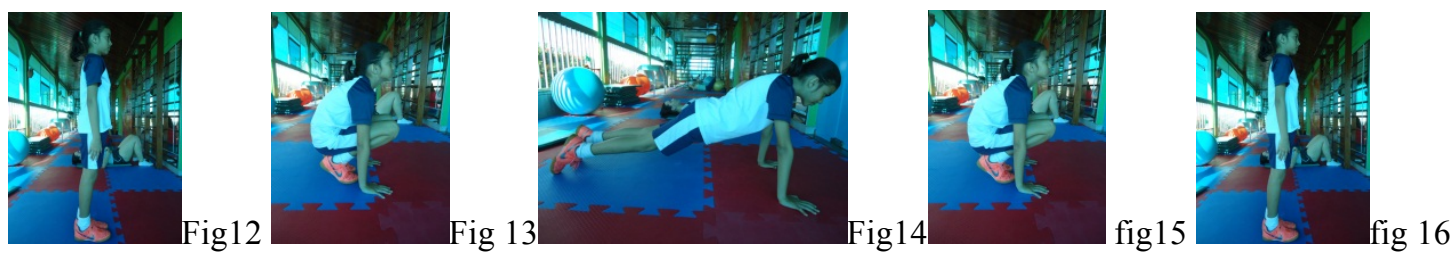

Figura 12 a 16 - Sequência do Teste de Burpee 


\section{Avaliação da Força Explosiva}

Para avaliação da Força explosiva, realizou-se o Teste de Impulsão Vertical Sargent Jump Test ${ }^{(75)}$.

Fidedignidade: tem sido assinalada como superior a 0,93.

Objetividade: o coeficiente de objetividade de 0,93 foi obtido por Clayton.

Validade: a validade de 0,78 (Fig. 17).

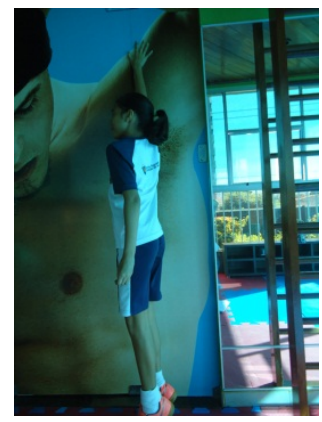

Figura 17 - Teste de Impulsão Vertical Sargent Jump Test

\subsubsection{INTERVENÇÃO}

Todos os grupos realizaram aulas de GR, durante o período de dezesseis semanas, com frequência de duas vezes por semana e com a duração de quarenta e cinco minutos cada aula, sendo dez minutos de aquecimento, trinta minutos de parte principal (ANEXO VI) e cinco minutos de volta à calma.

O Grupo Tradicional (GT) realizou a metodologia tradicional, que se baseia no fato da professora levar em consideração a série em que o indivíduo se encontra e a idade cronológica para o planejamento.

O Grupo Maturacional (GM) realizou a metodologia maturacional que é aquela em que, no momento do planejamento, adapta as atividades a serem desenvolvidas de acordo com o estágio maturacional e não-somente de acordo com a idade cronológica, segundo o método desenvolvido por Portal (2006).

Os dois grupos experimentais o Grupo Tradicional (GT) e o Grupo Maturacional (GM) realizaram aulas de GR que estimularam o desenvolvimento de qualidades físicas (coordenação, flexibilidade e força explosiva) durante o período de dezesseis semanas, 
duas vezes por semana, com a duração de quarenta e cinco minutos cada aula.

O grupo GT realizou a metodologia de formação esportiva tradicional (Anexo II), que preconiza a aplicação de exercícios de acordo com os elementos específicos básicos da GR, os quais abordam os pivôs, os saltos, as flexibilidades, os equilíbrios e as atividades rítmicas e expressivas, levando em consideração a idade cronológica.

O grupo GM realizou a metodologia de formação esportiva Maturacional (Anexo II) que preconiza a aplicação de atividades esportivas com ênfase no treinamento da coordenação (psicomotricidade), da resistência muscular localizada e da flexibilidade, em que as regras são adaptadas; as competições e os treinos devem ter caráter lúdico. O objetivo dessa metodologia é levar em consideração o nível de maturação biológica das crianças no momento da seleção das atividades aplicadas baseados nos estudos de Portal (2006).

O grupo GC não recebeu qualquer tratamento especial, a fim de servir como referência padrão às variáveis a que se submeteu o grupo experimental.

As aulas constavam de quinze minutos de aquecimento, trinta minutos de trabalho dentro das metodologias e quinze minutos de volta à calma.

\subsubsection{AVALIAÇÃO SOMATIVA}

Após as dezesseis semanas de intervenção, realizou-se o pós-teste, que consistiu dos mesmos procedimentos descritos no item 3.4.2, conforme apresentado no quadro 2.

Quadro 2 - Procedimentos, protocolos e instrumentos utilizados

\begin{tabular}{|c|c|c|}
\hline Procedimento & Protocolo & Instrumento \\
\hline Antropometria & $\begin{array}{c}\text { Massa corporal e } \\
\text { estatura corporal }\end{array}$ & $\begin{array}{l}\text { Balança com estadiômetro da } \\
\text { marca FILIZOLA - BRASIL. }\end{array}$ \\
\hline Maturação biológica & $\begin{array}{l}\text { Exame radiológico de Raio- } \\
X \text { de mão e punho }{ }^{(73)}\end{array}$ & $\begin{array}{l}\text { aparelho com modelo Villa } \\
\text { Medical Sistem (Italiano) } 630 \text { ma. }\end{array}$ \\
\hline Coordenação & Teste de Burpee ${ }^{(75)}$ & Cronômetro da marca Polar. \\
\hline Flexibilidade & $\begin{array}{l}\text { LABIFIE de Goniometria } \\
\text { (74) }\end{array}$ & $\begin{array}{ll}\text { Goniômetro } & \text { "Lafayette } \\
\text { Goniometer Set". } & \end{array}$ \\
\hline Força Explosiva & $\begin{array}{l}\text { Teste de Impulsão Vertical } \\
\text { Sargent Jump Test }{ }^{(75)}\end{array}$ & $\begin{array}{l}\text { Tábua de } 1.50 \mathrm{~m} \text { de comprimento } \\
\text { e } 30 \mathrm{~cm} \text { de largura. }\end{array}$ \\
\hline
\end{tabular}




\subsection{DIFICULDADES E LIMITAÇÕES DO ESTUDO}

O estudo não poderia controlar dificuldades em relação ao aspecto nutricional, meio ambiente em que vive o aluno e ao envolvimento dos pais.

As principais dificuldades encontradas estavam relacionadas com 0 deslocamento das crianças para realizar o exame radiológico fora da escola devido o horário ser o mesmo das atividades escolares.

Por fim, houve Impossibilidade de utilização de instrumentos gold Standard na qualidade força. Existem equipamentos para estas qualidades em Belém, porém todos os pesquisados estavam com problemas técnicos. Diversas formas de solucionar tais problemas não obtiveram sucesso por questões de cunho financeiro e burocrático.

\subsection{PROCEDIMENTOS DE ANÁLISE DOS DADOS}

Os procedimentos estatísticos, que foram propostos para a adequada análise dos dados, visaram caracterizar a amostra e testar as hipóteses formuladas. Os dados brutos (Anexo IV) foram tratados pelo pacote estatístico SPSS 14.0 e grupados da seguinte forma:

\subsubsection{ESTATÍSTICA DESCRITIVA}

Foram empregados os métodos da Estatística Descritiva com o objetivo de caracterizar o universo amostral, sob os seus aspectos de distribuição de freqüência, quando se tratou os dados discretos (média, desvio padrão).

\subsubsection{ESTATÍSTICA INFERENCIAL}

A normalidade e a homogeneidade de variância foram verificadas pelos testes de Shapiro-Wilk e de Levene, respectivamente. Utilizou-se o teste t-Student pareado e o 
teste de Wilcoxon para as comparações intragrupos quando apropriados. A ANOVA de medidas repetidas, seguida do post hoc de Tukey para identificar as possíveis diferenças intergrupos.

\subsubsection{NÍVEL DE SIGNIFICÂNCIA E POTÊNCIA DO EXPERIMENTO}

Com o propósito de manter a cientificidade da pesquisa, o presente estudo adotou o nível de significância estatística de $\alpha=5 \%$, ou seja, 95\% de probabilidade de que estejam certas as afirmativas e/ou negativas denotadas durante as investigações, admitindo-se, portanto, a probabilidade de 5\% para resultados obtidos por acaso.

A potência do experimento, ou poder do experimento, foi avaliado por meio do controle do erro tipo II, permitindo um nível de aceitação correspondente à um $\beta \leq 80 \%$, ou seja, admitindo-se $20 \%$ de chance de se aceitar que deveria ser rejeitada. Assim foi encontrado um poder do experimento de $99 \%$ em todas as variáveis analisadas. 
AVALIAÇÃO DOS EFEITOS DE DUAS METODOLOGIAS DE FORMAÇÃO ESPORTIVA EM DISTINTOS NÍVEIS DE MATURAÇÃO BIOLÓGICA SOBRE AS QUALIDADES FÍSICAS DE PRATICANTES DE GINÁSTICA RÍTMICA DE 8 E 9 ANOS

\section{CAPÍTULO V - RESULTADOS}




\section{CAPÍTULO V - RESULTADOS}

\subsection{CARACTERÍSTICAS DA AMOSTRA}

Depois de realizadas as coletas de dados no pré-teste dos grupos GT, GM e GC, os resultados descritivos foram organizados e colocados em tabelas.

Na tabela 1, são apresentados os índices descritivos do GT, GM e GC quanto às variáveis antropométricas e maturacional, quanto aos grupos precoce, normal e tardio na idade de 8 anos.

Tabela 1 - Características descritivas para a massa corporal (MC), estatura e maturação radiográfica (RX) nos grupos Precoce, Normal e Tardio no GT, GM e GC na idade de 8 anos

\begin{tabular}{|c|c|c|c|c|c|}
\hline Grupo & Variável & Subgrupo & Média & $\mathrm{DP}$ & p-valor $(\mathrm{SW})$ \\
\hline \multirow[t]{9}{*}{ TARDIO } & $\mathrm{MC}(\mathrm{kg})$ & GT & 25,00 & 3,70 & 0,475 \\
\hline & & GM & 24,79 & 1,04 & 0,686 \\
\hline & & $\mathrm{GC}$ & 24,21 & 1,82 & 0,073 \\
\hline & Estatura (m) & GT & 1,24 & 0,06 & 0,551 \\
\hline & & GM & 1,28 & 0,04 & 0,968 \\
\hline & & $\mathrm{GC}$ & 1,23 & 0,02 & 0,877 \\
\hline & RX (anos) & GT & 6,88 & 0,35 & 0,000 \\
\hline & & GM & 6,71 & 0,49 & 0,000 \\
\hline & & GC & 6,57 & 0,53 & 0,001 \\
\hline \multirow[t]{9}{*}{ NORMAL } & $\mathrm{MC}(\mathrm{kg})$ & GT & 24,43 & 1,69 & 0,528 \\
\hline & & GM & 25,30 & 1,80 & 0,715 \\
\hline & & $\mathrm{GC}$ & 25,47 & 2,45 & 0,964 \\
\hline & Estatura (m) & GT & 1,24 & 0,02 & 0,976 \\
\hline & & GM & 1,24 & 0,02 & 0,338 \\
\hline & & $\mathrm{GC}$ & 1,25 & 0,02 & 0,754 \\
\hline & RX (anos) & GT & 8,00 & 0,58 & 0,024 \\
\hline & & GM & 8,00 & 0,47 & 0,000 \\
\hline & & GC & 8,00 & 0,38 & 0,000 \\
\hline \multirow[t]{9}{*}{ PRECOCE } & $\mathrm{MC}(\mathrm{kg})$ & GT & 24,14 & 1,49 & 0,586 \\
\hline & & GM & 24,71 & 0,99 & 0,876 \\
\hline & & $\mathrm{GC}$ & 26,50 & 0,71 & 0,752 \\
\hline & Estatura (m) & GT & 1,25 & 0,02 & 0,432 \\
\hline & & GM & 1,23 & 0,02 & 0,772 \\
\hline & & GC & 1,24 & 0,02 & 0,954 \\
\hline & RX (anos) & GT & 9,14 & 0,38 & 0,000 \\
\hline & & GM & 9,43 & 0,53 & 0,001 \\
\hline & & GC & 9,57 & 0,53 & 0,001 \\
\hline
\end{tabular}

GT: Grupo Tradicional; GM: Grupo Maturacional: GC: Grupo Controle; SW: ShapiroWilk 
Analisando a tabela 1, pode- se observar que houve uma distribuição não-normal dos dados na descrição do RX.

Na tabela 2, são apresentados os índices descritivos do GT, GM e GC quanto às variáveis antropométricas e maturacional, quanto aos grupos precoce, normal e tardio na idade de 9 anos.

Tabela 2 - Características descritivas para a massa corporal (MC), estatura e maturação radiográfica (RX) nos grupos Precoce, Normal e Tardio no GT, GM e GC na idade de 9 anos

\begin{tabular}{|c|c|c|c|c|c|}
\hline Grupo & Variável & Subgrupo & Média & DP & p-valor (SW) \\
\hline \multirow[t]{9}{*}{ TARDIO } & $\mathrm{MC}(\mathrm{kg})$ & GT & 24,00 & 0,96 & 0,053 \\
\hline & & GM & 25,36 & 0,99 & 0,129 \\
\hline & & GC & 24,93 & 1,13 & 0,603 \\
\hline & Estatura (m) & GT & 1,28 & 0,02 & 0,467 \\
\hline & & GM & 1,32 & 0,04 & 0,563 \\
\hline & & GC & 1,30 & 0,02 & 0,772 \\
\hline & RX (anos) & GT & 8,14 & 0,38 & 0,000 \\
\hline & & GM & 8,00 & 0,58 & 0,024 \\
\hline & & GC & 8,14 & 0,69 & 0,099 \\
\hline \multirow[t]{9}{*}{ NORMAL } & $\mathrm{MC} \mathrm{kg)}$ & GT & 27,75 & 2,85 & 0,950 \\
\hline & & GM & 27,69 & 3,08 & 0,389 \\
\hline & & $\mathrm{GC}$ & 27,38 & 3,63 & 0,232 \\
\hline & Estatura (m) & GT & 1,38 & 0,07 & 0,095 \\
\hline & & GM & 1,41 & 0,07 & 0,212 \\
\hline & & GC & 1,38 & 0,07 & 0,327 \\
\hline & RX (anos) & GT & 9,00 & 0,53 & 0,005 \\
\hline & & GM & 9,13 & 0,35 & 0,000 \\
\hline & & GC & 8,92 & 0,29 & 0,000 \\
\hline \multirow[t]{9}{*}{ PRECOCE } & $\mathrm{MC}(\mathrm{kg})$ & GT & 27,86 & 2,93 & 0,056 \\
\hline & & GM & 27,00 & 0,93 & 0,050 \\
\hline & & GC & 27,14 & 1,55 & 0,494 \\
\hline & Estatura (m) & GT & 1,39 & 0,06 & 0,952 \\
\hline & & GM & 1,40 & 0,08 & 0,373 \\
\hline & & $\mathrm{GC}$ & 1,39 & 0,07 & 0,654 \\
\hline & RX (anos) & GT & 9,86 & 0,38 & 0,000 \\
\hline & & GM & 10,13 & 0,35 & 0,000 \\
\hline & & GC & 10,14 & 0,69 & 0,099 \\
\hline
\end{tabular}

GT: Grupo Tradicional; GM: Grupo Maturacional: GC: Grupo Controle; SW: ShapiroWilk

Observando a tabela 2, pode-se verificar que houve uma distribuição não-normal dos dados na descrição do RX, com exceção do GC nos grupos tardio e precoce. 


\subsection{RESULTADOS INTRA-GRUPOS NA FAIXA ETÁRIA DE 8 ANOS}

Na tabela 3, são apresentados os resultados da análise intragrupo das qualidades físicas do grupo tardio 8 anos nos subgrupos GT, GM e GC.

Tabela 3 - Análise comparativa das qualidades físicas do grupo tardio 8 anos nos subgrupos GT, GM e GC

\begin{tabular}{cccc}
\hline Qualidades físicas & Grupo & Média (pré) \pm DP & Média (pós) \pm DP \\
\hline Força $(\mathrm{cm})$ & GT & $17,88 \pm 4,19$ & $20,00 \pm 4,76$ \\
& GM & $16,00 \pm 1,15$ & $22,29 \pm 2,81 *$ \\
& GC & $17,57 \pm 1,27$ & $18,86 \pm 1,35$ \\
Coord (repetições) & GT & $18,75 \pm 3,85$ & $20,29 \pm 2,87$ \\
& GM & $17,00 \pm 2,31$ & $26,86 \pm 1,07 *$ \\
AAO (em graus) & GC & $19,43 \pm 1,51$ & $20,57 \pm 1,81$ \\
& GT & $112,25 \pm 2,05$ & $113,29 \pm 1,60$ \\
FCL (em graus) & GM & $114,43 \pm 3,10$ & $126,14 \pm 1,35^{*}$ \\
& GC & $115,29 \pm 1,80$ & $117,29 \pm 1,80$ \\
& GT & $22,13 \pm 2,23$ & $24,29 \pm 1,80$ \\
& GM & $22,86 \pm 1,35$ & $30,14 \pm 1,35^{*}$ \\
& GC & $22,00 \pm 1,73$ & $23,29 \pm 1,38$ \\
\hline
\end{tabular}

Coord: coordenação; AAO: abdução da articulação do ombro; FCL: flexão da coluna lombar; GT: Grupo Tradicional; GM: Grupo Maturacional; GC: Grupo Controle; DP: desvio padrão.

$* \mathrm{p}<0,05$, diferença intragrupo

Pode-se verificar, na tabela 3, que, o GM obteve resultados satisfatórios, significativos, no pós-teste, em todas as variáveis, a saber: potência $(\Delta=6,29 ; \mathrm{p}=0,021)$, coordenação $(\Delta=9,86$ repetições, $\mathrm{p}<0,001)$, AAO $\left(\Delta=11,71^{\circ}, \mathrm{p}<0,001\right)$ e FCL $(\Delta=$ $\left.7,29^{\circ}, \mathrm{p}<0,001\right)$.

$\mathrm{Na}$ tabela 4, são apresentados os resultados da análise intragrupo das qualidades físicas do grupo normal de 8 anos nos subgrupos GT, GM e GC. 
Tabela 4 - Análise comparativa das qualidades físicas do grupo normal 8 anos nos subgrupos GT, GM e GC

\begin{tabular}{cccc}
\hline Qualidades físicas & Grupo & Média (pré) \pm DP & Média (pós) \pm DP \\
\hline Força & GT & $17,43 \pm 1,27$ & $19,13 \pm 1,55$ \\
& GM & $21,00 \pm 2,36$ & $29,43 \pm 1,74 *$ \\
Coord (repetições) & GC & $21,13 \pm 2,50$ & $25,07 \pm 3,33$ \\
& GT & $21,57 \pm 2,37$ & $22,75 \pm 2,43$ \\
& GM & $20,10 \pm 2,77$ & $29,43 \pm 2,06 *$ \\
AAO (em graus) & GC & $22,47 \pm 1,60$ & $24,87 \pm 1,96$ \\
& GT & $113,57 \pm 2,07$ & $114,88 \pm 1,96$ \\
FCL (em graus) & GM & $112,90 \pm 2,38$ & $122,00 \pm 3,11 *$ \\
& GC & $114,47 \pm 2,39$ & $114,07 \pm 3,28$ \\
& GT & $23,71 \pm 2,36$ & $24,88 \pm 2,10$ \\
& GM & $23,30 \pm 2,06$ & $31,36 \pm 1,98 *$ \\
& GC & $22,53 \pm 2,23$ & $25,13 \pm 2,83$ \\
\hline
\end{tabular}

Coord: coordenação; AAO: abdução da articulação do ombro; FCL: flexão da coluna lombar; GT: Grupo Tradicional; GM: Grupo Maturacional; GC: Grupo Controle; DP: desvio padrão.

$* \mathrm{p}<0,05$, diferença intragrupo

Pode-se observar, na tabela 4, que, o GM obteve resultados satisfatórios, significativos, no pós-teste, em todas as variáveis, a saber: potência $(\Delta=8,43 ; \mathrm{p}<0,001)$, coordenação $(\Delta=9,33$ repetições, $\mathrm{p}<0,001)$, AAO $\left(\Delta=9,10^{\circ}, \mathrm{p}<0,001\right)$ e FCL $(\Delta=$ $\left.8,06^{\mathrm{o}}, \mathrm{p}<0,001\right)$.

Na tabela 5, são apresentados os resultados da análise intragrupo das qualidades físicas do grupo precoce de 8 anos nos subgrupos GT, GM e GC. 
Tabela 5 - Análise comparativa das qualidades físicas do grupo precoce 8 anos nos subgrupos GT, GM e GC

\begin{tabular}{cccc}
\hline Qualidades físicas & Grupo & Média (pré) \pm DP & Média (pós) \pm DP \\
\hline Potência & GT & $17,14 \pm 1,35$ & $19,00 \pm 1,15$ \\
& GM & $17,71 \pm 1,11$ & $25,00 \pm 1,15^{*}$ \\
& GC & $17,71 \pm 1,80$ & $25,14 \pm 2,41$ \\
Coord (repetições) & GT & $23,43 \pm 1,72$ & $25,71 \pm 1,80$ \\
& GM & $24,57 \pm 0,98$ & $32,00 \pm 1,41 *$ \\
AAO (em graus) & GC & $23,00 \pm 1,73$ & $28,43 \pm 2,82$ \\
& GT & $114,86 \pm 1,57$ & $116,71 \pm 1,50$ \\
FCL (em graus) & GM & $114,00 \pm 3,56$ & $122,29 \pm 3,20 *$ \\
& GC & $116,71 \pm 1,11$ & $121,71 \pm 3,45$ \\
& GT & $23,14 \pm 2,41$ & $25,14 \pm 1,95$ \\
& GM & $22,71 \pm 2,29$ & $30,43 \pm 2,23 *$ \\
& GC & $23,43 \pm 1,72$ & $26,71 \pm 3,25$ \\
\hline
\end{tabular}

Coord: coordenação; AAO: abdução da articulação do ombro; FCL: flexão da coluna lombar; GT: Grupo Tradicional; GM: Grupo Maturacional; GC: Grupo Controle; DP: desvio padrão.

$* \mathrm{p}<0,05$, diferença intragrupo

Pode ser observado, na tabela 5, que, o GM obteve resultados satisfatórios, significativos, no pós-teste, em todas as variáveis, a saber: potência $(\Delta=7,29 ; \mathrm{p}<0,001)$, coordenação $(\Delta=7,43$ repetições, $\mathrm{p}<0,001)$, AAO $\left(\Delta=8,29^{\circ}, \mathrm{p}<0,001\right)$ e FCL $(\Delta=$ $\left.7,71^{\mathrm{o}}, \mathrm{p}<0,001\right)$.

\subsection{RESULTADOS INTRA-GRUPOS NA FAIXA ETÁRIA DE 9 ANOS}

Na tabela 6, são apresentados os resultados da análise intragrupo das qualidades físicas do grupo tardio de 9 anos nos subgrupos GT, GM e GC.

Tabela 6 - Análise comparativa das qualidades físicas do grupo tardio 9 anos nos subgrupos GT, GM e GC

\begin{tabular}{cccc}
\hline Qualidades físicas & Grupo & Média (pré) \pm DP & Média (pós) \pm DP \\
\hline Potência & GT & $22,29 \pm 1,70$ & $24,14 \pm 1,68$ \\
& GM & $22,14 \pm 1,35$ & $27,43 \pm 1,51 *$ \\
& GC & $21,14 \pm 1,95$ & $21,57 \pm 1,72$ \\
Coord (repetições) & GT & $26,29 \pm 1,11$ & $29,29 \pm 1,38^{*}$ \\
& GM & $26,00 \pm 2,16$ & $30,14 \pm 1,35^{*}$ \\
AAO (em graus) & GC & $26,14 \pm 1,07$ & $26,43 \pm 0,98$ \\
& GT & $116,86 \pm 2,91$ & $122,14 \pm 2,48^{*}$ \\
FCL (em graus) & GM & $116,57 \pm 3,55$ & $123,57 \pm 3,21 *$ \\
& GC & $116,29 \pm 2,56$ & $120,29 \pm 3,64$ \\
& GT & $25,57 \pm 1,72$ & $27,71 \pm 1,11$
\end{tabular}




$\begin{array}{lcc}\text { GM } & 25,00 \pm 1,29 & 31,00 \pm 1,41 * \\ \text { GC } & 25,86 \pm 1,35 & 26,00 \pm 2,94\end{array}$

Coord: coordenação; AAO: abdução da articulação do ombro; FCL: flexão da coluna lombar; GT: Grupo Tradicional; GM: Grupo Maturacional; GC: Grupo Controle; DP: desvio padrão

$* \mathrm{p}<0,05$, diferença intragrupo

Pode ser verificado, na tabela 6, que, o GM obteve resultados satisfatórios, significativos, no pós-teste, em todas as variáveis, a saber: potência $(\Delta=5,29 ; \mathrm{p}<0,001)$, coordenação $(\Delta=4,14$ repetições, $\mathrm{p}<0,001)$, AAO $\left(\Delta=7,00^{\circ}, \mathrm{p}=0,002\right)$ e FCL $(\Delta=$ $\left.6,00^{\circ}, \mathrm{p}<0,001\right)$. O GT obteve melhoras significativas no pós-teste nas variáveis coordenação $(\Delta=3,00$ repetições, $\mathrm{p}=0,004)$ e $\operatorname{AAO}\left(\Delta=5,29^{\circ}, \mathrm{p}=0,032\right)$

Na tabela 7, são apresentados os resultados da análise intragrupo das qualidades físicas do grupo normal de 9 anos nos subgrupos GT, GM e GC.

Tabela 7 - Análise comparativa das qualidades físicas do grupo normal 9 anos nos subgrupos GT, GM e GC

\begin{tabular}{lccc}
\hline Qualidades físicas & Grupo & Média (pré) \pm DP & Média (pós) \pm DP \\
\hline Força & GT & $20,63 \pm 3,66$ & $23,80 \pm 4,02$ \\
& GM & $22,00 \pm 4,07$ & $30,30 \pm 2,75 *$ \\
\multirow{2}{*}{ Coord (repetições) } & GC & $20,67 \pm 2,50$ & $22,00 \pm 1,91$ \\
& GT & $24,75 \pm 1,98$ & $27,40 \pm 2,67$ \\
& GM & $25,50 \pm 2,67$ & $29,90 \pm 2,42 *$ \\
AAO (em graus) & GC & $25,08 \pm 3,00$ & $23,92 \pm 1,38$ \\
& GT & $115,38 \pm 1,92$ & $118,00 \pm 1,15$ \\
& GM & $116,63 \pm 1,69$ & $123,20 \pm 3,61 *$ \\
FCL (em graus) & GC & $115,92 \pm 2,47$ & $116,15 \pm 0,90$ \\
& GT & $25,75 \pm 2,12$ & $29,20 \pm 1,14$ \\
& GM & $25,25 \pm 3,77$ & $35,80 \pm 3,39 *$ \\
& GC & $24,83 \pm 4,32$ & $26,54 \pm 0,78$ \\
\hline
\end{tabular}

Coord: coordenação; AAO: abdução da articulação do ombro; FCL: flexão da coluna lombar; GT: Grupo Tradicional; GM: Grupo Maturacional; GC: Grupo Controle; DP: desvio padrão

$* \mathrm{p}<0,05$, diferença intragrupo

Pode-se observar, na tabela 7, que, o GM obteve resultados satisfatórios, significativos, no pós-teste, em todas as variáveis, a saber: potência $(\Delta=8,30 ; \mathrm{p}<0,001)$, coordenação $(\Delta=4,40$ repetições, $\mathrm{p}=0,019)$, AAO $\left(\Delta=6,57^{\circ}, \mathrm{p}<0,001\right)$ e FCL $(\Delta=$ $\left.10,55^{\circ}, \mathrm{p}<0,001\right)$.

Na tabela 8, são apresentados os resultados da análise intragrupo das qualidades físicas do grupo precoce de 9 anos nos subgrupos GT, GM e GC 
Tabela 8 - Análise comparativa das qualidades físicas do grupo precoce 9 anos nos subgrupos GT, GM e GC

\begin{tabular}{cccc}
\hline Qualidades físicas & Grupo & Média (pré) \pm DP & Média (pós) \pm DP \\
\hline Força & GT & $22,00 \pm 3,46$ & $26,29 \pm 1,89 *$ \\
& GM & $21,38 \pm 1,41$ & $26,50 \pm 1,41 *$ \\
& GC & $21,71 \pm 1,60$ & $22,57 \pm 2,37$ \\
Coord (repetições) & GT & $25,71 \pm 2,36$ & $28,00 \pm 2,00$ \\
& GM & $25,25 \pm 2,12$ & $29,00 \pm 3,12$ \\
AAO (em graus) & GC & $25,00 \pm 2,16$ & $25,14 \pm 0,90$ \\
& GT & $115,71 \pm 1,60$ & $117,86 \pm 1,68$ \\
FCL (em graus) & GM & $116,38 \pm 1,51$ & $122,88 \pm 2,75 *$ \\
& GC & $116,71 \pm 1,38$ & $116,86 \pm 3,13$ \\
& GT & $24,14 \pm 2,27$ & $29,29 \pm 1,89 *$ \\
& GM & $24,38 \pm 2,50$ & $29,88 \pm 3,00 *$ \\
\hline
\end{tabular}

Coord: coordenação; AAO: abdução da articulação do ombro; FCL: flexão da coluna lombar; GT: Grupo Tradicional; GM: Grupo Maturacional; GC: Grupo Controle; DP: desvio padrão.

$* \mathrm{p}<0,05$, diferença intragrupo

Pode ser verificado, na tabela 6, que, o GM obteve resultados satisfatórios, significativos, no pós-teste, nas qualidades físicas potência $(\Delta=5,12 ; \mathrm{p}=0,002)$, AAO $\left(\Delta=6,50^{\circ}, \mathrm{p}<0,001\right)$ e FCL $\left(\Delta=5,50^{\circ}, \mathrm{p}<0,007\right)$. O GT obteve melhoras significativas no pós-teste nas variáveis potência $(\Delta=4,29$ repetições, $\mathrm{p}=0,027)$ e FCL $\left(\Delta=5,14^{\circ}, \mathrm{p}=\right.$ $0,025)$.

\subsection{RESULTADOS INTER-GRUPOS NA FAIXA ETÁRIA DE 8 E 9 ANOS}

Na tabela 9, são apresentados os resultados da análise intergrupos dos grupos Precoce, Normal e Tardio no GT, GM e GC na faixa etária de 8 anos quanto à variável potência. 
Tabela 9 - Análise comparativa intergrupo da qualidade física força(potência) na idade de 8 anos dos subgrupos GT, GM e GC nos momentos pré e pós-teste

\begin{tabular}{|c|c|c|c|}
\hline Grupo (I) & Grupo $(\mathrm{J})$ & $\Delta$ (pós) & p-valor \\
\hline GT-tardio & GM-tardio & $-2,29$ & 0,942 \\
\hline GT-tardio & GC-tardio & 1,14 & 0,999 \\
\hline GT-tardio & GT-normal & 0,88 & 1,000 \\
\hline GT-tardio & GM-normal & $-9,4286^{*}$ & 0,000 \\
\hline GT-tardio & GC-normal & $-5,0667 *$ & 0,027 \\
\hline GT-tardio & GT-precoce & 1,00 & 1,000 \\
\hline GT-tardio & GM-precoce & $-5,00$ & 0,119 \\
\hline GT-tardio & GC-precoce & $-5,14$ & 0,097 \\
\hline GM-tardio & GC-tardio & 3,43 & 0,614 \\
\hline GM-tardio & GT-normal & 3,16 & 0,677 \\
\hline GM-tardio & GM-normal & $-7,1429 *$ & 0,000 \\
\hline GM-tardio & GC-normal & $-2,78$ & 0,684 \\
\hline GM-tardio & GT-precoce & 3,29 & 0,669 \\
\hline GM-tardio & GM-precoce & $-2,71$ & 0,856 \\
\hline GM-tardio & GC-precoce & $-2,86$ & 0,816 \\
\hline GC-tardio & GT-normal & $-0,27$ & 1,000 \\
\hline GC-tardio & GM-normal & $-10,5714^{*}$ & 0,000 \\
\hline GC-tardio & GC-normal & $-6,2095^{*}$ & 0,002 \\
\hline GC-tardio & GT-precoce & $-0,14$ & 1,000 \\
\hline GC-tardio & GM-precoce & $-6,1429 *$ & 0,018 \\
\hline GC-tardio & GC-precoce & $-6,2857 *$ & 0,013 \\
\hline GT-normal & GM-normal & $-10,3036^{*}$ & 0,000 \\
\hline GT-normal & GC-normal & $-5,9417 *$ & 0,000 \\
\hline GT-normal & GT-precoce & 0,13 & 1,000 \\
\hline GT-normal & GM-precoce & $-5,8750 *$ & 0,020 \\
\hline GT-normal & GC-precoce & $-6,0179^{*}$ & 0,015 \\
\hline GM-normal & GC-normal & $4,3619^{*}$ & 0,001 \\
\hline GM-normal & GT-precoce & $10,4286^{*}$ & 0,000 \\
\hline GM-normal & GM-precoce & 4,43 & 0,101 \\
\hline GM-normal & GC-precoce & 4,29 & 0,128 \\
\hline GC-normal & GT-precoce & $6,0667^{*}$ & 0,003 \\
\hline GC-normal & GM-precoce & 0,07 & 1,000 \\
\hline GC-normal & GC-precoce & $-0,08$ & 1,000 \\
\hline GT-precoce & GM-precoce & $-6,0000 *$ & 0,000 \\
\hline GT-precoce & GC-precoce & $-6,1429 *$ & 0,000 \\
\hline GM-precoce & GC-precoce & $-0,14$ & 1,000 \\
\hline
\end{tabular}

$\Delta$ : diferença de média $(\mathrm{em} \mathrm{cm}) * \mathrm{p}<0,05$.

Analisando-se a tabela 9, observa-se que houve diferenças intergrupos, no momento pós-teste, na variável analisada, entre os grupos: GT tardio com GM normal e GC normal, a favor dos grupos "normal"; GC tardio com GM normal, GC normal, GM precoce e GC normal, a favor dos grupos "normal” e "precoce"; GT normal com GM 
normal, GC normal, GM precoce e GC precoce, a favor destes últimos quatro grupos; GM normal com GC normal e GT precoce, a favor do GM normal; GT precoce a favor do GC normal e GT precoce com GM precoce e GC precoce, a favor dos dois últimos grupos. Desta forma, em última análise, pôde-se observar duas características: a superioridade do precoce em relação as demais classificações e do GM, em relação aos demais grupos.

Na tabela 10, são apresentados os resultados da análise intergrupos dos grupos Precoce, Normal e Tardio no GT, GM e GC na faixa etária de 8 anos quanto à variável coordenação. 
Tabela 10 - Análise comparativa intergrupo da qualidade física coordenação na idade de 8 anos dos subgrupos GT, GM e GC nos momentos pré e pós-teste

\begin{tabular}{|c|c|c|c|}
\hline Grupo (I) & Grupo (J) & $\Delta$ (pós) & p-valor \\
\hline GT-tardio & GM-tardio & $-6,5714^{*}$ & 0,000 \\
\hline GT-tardio & GC-tardio & $-0,29$ & 1,000 \\
\hline GT-tardio & GT-normal & $-2,46$ & 0,734 \\
\hline GT-tardio & GM-normal & $-9,1429 *$ & 0,000 \\
\hline GT-tardio & GC-normal & $-4,5810^{*}$ & 0,008 \\
\hline GT-tardio & GT-precoce & $-5,4286^{*}$ & 0,007 \\
\hline GT-tardio & GM-precoce & $-11,7143^{*}$ & 0,000 \\
\hline GT-tardio & GC-precoce & $-8,1429^{*}$ & 0,000 \\
\hline GM-tardio & GC-tardio & $6,2857^{*}$ & 0,002 \\
\hline GM-tardio & GT-normal & 4,11 & 0,091 \\
\hline GM-tardio & GM-normal & $-2,57$ & 0,535 \\
\hline GM-tardio & GC-normal & 1,99 & 0,822 \\
\hline GM-tardio & GT-precoce & 1,14 & 0,998 \\
\hline GM-tardio & GM-precoce & $-5,1429^{*}$ & 0,013 \\
\hline GM-tardio & GC-precoce & $-1,57$ & 0,980 \\
\hline GC-tardio & GT-normal & $-2,18$ & 0,847 \\
\hline GC-tardio & GM-normal & $-8,8571^{*}$ & 0,000 \\
\hline GC-tardio & GC-normal & $-4,2952 *$ & 0,018 \\
\hline GC-tardio & GT-precoce & $-5,1429 *$ & 0,013 \\
\hline GC-tardio & GM-precoce & $-11,4286^{*}$ & 0,000 \\
\hline GC-tardio & GC-precoce & $-7,8571^{*}$ & 0,000 \\
\hline GT-normal & GM-normal & $-6,6786^{*}$ & 0,000 \\
\hline GT-normal & GC-normal & $-2,12$ & 0,717 \\
\hline GT-normal & GT-precoce & $-2,96$ & 0,491 \\
\hline GT-normal & GM-precoce & $-9,2500^{*}$ & 0,000 \\
\hline GT-normal & GC-precoce & $-5,6786^{*}$ & 0,002 \\
\hline GM-normal & GC-normal & $4,5619^{*}$ & 0,000 \\
\hline GM-normal & GT-precoce & 3,71 & 0,084 \\
\hline GM-normal & GM-precoce & $-2,57$ & 0,535 \\
\hline GM-normal & GC-precoce & 1,00 & 0,997 \\
\hline GC-normal & GT-precoce & $-0,85$ & 0,999 \\
\hline GC-normal & GM-precoce & $-7,1333^{*}$ & 0,000 \\
\hline GC-normal & GC-precoce & $-3,56$ & 0,106 \\
\hline GT-precoce & GM-precoce & $-6,2857^{*}$ & 0,000 \\
\hline GT-precoce & GC-precoce & $-2,71$ & 0,658 \\
\hline GM-precoce & GC-precoce & $3,57 *$ & 0,038 \\
\hline
\end{tabular}

$\Delta$ : diferença de média (valores em número de repetições); ${ }^{*} \mathrm{p}<0,05$.

Analisando-se a tabela 10, observa-se que houve diferenças intergrupos, no momento pós-teste, na variável analisada, entre os grupos: GT tardio com GM tardio, GM normal, GC normal, GT precoce, GM precoce e GC normal a favor dos seis últimos 
grupos; GC tardio com GM tardio, a favor deste último; GC tardio com GM normal, GC normal, GT precoce, GM precoce e GC normal, a favor dos cinco últimos grupos; GT normal com GM normal, GM precoce e GC precoce, a favor destes últimos três grupos; GC normal com GM precoce e GM normal, a favor dos dois grupos maturacionais; GM precoce com GC precoce e GT precoce, a favor do grupo maturacional. Desta forma, pôde-se observar a predominância dos grupos "precoce" (principalmente o maturacional) em relação aos demais grupos.

Na tabela 11, são apresentados os resultados da análise intergrupos dos grupos Precoce, Normal e Tardio no GT, GM e GC na faixa etária de 8 anos quanto à variável flexibilidade, no movimento de AAO. 
Tabela 11 - Análise comparativa intergrupo da qualidade física AAO na idade de 8 anos dos subgrupos GT, GM e GC nos momentos pré e pós-teste

\begin{tabular}{|c|c|c|c|}
\hline Grupo (I) & Grupo $(\mathrm{J})$ & $\Delta$ (pós) & p-valor \\
\hline GT-tardio & GM-tardio & $-12,8571 *$ & 0,000 \\
\hline GT-tardio & GC-tardio & $-4,00$ & 0,453 \\
\hline GT-tardio & GT-normal & $-1,59$ & 0,995 \\
\hline GT-tardio & GM-normal & $-8,7143^{*}$ & 0,000 \\
\hline GT-tardio & GC-normal & $-0,78$ & 1,000 \\
\hline GT-tardio & GT-precoce & $-3,43$ & 0,668 \\
\hline GT-tardio & GM-precoce & $-9,0000^{*}$ & 0,000 \\
\hline GT-tardio & GC-precoce & $-8,4286^{*}$ & 0,000 \\
\hline GM-tardio & GC-tardio & $8,8571 *$ & 0,000 \\
\hline GM-tardio & GT-normal & $11,2679 *$ & 0,000 \\
\hline GM-tardio & GM-normal & 4,14 & 0,206 \\
\hline GM-tardio & GC-normal & $12,0762 *$ & 0,000 \\
\hline GM-tardio & GT-precoce & $9,4286^{*}$ & 0,000 \\
\hline GM-tardio & GM-precoce & 3,86 & 0,506 \\
\hline GM-tardio & GC-precoce & 4,43 & 0,305 \\
\hline GC-tardio & GT-normal & 2,41 & 0,926 \\
\hline GC-tardio & GM-normal & $-4,71$ & 0,086 \\
\hline GC-tardio & GC-normal & 3,22 & 0,544 \\
\hline GC-tardio & GT-precoce & 0,57 & 1,000 \\
\hline GC-tardio & GM-precoce & $-5,00$ & 0,158 \\
\hline GC-tardio & GC-precoce & $-4,43$ & 0,305 \\
\hline GT-normal & GM-normal & $-7,1250 *$ & 0,000 \\
\hline GT-normal & GC-normal & 0,81 & 1,000 \\
\hline GT-normal & GT-precoce & $-1,84$ & 0,986 \\
\hline GT-normal & GM-precoce & $-7,4107 *$ & 0,001 \\
\hline GT-normal & GC-precoce & $-6,8393 *$ & 0,005 \\
\hline GM-normal & GC-normal & $7,9333^{*}$ & 0,000 \\
\hline GM-normal & GT-precoce & $5,2857^{*}$ & 0,030 \\
\hline GM-normal & GM-precoce & $-0,29$ & 1,000 \\
\hline GM-normal & GC-precoce & 0,29 & 1,000 \\
\hline GC-normal & GT-precoce & $-2,65$ & 0,783 \\
\hline GC-normal & GM-precoce & $-8,2190^{*}$ & 0,000 \\
\hline GC-normal & GC-precoce & $-7,6476^{*}$ & 0,000 \\
\hline GT-precoce & GM-precoce & $-5,57 *$ & 0,017 \\
\hline GT-precoce & GC-precoce & $-5,00$ & 0,053 \\
\hline GM-precoce & GC-precoce & 0,57 & 1,000 \\
\hline
\end{tabular}

$\Delta:$ diferença de média (valores em graus); ${ }^{*} \mathrm{p}<0,05$.

Analisando-se a tabela 11, observa-se que houve diferenças intergrupos, no momento pós-teste, na variável analisada, entre os grupos: GT tardio com GM tardio, GM normal, GM precoce e GC precoce a favor dos quatro últimos grupos; GM tardio com GC tardio, GT normal, GC normal e GT precoce, a favor do GM tardio; GT normal 
com GM normal, GM precoce e GC precoce, a favor destes últimos três grupos; GC normal com GM precoce e GC precoce, a favor dos dois grupos precoces; GM normal com GC normal e GT precoce, a favor do grupo maturacional; GT precoce com GM precoce, a favor deste último. Nesse sentido, pôde-se verificar a predominância do grupo “ maturacional”, em relação aos demais grupos.

Na tabela 12, são apresentados os resultados da análise intergrupos dos grupos Precoce, Normal e Tardio no GT, GM e GC na faixa etária de 8 anos quanto à variável flexibilidade, no movimento de FCL. 
Tabela 12 - Análise comparativa intergrupo da qualidade física FCL na idade de 8 anos dos subgrupos GT, GM e GC nos momentos pré e pós-teste

\begin{tabular}{|c|c|c|c|}
\hline Grupo (I) & Grupo $(\mathrm{J})$ & $\Delta$ (pós) & p-valor \\
\hline GT-tardio & GM-tardio & $-5,8571 *$ & 0,000 \\
\hline GT-tardio & GC-tardio & 1,00 & 0,999 \\
\hline GT-tardio & GT-normal & $-0,59$ & 1,000 \\
\hline GT-tardio & GM-normal & $-7,0714^{*}$ & 0,000 \\
\hline GT-tardio & GC-normal & $-0,85$ & 1,000 \\
\hline GT-tardio & GT-precoce & $-0,86$ & 1,000 \\
\hline GT-tardio & GM-precoce & $-6,1429^{*}$ & 0,003 \\
\hline GT-tardio & GC-precoce & $-2,43$ & 0,842 \\
\hline GM-tardio & GC-tardio & $6,8571^{*}$ & 0,000 \\
\hline GM-tardio & GT-normal & $5,2679 *$ & 0,016 \\
\hline GM-tardio & GM-normal & $-1,21$ & 0,994 \\
\hline GM-tardio & GC-normal & $5,0095^{*}$ & 0,006 \\
\hline GM-tardio & GT-precoce & $5,0000 *$ & 0,040 \\
\hline GM-tardio & GM-precoce & $-0,29$ & 1,000 \\
\hline GM-tardio & GC-precoce & 3,43 & 0,426 \\
\hline GC-tardio & GT-normal & $-1,59$ & 0,983 \\
\hline GC-tardio & GM-normal & $-8,0714^{*}$ & 0,000 \\
\hline GC-tardio & GC-normal & $-1,85$ & 0,914 \\
\hline GC-tardio & GT-precoce & $-1,86$ & 0,963 \\
\hline GC-tardio & GM-precoce & $-7,1429 *$ & 0,000 \\
\hline GC-tardio & GC-precoce & $-3,43$ & 0,426 \\
\hline GT-normal & GM-normal & $-6,4821^{*}$ & 0,000 \\
\hline GT-normal & GC-normal & $-0,26$ & 1,000 \\
\hline GT-normal & GT-precoce & $-0,27$ & 1,000 \\
\hline GT-normal & GM-precoce & $-5,5536^{*}$ & 0,008 \\
\hline GT-normal & GC-precoce & $-1,84$ & 0,958 \\
\hline GM-normal & GC-normal & $6,2238^{*}$ & 0,000 \\
\hline GM-normal & GT-precoce & $6,2143^{*}$ & 0,000 \\
\hline GM-normal & GM-precoce & 0,93 & 0,999 \\
\hline GM-normal & GC-precoce & $4,6429 *$ & 0,019 \\
\hline GC-normal & GT-precoce & $-0,01$ & 1,000 \\
\hline GC-normal & GM-precoce & $-5,2952 *$ & 0,003 \\
\hline GC-normal & GC-precoce & $-1,58$ & 0,965 \\
\hline GT-precoce & GM-precoce & $-5,2857 *$ & 0,011 \\
\hline GT-precoce & GC-precoce & $-1,57$ & 0,987 \\
\hline GM-precoce & GC-precoce & 3,71 & 0,311 \\
\hline
\end{tabular}

$\Delta:$ diferença de média (valores em graus); ${ }^{*} \mathrm{p}<0,05$.

Analisando-se a tabela 12, observa-se que houve diferenças intergrupos, no momento pós-teste, na variável analisada, entre os grupos: GT tardio com GM tardio, GM normal e GM precoce, a favor dos três últimos grupos; GM tardio com GC tardio, GT normal, GC normal e GT precoce, a favor do GM tardio; GT normal com GM 
normal e GM precoce, a favor destes últimos dois grupos; GC tardio com GM precoce e GM normal, a favor dos dois grupos precoces; GM normal com GC normal, GC precoce e GT precoce, a favor do grupo maturacional; GM precoce com GC normal e GT precoce, a favor do GM precoce. Nesse sentido, é clara a predominância do grupo “ maturacional", em relação aos demais grupos.

Na tabela 13, são apresentados os resultados da análise intergrupos dos grupos Precoce, Normal e Tradio no GT, GM e GC na faixa etária de 9 anos quanto à variável força. 
Tabela 13 - Análise comparativa intergrupo da qualidade física força explosiva (potência) na idade de 9 anos dos subgrupos GT, GM e GC nos momentos pré e pós-teste

\begin{tabular}{|c|c|c|c|}
\hline Grupo (I) & Grupo $(\mathrm{J})$ & $\Delta$ (pós) & p-valor \\
\hline GT-tardio & GM-tardio & $-3,29 *$ & 0,009 \\
\hline GT-tardio & GC-tardio & 2,57 & 0,840 \\
\hline GT-tardio & GT-normal & 0,34 & 1,000 \\
\hline GT-tardio & GM-normal & $-6,1571 *$ & 0,002 \\
\hline GT-tardio & GC-normal & 2,14 & 0,875 \\
\hline GT-tardio & GT-precoce & $-2,14$ & 0,938 \\
\hline GT-tardio & GM-precoce & $-2,36$ & 0,878 \\
\hline GT-tardio & GC-precoce & 1,57 & 0,991 \\
\hline GM-tardio & GC-tardio & $5,8571 *$ & 0,000 \\
\hline GM-tardio & GT-normal & 3,63 & 0,307 \\
\hline GM-tardio & GM-normal & $-2,87$ & 0,641 \\
\hline GM-tardio & GC-normal & $5,4286^{*}$ & 0,006 \\
\hline GM-tardio & GT-precoce & 1,14 & 0,999 \\
\hline GM-tardio & GM-precoce & 0,93 & 1,000 \\
\hline GM-tardio & GC-precoce & 4,86 & 0,084 \\
\hline GC-tardio & GT-normal & $-2,23$ & 0,882 \\
\hline GC-tardio & GM-normal & $-8,7286^{*}$ & 0,000 \\
\hline GC-tardio & GC-normal & $-0,43$ & 1,000 \\
\hline GC-tardio & GT-precoce & $-4,71$ & 0,106 \\
\hline GC-tardio & GM-precoce & $-4,93$ & 0,057 \\
\hline GC-tardio & GC-precoce & $-1,00$ & 1,000 \\
\hline GT-normal & GM-normal & $-6,5000^{*}$ & 0,002 \\
\hline GT-normal & GC-normal & 1,80 & 0,912 \\
\hline GT-normal & GT-precoce & $-2,49$ & 0,800 \\
\hline GT-normal & GM-precoce & $-2,70$ & 0,670 \\
\hline GT-normal & GC-precoce & 1,23 & 0,997 \\
\hline GM-normal & GC-normal & $8,3000^{*}$ & 0,000 \\
\hline GM-normal & GT-precoce & 4,01 & 0,181 \\
\hline GM-normal & GM-precoce & 3,80 & 0,199 \\
\hline GM-normal & GC-precoce & $7,7286^{*}$ & 0,000 \\
\hline GC-normal & GT-precoce & $-4,29$ & 0,080 \\
\hline GC-normal & GM-precoce & $-4,5000 *$ & 0,035 \\
\hline GC-normal & GC-precoce & $-0,57$ & 1,000 \\
\hline GT-precoce & GM-precoce & $-0,21$ & 1,000 \\
\hline GT-precoce & GC-precoce & 3,71 & 0,389 \\
\hline GM-precoce & GC-precoce & $3,93 *$ & 0,043 \\
\hline
\end{tabular}

$\Delta$ : diferença de média (valores em $\mathrm{cm}$ ) ${ }^{*} \mathrm{p}<0,05$. 
Analisando-se a tabela 13, observa-se que houve diferenças intergrupos, no momento pós-teste, na variável analisada, entre os grupos: GM normal com GT tardio, GC tardio, GT normal, GC normal e GC precoce, a favor do GM normal; GM tardio com GT tardio, GC tardio e GC normal, a favor do GM tardio; GM precoce com GC normal e GC precoce, a favor do grupo maturacional. Dessa forma, ressalta-se a predominância dos três grupos maturacionais (normal, tardio e precoce), em relação aos demais grupos.

Na tabela 14, são apresentados os resultados da análise intergrupos dos grupos Precoce, Normal e Tardio no GT, GM e GC na faixa etária de 9 anos quanto à variável coordenação. 
Tabela 14 - Análise comparativa intergrupo da qualidade física coordenação na idade de 9 anos dos subgrupos GT, GM e GC nos momentos pré e pós-teste

\begin{tabular}{|c|c|c|c|}
\hline Grupo (I) & Grupo $(\mathrm{J})$ & $\Delta$ (pós) & p-valor \\
\hline GT-tardio & GM-tardio & $-0,86$ & 1,000 \\
\hline GT-tardio & GC-tardio & $2,86^{*}$ & 0,006 \\
\hline GT-tardio & GT-normal & 1,89 & 0,878 \\
\hline GT-tardio & GM-normal & $-0,61$ & 1,000 \\
\hline GT-tardio & GC-normal & $5,3626^{*}$ & 0,000 \\
\hline GT-tardio & GT-precoce & 1,29 & 0,993 \\
\hline GT-tardio & GM-precoce & 0,29 & 1,000 \\
\hline GT-tardio & GC-precoce & 4,14 & 0,075 \\
\hline GM-tardio & GC-tardio & $3,71 *$ & 0,000 \\
\hline GM-tardio & GT-normal & 2,74 & 0,460 \\
\hline GM-tardio & GM-normal & 0,24 & 1,000 \\
\hline GM-tardio & GC-normal & $6,2198^{*}$ & 0,000 \\
\hline GM-tardio & GT-precoce & 2,14 & 0,846 \\
\hline GM-tardio & GM-precoce & 1,14 & 0,996 \\
\hline GM-tardio & GC-precoce & $5,0000^{*}$ & 0,011 \\
\hline GC-tardio & GT-normal & $-0,97$ & 0,998 \\
\hline GC-tardio & GM-normal & $-3,47$ & 0,151 \\
\hline GC-tardio & GC-normal & 2,51 & 0,520 \\
\hline GC-tardio & GT-precoce & $-1,57$ & 0,973 \\
\hline GC-tardio & GM-precoce & $-2,57$ & 0,622 \\
\hline GC-tardio & GC-precoce & 1,29 & 0,993 \\
\hline GT-normal & GM-normal & $-2,50$ & 0,454 \\
\hline GT-normal & GC-normal & $3,4769^{*}$ & 0,042 \\
\hline GT-normal & GT-precoce & $-0,60$ & 1,000 \\
\hline GT-normal & GM-precoce & $-1,60$ & 0,938 \\
\hline GT-normal & GC-precoce & 2,26 & 0,722 \\
\hline GM-normal & GC-normal & $5,9769 *$ & 0,000 \\
\hline GM-normal & GT-precoce & 1,90 & 0,873 \\
\hline GM-normal & GM-precoce & 0,90 & 0,999 \\
\hline GM-normal & GC-precoce & $4,7571^{*}$ & 0,007 \\
\hline GC-normal & GT-precoce & $-4,0769 *$ & 0,025 \\
\hline GC-normal & GM-precoce & $-5,0769 *$ & 0,001 \\
\hline GC-normal & GC-precoce & $-1,22$ & 0,987 \\
\hline GT-precoce & GM-precoce & $-1,00$ & 0,998 \\
\hline GT-precoce & GC-precoce & 2,86 & 0,520 \\
\hline GM-precoce & GC-precoce & 3,86 & 0,102 \\
\hline
\end{tabular}

$\Delta$ : diferença de média (valores em número de repetições); ${ }^{*} \mathrm{p}<0,05$. 
Analisando-se a tabela 14, observa-se que houve diferenças intergrupos, no momento pós-teste, na variável analisada, entre os grupos: GC tardio com GM tardio e GT tardio, a favor dos dois grupos de treinamento; GC precoce com GM tardio, a favor deste último; O GC normal foi desfavorável a todos os grupos (tardio, normal e precoce) do treinamento tradicional e maturacional. Nesse caso, pode ser observado uma vantagem em ambos os grupos de treinamento.

Na tabela 15, são apresentados os resultados da análise intergrupos dos grupos Precoce, Normal e Tardio no GT, GM e GC na faixa etária de 9 anos quanto à variável flexibilidade, no movimento de AAO. 
Tabela 15 - Análise comparativa intergrupo da qualidade física AAO na idade de 9 anos dos subgrupos GT, GM e GC nos momentos pré e pós-teste

\begin{tabular}{|c|c|c|c|}
\hline Grupo (I) & Grupo $(\mathrm{J})$ & $\Delta$ (pós) & p-valor \\
\hline GT-tardio & GM-tardio & $-1,43$ & 0,997 \\
\hline GT-tardio & GC-tardio & 1,86 & 0,985 \\
\hline GT-tardio & GT-normal & 4,14 & 0,245 \\
\hline GT-tardio & GM-normal & $-1,06$ & 0,999 \\
\hline GT-tardio & GC-normal & $5,9890 *$ & 0,005 \\
\hline GT-tardio & GT-precoce & 4,29 & 0,308 \\
\hline GT-tardio & GM-precoce & $-0,73$ & 1,000 \\
\hline GT-tardio & GC-precoce & 5,29 & 0,085 \\
\hline GM-tardio & GC-tardio & 3,29 & 0,682 \\
\hline GM-tardio & GT-normal & $5,5714 *$ & 0,024 \\
\hline GM-tardio & GM-normal & 0,37 & 1,000 \\
\hline GM-tardio & GC-normal & $7,4176^{*}$ & 0,000 \\
\hline GM-tardio & GT-precoce & $5,7143^{*}$ & 0,043 \\
\hline GM-tardio & GM-precoce & 0,70 & 1,000 \\
\hline GM-tardio & GC-precoce & $6,7143 *$ & 0,007 \\
\hline GC-tardio & GT-normal & 2,29 & 0,914 \\
\hline GC-tardio & GM-normal & $-2,91$ & 0,727 \\
\hline GC-tardio & GC-normal & 4,13 & 0,189 \\
\hline GC-tardio & GT-precoce & 2,43 & 0,924 \\
\hline GC-tardio & GM-precoce & $-2,59$ & 0,873 \\
\hline GC-tardio & GC-precoce & 3,43 & 0,628 \\
\hline GT-normal & GM-normal & $-5,2000 *$ & 0,000 \\
\hline GT-normal & GC-normal & 1,85 & 0,937 \\
\hline GT-normal & GT-precoce & 0,14 & 1,000 \\
\hline GT-normal & GM-precoce & $-4,88$ & 0,062 \\
\hline GT-normal & GC-precoce & 1,14 & 0,999 \\
\hline GM-normal & GC-normal & $7,0462 *$ & 0,000 \\
\hline GM-normal & GT-precoce & $5,3429 *$ & 0,038 \\
\hline GM-normal & GM-precoce & 0,33 & 1,000 \\
\hline GM-normal & GC-precoce & $6,3429 *$ & 0,005 \\
\hline GC-normal & GT-precoce & $-1,70$ & 0,980 \\
\hline GC-normal & GM-precoce & $-6,7212 *$ & 0,000 \\
\hline GC-normal & GC-precoce & $-0,70$ & 1,000 \\
\hline GT-precoce & GM-precoce & $-5,02 *$ & 0,004 \\
\hline GT-precoce & GC-precoce & 1,00 & 1,000 \\
\hline GM-precoce & GC-precoce & $6,0179 *$ & 0,000 \\
\hline
\end{tabular}

$\Delta:$ diferença de média (valores em graus); ${ }^{*} \mathrm{p}<0,05$.

Analisando-se a tabela 15, observa-se que houve diferenças intergrupos, no momento pós-teste, na variável analisada, entre os grupos: GC normal e GT tardio, a favor deste último; GM tardio com GT normal, GT precoce, GC normal e GC precoce, a favor do GM tardio; GM normal com GT normal, GC normal, GT precoce e GC 
precoce, a favor do GM normal; GM precoce com GT precoce, GC normal e GC precoce, a favor do GM precoce. Em última análise, infere-se a superioridade do treinamento maturacional nos grupos tardio, normal e precoce.

Na tabela 16, são apresentados os resultados da análise intergrupos dos grupos Precoce, Normal e Tardio no GT, GM e GC na faixa etária de 9 anos quanto à variável flexibilidade, no movimento de FCL. 
Tabela 16 - Análise comparativa intergrupo da qualidade física FCL na idade de 9 anos dos subgrupos GT, GM e GC nos momentos pré e pós-teste

\begin{tabular}{|c|c|c|c|}
\hline Grupo (I) & Grupo $(\mathrm{J})$ & $\Delta$ (pós) & p-valor \\
\hline GT-tardio & GM-tardio & $-3,29 *$ & 0,014 \\
\hline GT-tardio & GC-tardio & 1,71 & 0,979 \\
\hline GT-tardio & GT-normal & $-1,49$ & 0,986 \\
\hline GT-tardio & GM-normal & $-8,0857^{*}$ & 0,000 \\
\hline GT-tardio & GC-normal & 1,18 & 0,996 \\
\hline GT-tardio & GT-precoce & $-1,57$ & 0,988 \\
\hline GT-tardio & GM-precoce & $-2,16$ & 0,901 \\
\hline GT-tardio & GC-precoce & 2,43 & 0,848 \\
\hline GM-tardio & GC-tardio & $5,0000 *$ & 0,000 \\
\hline GM-tardio & GT-normal & 1,80 & 0,953 \\
\hline GM-tardio & GM-normal & $-4,8000 *$ & 0,029 \\
\hline GM-tardio & GC-normal & $4,4615^{*}$ & 0,036 \\
\hline GM-tardio & GT-precoce & 1,71 & 0,979 \\
\hline GM-tardio & GM-precoce & 1,13 & 0,998 \\
\hline GM-tardio & GC-precoce & $5,7143^{*}$ & 0,010 \\
\hline GC-tardio & GT-normal & $-3,20$ & 0,420 \\
\hline GC-tardio & GM-normal & $-9,8000 *$ & 0,000 \\
\hline GC-tardio & GC-normal & $-0,54$ & 1,000 \\
\hline GC-tardio & GT-precoce & $-3,29$ & 0,501 \\
\hline GC-tardio & GM-precoce & $-3,88$ & 0,224 \\
\hline GC-tardio & GC-precoce & 0,71 & 1,000 \\
\hline GT-normal & GM-normal & $-6,6000 *$ & 0,001 \\
\hline GT-normal & GC-normal & 2,66 & 0,458 \\
\hline GT-normal & GT-precoce & $-0,09$ & 1,000 \\
\hline GT-normal & GM-precoce & $-0,68$ & 1,000 \\
\hline GT-normal & GC-precoce & 3,91 & 0,158 \\
\hline GM-normal & GC-normal & $9,2615^{*}$ & 0,000 \\
\hline GM-normal & GT-precoce & $6,5143^{*}$ & 0,000 \\
\hline GM-normal & GM-precoce & $5,9250 *$ & 0,001 \\
\hline GM-normal & GC-precoce & $10,5143 *$ & 0,000 \\
\hline GC-normal & GT-precoce & $-2,75$ & 0,569 \\
\hline GC-normal & GM-precoce & $-3,34$ & 0,234 \\
\hline GC-normal & GC-precoce & 1,25 & 0,994 \\
\hline GT-precoce & GM-precoce & $-0,59$ & 1,000 \\
\hline GT-precoce & GC-precoce & 4,00 & 0,224 \\
\hline GM-precoce & GC-precoce & $4,59 *$ & 0,048 \\
\hline
\end{tabular}

$\Delta:$ diferença de média (valores em graus); ${ }^{*} \mathrm{p}<0,05$.

Analisando-se a tabela 16, observa-se que houve diferenças intergrupos, no momento pós-teste, na variável analisada, entre os grupos: GM tardio com GT tardio, GC tardio, GC normal e GC precoce, a favor do GM tardio; GM precoce com GC precoce, a favor do grupo maturacional; o GM normal foi significativamente melhor 
que todos os demais grupos. Nessa variável, em particular, observou-se uma superioridade do GM normal. 
AVALIAÇÃO DOS EFEITOS DE DUAS METODOLOGIAS DE FORMAÇÃO ESPORTIVA EM DISTINTOS NÍVEIS DE MATURAÇÃO BIOLÓGICA SOBRE AS QUALIDADES FÍSICAS DE PRATICANTES DE GINÁSTICA RÍTMICA DE 8 E 9 ANOS

\section{CAPÍTULO VI - DISCUSSÃO DOS RESULTADOS}




\section{CAPÍTULO VI - DISCUSSÃO DOS RESULTADOS}

A avaliação da maturação biológica é uma prática comum na área da Medicina e da Auxologia Desportiva. Na literatura, são referenciados os seguintes sistemas: maturação esquelética, sexual, somática, dentária e bioquímica/hormonal. É unânime considerar que a maturação esquelética é o melhor sistema para avaliar a idade biológica e o estatuto maturacional de uma criança ou jovem, embora grande parte dos estudos avalie pela observação da pilosidade ${ }^{(76-78)}$. As mudanças que ocorrem em cada osso desde o início do seu processo de ossificação até à morfologia adulta são uniformes e ocorrem de modo regular e irreversível. A estimação da idade óssea de uma criança ou jovem exige uma elevada precisão ${ }^{(79)}$. Nesse sentido, deve ser ressaltada a significância desse trabalho para a comunidade científica, uma vez que se propôs a utilização da avaliação radiológica dessa maturação biológica.

Semelhante ao método de Greulich \& Pyle ${ }^{(73)}$, utilizado no presente artigo, Haiter Neto et al. ${ }^{(44)}$ realizaram uma pesquisa, na população brasileira, que teve como objetivo verificar se os métodos de estimativa da idade óssea de Greulich \& Pyle ${ }^{(73)}$ e Tanner \& Whitehouse ${ }^{(80)}$ poderiam ser aplicados à população brasileira e qual desses métodos seria o mais confiável quando comparados à idade cronológica. Foram analisadas 160 radiografias de crianças de ambos os sexos, dos 6 aos 14 anos de idade. Em ambos os métodos, os resultados demonstraram correlações elevadas com a idade cronológica das crianças $(\mathrm{r}=0,95)$. Face a fatores de correção introduzidos, os autores concluíram que os dois métodos aplicáveis à população Brasileira, dão sustentação à escolha da técnica utilizada em nosso estudo.

$\mathrm{Na}$ faixa etária dos 6 aos 10 anos que acontece a transição do refinamento das habilidades motoras fundamentais para as habilidades motoras refinadas que propiciam o estabelecimento de jogos de liderança e o desenvolvimento de habilidades atléticas. Ambientes inadequados, inibidores ou pouco estimulantes podem repercutir de forma negativa no desenvolvimento infantil ${ }^{(81)}$. Devido a esta extensão de faixa etária é que o vigente estudo optou na análise de crianças com idade de 8 e 9 anos.

Baseado no exposto do parágrafo anterior, Valdivia et al. ${ }^{(82)}$ encontraram níveis mais elevados de desempenho motor nas crianças de 8 e 9 anos quando comparadas com as de idade mais elevada como de 12 a 14 anos; provavelmente, devido à diminuição da procura e participação de atividades recreativas e esportivas de forma espontânea entre as 
crianças mais velhas. Contrariamente, os estudos de Lopes e Maia ${ }^{(83)}$ e Deus et al. ${ }^{(84)}$ encontraram resultados diversos, que indicam aumentos nos níveis de desempenho motor na proporção em que a idade da criança avança. Tal achado, segundo Valdivia et al. ${ }^{(82)}$ pode estar relacionado aos efeitos do processo de crescimento e maturação.

O processo de detecção e seleção é objeto de pesquisa na ciência do esporte. Embora a "escola" seja mencionada pelos técnicos como estratégia de seleção, de jovens para determinadas práticas desportivas, na investigação de Silva Filho et al. ${ }^{\left({ }^{85)}\right.}$ observouse que as variáveis antropométricas, especialmente a estatura, são as mais consideradas, seguidas das capacidades cognitivas e habilidades técnicas. Dedicação, aspectos psicológicos, capacidades condicionais e maturação, destacados na literatura como importantes nesse processo, foram pouco citados pelos entrevistados. Dessa forma, contrapondo a ideia principal do vigente estudo, bem como de outros trabalhos ${ }^{(42,86)}$, o estágio de maturação biológica da criança não foi levado em consideração.

Dados semelhantes foram encontrados na pesquisa de Neris et al. ${ }^{(87)}$, os autores não escolheram os jovens para as modalidades esportivas de acordo com suas características morfológicas; porém, o seu objetivo principal foi verificar que $\mathrm{o}$ desenvolvimento locomotor, manipulativo e a aptidão física fazem relação direta com o esporte treinado, ou seja, a criança entre 7 e 10 anos, desenvolve melhor padrões de movimentos utilizados no esporte que prática, assim como os padrões menos utilizados, são menos desenvolvidos.

Interessante ressaltar que, o baixo número amostral do grupo precoce reflete a realidade maturacional desse grupo particular de desportivas: as ginastas. Um estudo longitudinal que comparou 81 ginastas, 60 nadadores e 81 tenistas entre os oito e os 19 anos de idade, verificou que nadadores e tenistas entravam em Tanner 2 para mama e

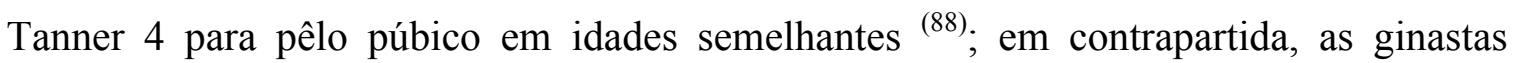
entravam nesse estágio cinco mais tardiamente, sugerindo que o crescimento é mais lento em ginastas que em tenistas ou nadadores durante esse último período de maturação sexual. Embora essa avaliação não tenha sido radiológica, de uma forma geral, sabe-se que o desenvolvimento pubertário decorre de acordo com a idade óssea.

Quando comparados os resultados de maturação biológica entre meninos e meninas, independente da prática desportiva, estas apresentam uma maturação mais precoce quando comparada àqueles. Esses dados foram sustentados no estudo de Machado e Barbanti ${ }^{(89)}$, cujo objeto de estudo foi a comparação entre os sexos, da idade 
óssea (IO), em 233 escolares de 9 a 16 anos (fem=109; masc=114). A IO foi determinada por radiografia de punho e mão. Os resultados mostraram que a IO foi em média maior que a IC e com maior variabilidade no sexo feminino: o sexo feminino estava mais maduro que o sexo masculino em todas as idades. Por isso a importância e relevância do vigente trabalho com o sexo feminino e dos melhores resultados terem sido aqueles encontrados no GM, o qual levou em consideração o treinamento segundo a idade biológica.

O treinamento sistematizado e personalizado, como aquele realizado pelo GM, mostrou nos resultados apresentados superioridade em relação aos demais grupos, principalmente ao GC. A avaliação da importância da atividade física programada foi objeto de estudo de Farias et al. ${ }^{(90)}$. Os autores verificaram o efeito do controle dessa atividade sobre os testes de aptidão física em escolares adolescentes durante um ano de período letivo. A amostra foi composta de 383 alunos, divididos em dois grupos: grupo experimental (GE), com 186 (96 meninos e 90 meninas) e controle (GC), com 197 (108 meninos e 89 meninas), com idade entre 10 e 15 anos. O desempenho motor verificado nos três testes analisados (flexibilidade, força e resistência) não apresentou melhora significativa quando envolveu a variável tempo do pré para o pós-teste, em ambos os grupos, mas quando comparado (tipo) o GE com o GC, mostrou diferença significativa $(\mathrm{p}<0,05)$ com melhora nos testes de força e resistência em ambos os sexos para o GE.

Além da vantagem, ressaltada no GM, a presente pesquisa também observou, em alguns momentos, a melhora significativa $(p<0,05)$ de grupos "precoce" em relação aos "normal" e "tardio". Esses dados são sustentados aos achados de Lima et al. ${ }^{(91)}$, os quais inferiram que indivíduos em estágios púberes e pós-púberes podem apresentar vantagens no desempenho esportivo, momentaneamente, sobre indivíduos de mesma idade cronológica que estão no estágio tardio. No entanto, deve-se atentar para que indivíduos no estágio tardio não sejam excluídos do processo de seleção e promoção do talento esportivo por não apresentarem sucesso competitivo na mesma idade cronológica que um atleta precoce. Dessa forma, a maturação sexual deve ser levada em consideração, mas indivíduos tardios não devem ser excluídos do processo de formação sem que haja uma avaliação mais criteriosa sobre todas as variáveis de crescimento, desenvolvimento, maturação e treinamento desportivo.

Contrapondo os achados do vigente trabalho e de Lima et al. ${ }^{(91)}$, Bojikian et al. (92) observaram a idade de menarca e de início de treinamento, de atletas de destaque no 
voleibol feminino brasileiro (79 atletas pertencentes às seleções brasileiras infantojuvenil, juvenil e adulta, e mais três equipes adultas). Nos resultados foi verificado que as atletas de maior nível de desempenho apresentaram a idade de menarca e de início no treinamento tardia, concluindo que a especialização precoce não é o caminho mais indicado para o sucesso.

Dessa forma, após a discussão dos resultados, pôde-se observar, como limitação deste trabalho, a carência na comunidade científica de artigos voltados a faixa etária de 8 e 9 anos, pois grande parte da literatura tem o foco na avaliação da maturação biológica, porém, na fase da puberdade, o que restringe a discussão dos achados da vigente pesquisa. Semelhantemente, em relação à originalidade do treinamento "maturacional", não se encontram estudos nas principais bases de dados (pub med, scielo, CINAHAL, embase, LILACS) para a análise comparatória. O que foi encontrado, a fim de realizar uma comparação em paralelo, foi a importância do treinamento personalizado, sistematizado e com o alcance de valências específicas, sendo levadas em consideração no programa estruturado ${ }^{(93-95)}$. 
AVALIAÇÃO DOS EFEITOS DE DUAS METODOLOGIAS DE FORMAÇÃO ESPORTIVA EM DISTINTOS NÍVEIS DE MATURAÇÃO BIOLÓGICA SOBRE AS QUALIDADES FÍSICAS DE PRATICANTES DE GINÁSTICA RÍTMICA DE 8 E 9 ANOS

\section{CAPÍTULO VII - CONCLUSÕES}




\section{CAPÍTULO VII - CONCLUSÕES}

O Esporte é um fator de grande importância para a formação dos indivíduos, devido às contribuições que trazem ao desenvolvimento nos aspectos maturacionais, tanto biológicos quanto psicossociais. No entanto, para que os benefícios proporcionados pela prática esportiva não sejam transformados em influências negativas, é necessário que ela seja devidamente adequada à idade de seus praticantes, afim de que não exista nenhum tipo de alteração dos padrões maturacionais. $\mathrm{Na}$ adolescência, esses cuidados devem ser ainda mais reforçados, devido à grande vulnerabilidade do período. Todas as modalidades possuem suas vantagens e desvantagens, tanto do ponto de vista do desenvolvimento como da maturação.

O caso da Ginástica Artística, geralmente condenada pelas conseqüências morfológicas que gera nas suas praticantes, deve ser analisado atentamente. Não se pode condenar a modalidade analisando-a superficialmente, portanto, os aspectos maturacionais dos ginastas, apesar de terem um padrão próprio, estão de acordo com o que lhes é exigido na modalidade, principalmente do ponto de vista morfológico.

Infelizmente, na maioria dos clubes onde se trabalha com treinamento e competição na infância e adolescência, há uma busca de resultados competitivos desde as categorias menores, o que leva treinadores, às vezes, a selecionarem um(a) jovem de maturação precoce por estar, no momento da seleção, mais adiantado(a) em tamanho e condições de força, em detrimento daquele(a) que é mais tardio(a) e, portanto, vai demorar um pouco mais para alcançar resultados.

Após a discussão dos resultados, chama-se a atenção para o fato de que é importante que a idade biológica seja considerada nos processo de seleção de atletas e que não sejam excluídas do processo de formação, atletas de maturação tardia, ainda que essas não apresentem resultados de desempenho tão precocemente quanto às demais. Esse desenvolvimento atrasado do grupo tardio, em relação ao grupo precoce, também foi evidenciado nos achados deste estudo.

Este trabalho indica que são pouco conhecidas as inter-relações entre crescimento, desenvolvimento físico e maturação das crianças brasileiras entre 8 e 9 anos. Carece-se de informações também quanto às relações entre idade biológica e os picos de velocidade de crescimento físico. 
Por causa das mudanças em importantes parâmetros para o treinamento físico, pela maturação, a seleção de crianças e adolescentes para a atividade desportiva não se deve fundamentar apenas na idade cronológica, mas, sobretudo, na maturação sexual, visando à melhor avaliação física e o treinamento apropriado para essa população. Essa afirmação pôde ser confirmada após a apresentação dos resultados, os quais revelaram melhora significativa no grupo submetido ao treinamento maturacional, quando comparado seus valores no pós-teste e com os demais grupos, principalmente o grupo controle, levando a recusar a hipóstese nula $\left(\mathrm{H}_{0}\right)$.

A utilização da idade óssea, para a determinação de idade biológica, foi eficiente e satisfatória, dada à sua grande sensibilidade e precisão nas medidas, relatadas na literatura. Assim, sua utilização é recomendada quando se pretende maior precisão na determinação de idade biológica, muito embora as comparações metodológicas com outros recursos devam ser evitadas. 
AVALIAÇÃO DOS EFEITOS DE DUAS METODOLOGIAS DE FORMAÇÃO ESPORTIVA EM DISTINTOS NÍVEIS DE MATURAÇÃO BIOLÓGICA SOBRE AS QUALIDADES FÍSICAS DE MENINOS DE 10 a 13 ANOS.

\section{REFERÊNCIAS BIBLIOGRÁFICAS}




\section{REFERÊNCIAS BIBLIOGRÁFICAS}

1. Gaio R. Ginástica Rítmica “ Popular”: uma proposta educacional. 2 ed. Jundiaí: Fontoura; 2007.

2. Velardi M. Ginástica Rítmica: A necessidade de novos modelos Pedagógicos. Campinas: Papirus; 1999.

3. Vieira RMM. O fenômeno da expressão na ginástica rítmica desportiva. . São Paulo: Ibrasa; 1989. 29-40 p.

4. Delev M. The nest of the Golden birds. World Rhytmic Gymnastics Championship. Bulgária: Varna; 1987.

5. Ginástica CBD. Regras oficias de ginástica rítmica desportiva. Rio de Janeiro: Palestra; 2004.

6. Rossete EFC. O julgamento na ginástica rítmica desportiva. Minas Gerais: Universidade Federal de Minas Gerais; 1994.

7. Laffranchi B. Treinamento desportivo aplicado à ginástica rítmica: UNOPAR; 2001 .

8. Alonso H, editor. Meu corpo, minha cultura, minha Ginástica Rítmica. 2004.

9. Pallarés Z. Ginástica Rítmica. Porto Alegre: Prodil; 1993.

10. Nunomura M, Carrara PDS, Carbinatto MV. Análise dos objetivos dos técnicos na Ginástica Artística. Motriz: Revista de Educação Física. 2010;16(1):95-102.

11. Nunomura M. Ginástica Educacional ou Ginástica Olímpica. Motriz. 1998;4(1):65-8.

12. Molinari AMP. Ginástica Rítmica: Esporte, História e Desenvolvimento: Cooperativa do Fitness; 2004.

13. Oliveira V, Paes RR. A pedagogia da iniciação esportiva: um estudo sobre o ensino dos jogos desportivos coletivos. Revista digital. 2004;10(71). 
14. Ducati M. O treinamento desportivo na ginástica artística: uma análise do discurso infantil. 2008.

15. Vargas Neto FX. A iniciação nos esportes e os riscos de uma especialização precoce. Revista Perfil. 2010;3:70-6.

16. Samulski D. Psicologia do esporte: teoria e aplicação prática. Universidad Federal de Mina Gerais; 1992.

17. Ginástica FId. Código de Pontuação de Ginástica Rítmica. 2005. 1 p.

18. Santos S, Dantas L, Oliveira JA. Desenvolvimento motor de crianças, de idosos e de pessoas com transtornos da coordenação. Rev Paul Educ Fís. 2004;18:3344.

19. Peuker I, editor. Ginástica moderna sem aparelhos. 1973: Forum.

20. Burns EMN, Lerner RE, Standish M. História da Civilização Ocidental, do Homem das Cavernas as Naves Espaciais. M tD, editor. São Paulo Ed. Globo; 1993. $444 \mathrm{p}$.

21. Schmid A. Gymnastique rytmique sportive. Paris: Vigot; 1978. 17-25 p.

22. Langlade A, Langlade NRD. Teoria general de la gimanasia. Buenos Aires Stadium; 1970. 161-6 p.

23. Ramos VP, Romeral MTN. Los pioneiros: la gimnasia natural. Gimansia Rítmica1984.

24. Langlade A, Langlade AL. Teoría general de la gimnasia: Editorial Stadium SRL; 1986.

25. Bizzocchi LAG, Guimarães MDS. Manual de ginástica rítmica desportiva. São Paulo: Leme. 1985;1.

26. Le Camus C. La gymnastique rythmique sportive et sa valeur éducative: Vrin; 1982.

27. Schmid A. Gymnastique rytmique sportive. Paris: Vigot; 1978. 161-6 p. 
28. Crauze I. História da ginástica rítmica desportiva. In: CONFEDERAÇÃO BRASILEIRA DE GINÁSTICA. . GRD. Cdp, editor. Rio de Janeiro: Palestra Edições Esportivas; 1984.

29. Róbeva N, Rankélova M, de Moura G. Escola de campeãs: ginástica rítmica desportiva: Icone; 1991.

30. Barbosa-Rinald IP, Martineli TAP, Teixeira RTS. Ginástica Rítmica: História, características e elementos corporais. Maringá2008. 49-56 p.

31. Viebig RF, Polpo AN, Corrêa PH. Ginástica Rítmica na infância e adolescência: características e necessidades nutricionais. História. 2006;1:1.

32. Weineck J, Carvalho BMR, Barbanti VJ. Treinamento ideal: instruções técnicas sobre o desempenho fisiológico, incluindo considerações específicas de treinamento infantil e juvenil: Manole; 2003.

33. Gallahue DL, Ozmun JC, Araújo MASP, de Medeiros Ribeiro J, e Silva JPS. Compreendendo o desenvolvimento motor: bebês, crianças, adolescentes e adultos: Phorte; 2005.

34. Barbanti VJ. Treinamento físico: bases científicas. São Paulo: CLR Balieiro. 1996.

35. Schimidtbleicher D. O treino da força e da potência em atletas de alto rendimento Lisboa: Universidade Técnica de Lisboa: Faculdade de Motricidade Humana.; 1996. 161-6 p.

36. Tibeau C. Ensino da Ginástica Rítmica Desportiva pelo método global: Viabilidade e Eficácia. São Paulo. 1988.

37. Oliveira AR. Um estudo sobre os fatores influenciadores na iniciação esportiva precoce da criança. Semina: Ciências Sociais e Humanas. 2011;15(3):308-15.

38. Malina RM, Bouchard C, Rocha CA, de Mello LSF. Atividade física do atleta jovem: do crescimento à maturação: Editora Roca; 2002. 
39. Caçola P. A iniciação esportiva na ginástica rítmica. Revista Brasileira de Educação Física, Esporte, Lazer e Dança. 2007;2(1):9-15.

40. Fonseca Junior SJ, Dantas PMS, Fernades Filho J. Antropometria, composição corporal, somatotipo e qualidades físicas básicas em escolares nos períodos pré e pós-menarca. Arquivos em Movimento. 2009;5(1):45-60.

41. Freitas D, Silva C, Maia J, Beunen G, Lefevre J, Claessens A, et al. Maturação biológica, prática desportiva e somatótipo de crianças e jovens madeirenses dos 10 aos 16 anos. Rev Port Ciên Desp. 2004;4(3):66-75.

42. Linhares RV, Matta MO, Lima JRP, Dantas PMS, Costa MB, Fernades Filho J. Efeitos da maturação sexual na composição corporal, nos dermatóglifos, no somatótipo e nas qualidades físicas básicas de adolescentes. Arq Bras Endocrinol Metab. 2009;53(1):47-54.

43. Malina RM, Cumming SP, Morano PJ, Barron M, Miller SJ. Maturity status of youth football players: a noninvasive estimate. Medicine \& Science in Sports \& Exercise. 2005;37(6):1044.

44. Haiter Neto F, Almeida SM, Leite CC. Estudo comparativo dos métodos de estimativa da idade óssea de Greulich \& Pyle e Tanner \& Whitehouse. Revista Brasileira de Medicina do Esporte. 2000;10 (1):16-23.

45. Bee H, Veronese MAV, Pereira ACA. A criança em desenvolvimento. São Paulo: Artmed; 2003.

46. Platonov VN, Bulatova MM. A preparação física: Sprint; 2003.

47. Platonov VN, Pinto RS. Teoria geral do treinamento desportivo olímpico: Artmed; 2004.

48. Pellegrini AM, Samuel de Souza N, Bueno FCR, Alleoni BN, Motta AI. Desenvolvendo a coordenação motora no ensino fundamental. São Paulo: UNESP. 2005.

49. Lopes VP, Maia JAR, Silva R, Morais F. Estudo do nível de desenvolvimento da coordenação motora da população escolar (6 a 10 anos de idade) da Região 
Autónoma dos Açores. Revista Portuguesa de Ciências do Desporto ISSN. 2003:1645-0523.

50. Dantas EHM. A prática da preparação física. Rio de Janeiro: Shape, 2003.

51. Bompa TO. Treinamento total para jovens campeões. São Paulo: Manole; 2002.

52. Serbescu C, Flora D, Hantiu I, Greene D, Benhamou CL, Courteix D. Effect of a six-month training programme on the physical capacities of Romanian schoolchildren. Acta Paediatrica. 2006;95(10):1258-65.

53. Silva Dantas P. Relação entre estado e predisposição genética no futsal brasileiro: tese]. Natal: Universidade Federal do Rio Grande do Norte; 2004.

54. Caetano MJD, Silveira CRA, Gobbi LTB. Desenvolvimento motor de préescolares no intervalo de 13 meses. Rev Bras Cineantropom Desempenho Hum. 2005;7(2):05-13.

55. Dias RMR, Cyrino ES, Salvador EP, Nakamura FY, Pina FLC, Oliveira AR. Impacto de oito semanas de treinamento com pesos sobre a força muscular de homens e mulheres. Rev Bras Med Esporte. 2005;11(4):224-8.

56. Benetti G, Schneider P, Meyer F. Os benefícios do esporte ea importância da treinabilidade da força muscular de pré-púberes atletas de voleibol. Revista Brasileira de Cineantropometria e Desempenho Humano. 2005;7(2):87-93.

57. Mascarenhas LPG, Stabelini Neto A, Bozza R, Campos W. Comportamento do consumo máximo de oxigênio e da composição corporal durante o processo maturacional em adolescentes do sexo masculino participantes de treinamento de futebol; Comportment of maximal oxygen consumption and body composition during the maturational stages in male adolescents participants of soccer training. Rev bras ciênc mov. 2006;14(2):49-56.

58. Tubino MJG. Metodologia científica do treinamento desportivo: Ibrasa; 2003.

59. Fleck SJ, Kraemer WJ, Ribeiro JL. Fundamentos do treinamento de força muscular: Artmed; 2006. 
60. Badillo JJG, Ayestarán EG, dos Santos Dornelles M. Fundamentos do treinamento de força: aplicação ao alto rendimento desportivo. . Porto Alegre: Artmed; 2001.

61. Hollmann W, Hettinger T. Medicina de esporte. Editora manole; 1983.

62. de Araújo CGS, de Araújo DSMS. Flexiteste: utilização inapropriada de versões condensadas. 2004.

63. Alter MJ. Alongamento para os Esportes: Editora Manole Ltda; 1999.

64. Hamill J, Knutzen KM, Ribeiro LB, Barbanti VJ. Bases biomecânicas do movimento humano: Manole; 2008.

65. Dantas EHM. Flexibilidade: alongamento e flexionamento. Rio de Janeiro: Shape; 2005.

66. da Silva SB, Daniel JF, Siqueira F, Correa R, Da Silva LS. Avaliação física em meninas participantes do projeto Segundo Tempo da cidade de Ameicana-SP. Conexões. 2008;6(Especial):1-10.

67. Antualpa KF. Ginástica Rítmica e contorcionismo: primeiras aproximações [ Trabalho de conclusão de curso (graduação)]. Campinas: Universidadampinase Estadual de C; 2005.

68. Thomas JR, Nelson JK, Silverman SJ. Métodos de pesquisa em atividade física. Porto Alegre: Artmed; 2007.

69. Barreto A, Ribeiro L. Determinação do tamanho amostral. Fitness e Performance Journal. 2004;3(3):124.

70. Saúde CNd. Resolução 196/96: Critérios sobre pesquisas envolvendo seres humanos 1996.

71. Mundial AM. Declaração de Helsinque. $41^{\mathrm{a}}$ Assembléia Médica Mundial, Hong Kong. 1989. 
72. Marfell-Jones TOM, Stewart A, Carter L. International standards for anthropometric assessment: International Society for the Advancement of Kinanthropometry.; 2006.

73. Greulich WW, Pyle SI. Radiographic atlas of skeletal development of the hand and wrist. Stanford Univ Pr.1959. 1902 p.

74. Dantas E, Carvalho J, Fonseca R. O protocolo LABIFIE de goniometria. Revista Treinamento Desportivo. 1997;2(3):21-34

75. Johnson BL, Nelson JK. Practical Measurements for Evaluation in Physical Education 1969.

76. Arruda GA, Pianca HJC, Oliveira AR. Correlação do teste de 1RM com aspectos maturacionais, neuromotores, antropométricos ea composição corporal em crianças e adolescentes; Correlation between the 1RM test and maturational, neuromotor, anthropometric aspects and body composition in children and adolescents. Rev bras med esporte. 2011;17(3):179-83.

77. Portal MND, SILVA JB, Saraiva A. Avaliação dos Efeitos do Treinamento em crianças futebolistas da Vila Olímpica da Mangueira. Revista de Desporto e Saúde. 2008:47-54.

78. Ribeiro LG, Portal MND, da Silva JB, Saraiva A, da Cruz Monte Jr G, Dantas EHM. Effects of Two Modes of Exercise Training on Physical Fitness of 10 Year-Old Children. Biomedical Human Kinetics. 2010;2:4.

79. Silva DAS, Oliveira A. Impacto da maturação sexual na força de membros superiores e inferiores em adolescentes. Rev Bras Cineantropom Desempenho Hum. 2010;12(3):144-50.

80. Tanner JM, Whitehouse R, Takaishi M. Standards from birth to maturity for height, weight, height velocity, and weight velocity: British children, 1965. I. Archives of Disease in Childhood. 1966;41(219):454-71.

81. Boato EM. Henri Wallon e a deficiência múltipla: uma proposta de intervenção pedagógica. Brasilia: Hildebrando; 2003. 107 p. 
82. Valdivia AB, Cartagena LC, Sarria NE, Távara IS, Seabra A, Silva R, et al. Coordinación Motora: influencia de la edad, sexo, estatus socio-económico y niveles de adiposidad en ninõs Peruanos. Revista Brasileira de Cineantropometria \& Desempenho Humano, Florianópolis. 2008;10(1):25-34.

83. Lopes V, Maia JAR. Actividade física, recreio escolar e desenvolvimento motor: estudos exploratórios em crianças do 1.0 ciclo do ensino básico. . Criança. DMeEd, editor. Portugal.2006.

84. Deus RK, Bustamante A, Lopes VP, Seabra A, Silva R, Maia JAR. Coordenação motora: um estudo de tracking em crianças dos 6 aos 10 anos da Região Autónoma dos Açores, Portugal. 2008.

85. Silva Filho FJ, Luguetti CN, Paes FO, Böhme MTS. Critérios para detecção e seleção de jovens atletas de basquetebol na cidade de São Paulo. REMEFERevista Mackenzie de Educação Física e Esporte. 2012;10(2).

86. da Silva Pinto IC, de Arruda IKG, da Silva Diniz A, de Souza Cavalcanti AMT. Prevalência de excesso de peso e obesidade abdominal, segundo parâmetros antropométricos, e associação com maturação sexual em adolescentes escolares Prevalence of overweight and abdominal obesity. Cad saúde pública. 2010;26(9):1727-37.

87. Neris KCF, Tkac CM, Braga RK. A influência das diferentes práticas esportivas no desenvolvimento motor em crianças. Acta Brasleira do Movimento HumanoRevista de Educação Física. 2012;2(1):58-64.

88. Erlandson MC, Sherar LB, Mirwald RL, Maffulli N, Baxter-Jones ADG. Growth and maturation of adolescent female gymnasts, swimmers, and tennis players. Medicine \& Science in Sports \& Exercise. 2008;40(1):34.

89. Machado D, Barbanti VJ. Maturação esquelética e crescimento em crianças e adolescentes. São Paulo Rev Bras Cineantropometria e Desempenho Humano. 2007;9(1):12-20.

90. Farias ES, de Carvalho WRG, Gonçalves EM, Guerra-Júnior G. Efeito da atividade física programada sobre a aptidão física em escolares adolescentes. 
Revista Brasileira de Cineantropometria e Desempenho Humano. 2010;12(2):98-105.

91. Lima DA, Estrada LFG, Massa M, Hirota VB. A maturação sexual ea idade cronológica durante um processo de detecção, seleção e promoção do talento esportivo nas categorias de base do futebol de campo. REMEFE-Revista Mackenzie de Educação Física e Esporte. 2009;7(3).

92. Bojikian JCM, Oliveira da Silva AV, Pires LC, de Lima DA, Bojikian LP. Talento esportivo no voleibol feminino do Brasil: maturação e iniciação esportiva. REMEFE-Revista Mackenzie de Educação Física e Esporte. 2009;6(3).

93. Ingle L, Sleap M, Tolfrey K. The effect of a complex training and detraining programme on selected strength and power variables in early pubertal boys. Journal of sports Sciences. 2006;24(9):987-97.

94. Matthews BL, Bennell KL, Mckay HA, Khan KM, Baxter-Jones ADG, Mirwald $\mathrm{RL}$, et al. The influence of dance training on growth and maturation of young females: a mixed longitudinal study. Annals of Human Biology. 2006;33(3):34256.

95. McKay H, Tsang G, Heinonen A, MacKelvie K, Sanderson D, Khan K. Ground reaction forces associated with an effective elementary school based jumping intervention. British journal of sports medicine. 2005;39(1):10-4. 
AVALIAÇÃO DOS EFEITOS DE DUAS METODOLOGIAS DE FORMAÇÃO ESPORTIVA EM DISTINTOS NÍVEIS DE MATURAÇÃO BIOLÓGICA SOBRE AS QUALIDADES FÍSICAS DE MENINOS DE 10 a 13 ANOS.

ANEXOS 
ANEXO I

Comitê de Ética em Pesquisa 
FUNDAÇAO PUBLICA ESTADUAL

HOSPITAL DE CLÍNICAS GASPAR VIANNA

GERENCIA DE ENSINO E PESQUISA

COMITÊ DE ÉTICA EM PESQUISA/

Trav. Alferes Costas $\mathrm{s} / \mathrm{n}^{\circ}$ - Bairro: Pedreira

CEP:66.087.660 - FAX: (91) 4005-2676

Belém, 01 de julho de 2011

\section{PARECER DE ÉTICA DE PROJETO DE PESQUISA ENVOLVENDO SERES HUMANOS}

\section{Protocolo: $N^{\circ} 031 / 2011$ - CEP/FHCGV}

2. Projeto de Pesquisa: "Avaliação dos efeitos de duas metodologias de formação esportiva em distintos níveis de maturação biológica sobre as qualidades físicas de praticantes de ginástica rítmica de 08 a 09 anos"

3. Pesquisador Responsável: Maria Francisca de Souza Bordalo

4. Instituição/Unidade: Secretaria de Estado de Esporte e Lazer do Pará

5. Data de Entrada: 01/03/2011

6. Data do $1^{\circ}$ Parecer: $23 / 03 / 2011$

7. Data da entrada da $1^{\text {a }}$ correção: 06/04/2011

8. Data do $2^{\circ}$ Parecer: 02/05/2011

9. Data de entrada da $2^{\circ}$ Correção: 17/06/2011

10. Data do Parecer Final: 30/06/2011

PARECER: O Comitê de Ética em Pesquisa da FHCGV analisou o Projeto supra-citado de acordo com as normas da Resolução 196/96 CNS/MS, e conforme parecer datado de 30/06/2011, verificpou-se que as recomendações solicitadas foram todas atendidas. Portanto, manifesta-se por sua aprovação.

PARECER: APROVADO

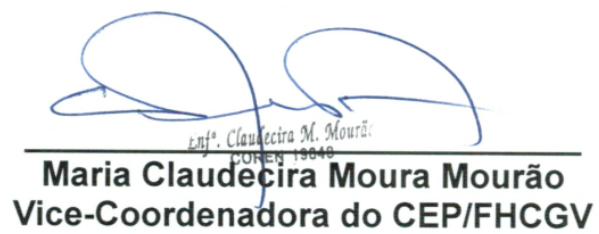

ATENÇÃO: Cabe ao pesquisador responsável elaborar e apresentar a este Comitê de Ética os relatórios parcial (a cada seis meses) e final da pesquisa supracitada, conforme resolução $n^{\circ}$ 196/10, inciso IX, letra "c" do Conselho Nacional de Saúde/MS. 
ANEXO II

METODOLOGIA DE FORMAÇÃO

ESPORTIVA TRADICIONAL 
QUADRO DE ATIVIDADES DA METODOLOGIA TRADICIONAL PARTE PRINCIPAL

\begin{tabular}{|c|c|c|}
\hline AULA & TEMA & ATIVIDADE \\
\hline 1 & Conhecimentos sobre o corpo & Exame biométrico \\
\hline 2 & Conhecimentos sobre o corpo & Formas variadas de aquecimento \\
\hline 3 & Conhecimentos sobre o corpo & Aquecimentos específicos muscular \\
\hline 4 & Conhecimentos sobre o corpo & Conhecimento corporal, varias de andar e correr \\
\hline 5 & Conhecimentos sobre o corpo & \\
\hline 6 & Movimentos básicos da Ginástica & Andar, correr, saltitar e saltar \\
\hline 7 & Movimentos locomotores & Várias formas básicas de andar \\
\hline 8 & Movimentos locomotores & Várias formas básicas de andar \\
\hline 9 & Movimentos locomotores & Várias formas básicas de correr \\
\hline 10 & Movimentos locomotores & Várias formas básicas de correr \\
\hline 11 & Movimentos locomotores & Várias formas básicas de saltitar \\
\hline 12 & Movimentos locomotores & Várias formas básicas de saltitar \\
\hline 13 & Movimentos locomotores & Várias formas básicos de saltar \\
\hline 14 & Movimentos locomotores & Várias formas básicas de saltar \\
\hline 15 & Movimentos estabilizadores & Movimentos de circundação do tronco \\
\hline 16 & Movimentos estabilizadores & Movimento estático lateral do tronco \\
\hline 17 & Movimentos estabilizadores & Movimento de flexão do tronco para frente \\
\hline 18 & Movimento estabilizadores & Movimentos de extenção e flexão dos pés \\
\hline 19 & Flexibilidade & Alongamento dos grupos musculares \\
\hline 20 & Flexibilidade & $\begin{array}{l}\text { Aquecimentos das articulação e flexibilidade } \\
\text { dos braços }\end{array}$ \\
\hline 21 & Flexibilidade & Exercícios variados: Flexibilidade dos braços \\
\hline 22 & Flexibilidade & $\begin{array}{c}\text { Exercícios Variados: Flexibilidade dos braços e } \\
\text { tronco }\end{array}$ \\
\hline 23 & Flexibilidade & Ondas e movimentos do tronco \\
\hline 24 & Flexibilidade & Exercícios variados: flexão de pernas e tronco \\
\hline 25 & Flexibilidade & Exercícios variados: flexão do tronco \\
\hline 26 & Saltos & Exercícios de saltos em varias direções \\
\hline 27 & Saltos & Saltos em vários deslocamentos \\
\hline 28 & Saltos & Vários saltos básicos da ginástica \\
\hline 29 & Coordenação & Exercícios de formas coreográficas \\
\hline 30 & Atividades rítmicas e expressivas & Exercícios de formas coreográficas \\
\hline 31 & Atividades rítmicas e expressivas & Exercícios com acompanhamento musical \\
\hline 32 & Atividades rítmicas e expressivas & $\begin{array}{l}\text { Coreografias e sequências de séries dos } \\
\text { aparelhos }\end{array}$ \\
\hline
\end{tabular}


METODOLOGIA DE FORMAÇÃO

ESPORTIVA MATURACIONAL 
QUADRO DE ATIVIDADES METODOLOGIA MATURACIONAL

PARTE PRINCIPAL

\begin{tabular}{|c|c|c|}
\hline AULA & QUALIDADE FÍSICA & ATIVIDADE \\
\hline 1 & Coordenação e flexibilidade & $\begin{array}{l}\text { Imitar o chefe, cesta de frutas,pira cola- } \\
\text { americana }\end{array}$ \\
\hline 2 & Coordenação e flexibilidade & $\begin{array}{l}\text { Corre cotia,caminhar para frente para trás em } \\
\text { linha reta.subir e descer pequenos obstáculos. }\end{array}$ \\
\hline 3 & Coordenação e flexibilidade & $\begin{array}{c}\text { Corrida com obstáculos,caminhar de diversas } \\
\text { maneiras: na ponta dos pés, sobre os } \\
\text { calcanhares. }\end{array}$ \\
\hline 4 & Força, coordenação e flexibilidade & $\begin{array}{l}\text { Correio dos estados,caminhar imitando o } \\
\text { movimento de diferentes animais como: } \\
\text { cavalo, coelho, urso, sapo etc. }\end{array}$ \\
\hline 5 & Coordenação, flexibilidade e força & $\begin{array}{l}\text { Amarelinha, Imite a cobra, porre-corre, o } \\
\text { rodeio,livrar-se das bolas. }\end{array}$ \\
\hline 6 & $\begin{array}{l}\text { Coordenação, f lexibilidade, força explosiva e } \\
\text { Agilidade. }\end{array}$ & $\begin{array}{l}\text { Achar o par e Imite o chefe, bola no aro, jogo } \\
\text { capturando, jogo capturando por pares. }\end{array}$ \\
\hline 7 & Coordenação, flexibilidade e força explosiva & $\begin{array}{l}\text { pira cócoras, pira cola americana, passa a bóia } \\
\text { (estafeta), volta ao mundo, pará cabrito. }\end{array}$ \\
\hline 8 & Coordenação, flexibilidade, e agilidade & $\begin{array}{l}\text { Pira cola alta, bola ao paredão,capturando } \\
\text { com ilhas e corre cabrito. }\end{array}$ \\
\hline 9 & $\begin{array}{l}\text { Coordenação, força explosiva, flexibilidade, } \\
\text { velocidade. }\end{array}$ & $\begin{array}{l}\text { Bandeirinha, Bola difícil, Cabo de guerra, O } \\
\text { mestre mandou }\end{array}$ \\
\hline 10 & Coordenação, força explosiva e flexibilidade. & $\begin{array}{c}\text { Capturando com ilhas, animais e seus } \\
\text { alimentos, bolinhas, como ganhar balas, o } \\
\text { mestre mandou }\end{array}$ \\
\hline 11 & Coordenação, força explosiva e flexibilidade. & $\begin{array}{c}\text { O mar e os peixes, aniversário do mês, esta de } \\
\text { anjo, a caça das raposas. }\end{array}$ \\
\hline 12 & $\begin{array}{l}\text { Coordenação, força explosiva, flexibilidade, } \\
\text { velocidade e agilidade }\end{array}$ & O labirinto, o mar e o peixes, sela, pac man. \\
\hline 13 & Coordenação, força explosiva e flexibilidade & $\begin{array}{l}\text { A pesca, aracatu, arca de noé, quem pega o } \\
\text { bombom, imitando objetos }\end{array}$ \\
\hline 14 & Coordenação, força explosivae flexibilidade. & $\begin{array}{c}\text { Capturem a fita, argolas coloridas, pula pula, } \\
\text { contorcionismo. }\end{array}$ \\
\hline 15 & Coordenação, força explosiva e flexibilidade. & $\begin{array}{l}\text { A pesca ,arranca rabo, pula corda, alonga na } \\
\text { corda, pegar o ladrão e contorcionismo. }\end{array}$ \\
\hline 16 & Coordenação, força explosiva e flexibilidade. & $\begin{array}{l}\text { Roubando as bolas, ataque contra defesa } \\
\text { futebol, quem salta mais alto, imite os animais } \\
\text { se espreguiçando, pira mãe }\end{array}$ \\
\hline 17 & Coordenação, força explosiva e flexibilidade & $\begin{array}{l}\text { Pega cabrito, aumenta - aumenta, } \\
\text { contorcionismo, pira ajuda. }\end{array}$ \\
\hline 18 & Coordenação, força explosiva e flexibilidade. & $\begin{array}{l}\text { Pegar ladrão, pula corda, passa a corda, } \\
\text { alcança a corda. }\end{array}$ \\
\hline 19 & Coordenação, força explosiva e flexibilidade. & $\begin{array}{l}\text { Roubando as bolas, bobinho gigante, estique } \\
\text { o boneco, estafeta de dupla. }\end{array}$ \\
\hline 20 & Coordenação, força explosiva e flexibilidade. & $\begin{array}{l}\text { Pira cola americana, barata assustada, a pesca, } \\
\text { o mar e os peixes, mãe da rua. }\end{array}$ \\
\hline 21 & Coordenação, força explosiva e flexibilidade. & $\begin{array}{l}\text { Bola na cesta ,barbante maluco, barra } \\
\text { manteiga, volta ao mundo, canguru saltitante }\end{array}$ \\
\hline 23 & Coordenação, flexibilidade, velocidade e agilidade & $\begin{array}{l}\text { Perseguição em pernas de pau, beisebol, o } \\
\text { gavião e os pintinhos, Imite o chefe. }\end{array}$ \\
\hline 24 & $\begin{array}{l}\text { Coordenação, flexibilidade, força explosiva e } \\
\text { agilidade }\end{array}$ & $\begin{array}{l}\text { Os caranguejos caseiros, batata quente, } \\
\text { carimbo, Imitando o bichos se espreguiçarem. }\end{array}$ \\
\hline 25 & Coordenação, flexibilidade e força explosiva. & $\begin{array}{l}\text { O túnel, bola numerada, balança caixão, } \\
\text { estafeta de dupla, vamos espreguiçar. }\end{array}$ \\
\hline 26 & Coordenação, flexibilidade, e força explosiva. & $\begin{array}{l}\text { Bola numerada, quatro cantos, boca de forno, } \\
\text { caracol, dance dance, contorcionismo. }\end{array}$ \\
\hline 27 & Coordenação,, força explosiva e Flexibilidade. & $\begin{array}{c}\text { Bola ao túnel, bola ao alto, Xô preguiça, jogo } \\
\text { a onda, bola capitã. }\end{array}$ \\
\hline
\end{tabular}




\begin{tabular}{|c|l|c|}
\hline 28 & Coordenação, força explosiva e flexibilidade. & $\begin{array}{c}\text { Jogo pegando as bolas, corrida por grupos, } \\
\text { bola ao guarda e contorcionismo. }\end{array}$ \\
\hline 29 & Flexibilidade, força explosiva e coordenação & $\begin{array}{c}\text { Mar agitado, bola caçadora, circuito com } \\
\text { bancos suecos e trocando de árvores. }\end{array}$ \\
\hline 30 & $\begin{array}{l}\text { Flexibilidade, velocidade, coordenação e força } \\
\text { explosiva. }\end{array}$ & $\begin{array}{c}\text { Casinha de cachorro, vem ou correr, luta com } \\
\text { as plantas do pé e imagem refletida. }\end{array}$ \\
\hline 31 & Flexibilidade, força explosiva e flexibilidade. & $\begin{array}{c}\text { Canguru (estafeta)luta de tração, } \\
\text { deslocamento com varas, resgate e } \\
\text { contorcionismo. }\end{array}$ \\
\hline & $\begin{array}{l}\text { Flexibilidade, velocidade, força explosiva e } \\
\text { coordenação. }\end{array}$ & $\begin{array}{c}\text { A roda, livra-se das bolas, caça fantasma, } \\
\text { contorcionismo e Imite o chefe }\end{array}$ \\
\hline
\end{tabular}




\section{ANEXO IV}

QUADRO DOS DADOS BRUTOS COLHIDOS 
TARDIO PRÉ- 8 ANOS

\begin{tabular}{|c|c|c|c|c|c|c|c|c|}
\hline SUJEITO & IDADE & Peso & Estat & Potên & Coor & AAO & FCL & RX \\
\hline GT PRÉ & 8 & 20,5 & 1,18 & 15 & 20 & 114 & 25 & 7 \\
\hline GT PRÉ & 8 & 24 & 1,19 & 16 & 23 & 110 & 23 & 7 \\
\hline GT PRÉ & 8 & 29 & 1,27 & 16 & 21 & 115 & 21 & 7 \\
\hline GT PRÉ & 8 & 26 & 1,21 & 14 & 19 & 113 & 19 & 7 \\
\hline GT PRÉ & 8 & 30 & 1,29 & 16 & 19 & 110 & 25 & 7 \\
\hline GT PRÉ & 8 & 27,5 & 1,34 & 20 & 12 & 114 & 21 & 7 \\
\hline GT PRÉ & 8 & 22,5 & 1,24 & 27 & 22 & 110 & 23 & 7 \\
\hline GT PRÉ & 8 & 20,5 & 1,17 & 19 & 14 & 112 & 20 & 6 \\
\hline GM PRÉ & 8 & 25,5 & 1,35 & 18 & 17 & 113 & 22 & 7 \\
\hline GM PRÉ & 8 & 24 & 1,31 & 15 & 14 & 110 & 23 & 7 \\
\hline GM PRÉ & 8 & 25,5 & 1,25 & 15 & 21 & 120 & 25 & 7 \\
\hline GM PRÉ & 8 & 26 & 123 & 17 & 18 & 116 & 21 & 7 \\
\hline GM PRÉ & 8 & 23 & 1,27 & 15 & 15 & 113 & 23 & 7 \\
\hline GC PRÉ & 8 & 22 & 1,25 & 18 & 17 & 115 & 24 & 7 \\
\hline GC PRÉ & 8 & 26 & 1,23 & 16 & 20 & 114 & 20 & 6 \\
\hline GC PRÉ & 8 & 25,5 & 1,2 & 19 & 21 & 118 & 22 & 7 \\
\hline
\end{tabular}

TARDIO PÓS 8 ANOS

\begin{tabular}{|c|c|c|c|c|c|c|c|c|}
\hline SUJEITO & IDADE & Peso & Estat & Potên & Coor & AAO & FCL & RX \\
\hline GT PRÉ & 8 & 21 & 1,19 & 16 & 21 & 115 & 26 & 7 \\
\hline GT PRÉ & 8 & 25 & 1,24 & 16 & 20 & 114 & 23 & 7 \\
\hline GT PRÉ & 8 & 31 & 1,31 & 18 & 20 & 112 & 27 & 7 \\
\hline GT PRÉ & 8 & 24 & 1,26 & 29 & 25 & 112 & 24 & 7 \\
\hline GT PRÉ & 8 & 22 & 1,20 & 21 & 16 & 114 & 22 & 6 \\
\hline GM PRÉ & 8 & 26 & 1,26 & 22 & 27 & 126 & 30 & 7 \\
\hline GC PRÉ & 8 & 22 & 1,26 & 19 & 18 & 116 & 25 & 7 \\
\hline GC PRÉ & 8 & 27 & 1,24 & 18 & 22 & 116 & 21 & 6 \\
\hline GC PRÉ & 8 & 27 & 1,22 & 21 & 23 & 120 & 24 & 7 \\
\hline
\end{tabular}


NORMAL PRÉ 08 ANOS

\begin{tabular}{|c|c|c|c|c|c|c|c|c|}
\hline SUJEITO & IDADE & Peso & Estat & Potên & Coor & AAO & FCL & RX \\
\hline GT PRÉ & 8 & 22,5 & 1,22 & 18 & 22 & 110 & 27 & 8 \\
\hline GT PRÉ & 8 & 23 & 1,21 & 19 & 25 & 114 & 24 & 8 \\
\hline GT PRÉ & 8 & 26 & 1,26 & 17 & 23 & 117 & 22 & 8 \\
\hline GT PRÉ & 8 & 25 & 1,23 & 15 & 18 & 114 & 20 & 8 \\
\hline GT PRÉ & 8 & 27 & 1,28 & 18 & 20 & 113 & 26 & 8 \\
\hline GM PRÉ & 8 & 26 & 1,29 & 21 & 15 & 110 & 23 & 8 \\
\hline GM PRÉ & 8 & 24 & 1,26 & 24 & 20 & 110 & 25 & 8 \\
\hline GM PRÉ & 8 & 23 & 1,25 & 22 & 17 & 116 & 21 & 8 \\
\hline GM PRÉ & 8 & 22,5 & 1,23 & 18 & 18 & 113 & 22 & 8 \\
\hline GM PRÉ & 8 & 26 & 1,22 & 20 & 21 & 114 & 20 & 8 \\
\hline GM PRÉ & 8 & 28 & 1,21 & 17 & 22 & 115 & 24 & 8 \\
\hline GM PRÉ & 8 & 25,5 & 1,24 & 20 & 24 & 116 & 23 & 8 \\
\hline GM PRÉ & 8 & 27,5 & 1,23 & 21 & 23 & 112 & 25 & 8 \\
\hline GM PRÉ & 8 & 24,5 & 1,23 & 24 & 21 & 110 & 27 & 8 \\
\hline GM PRÉ & 8 & 26 & 1,24 & 23 & 20 & 113 & 23 & 8 \\
\hline GC PRÉ & 8 & 25 & 1,25 & 21 & 22 & 115 & 20 & 8 \\
\hline GC PRÉ & 8 & 24 & 1,26 & 17 & 21 & 114 & 21 & 8 \\
\hline GC PRÉ & 8 & 29 & 1,25 & 18 & 24 & 117 & 24 & 8 \\
\hline GC PRÉ & 8 & 27 & 1,27 & 20 & 20 & 112 & 22 & 8 \\
\hline GC PRÉ & 8 & 26 & 1,24 & 22 & 22 & 119 & 21 & 8 \\
\hline GC PRÉ & 8 & 21 & 1,21 & 17 & 25 & 115 & 26 & 8 \\
\hline GC PRÉ & 8 & 30 & 1,29 & 21 & 21 & 114 & 27 & 8 \\
\hline GC PRÉ & 8 & 28 & 1,26 & 20 & 23 & 113 & 21 & 8 \\
\hline GC PRÉ & 8 & 24 & 1,25 & 23 & 22 & 110 & 20 & 8 \\
\hline GC PRÉ & 8 & 23 & 1,24 & 21 & 25 & 116 & 22 & 8 \\
\hline GC PRÉ & 8 & 26 & 1,26 & 22 & 24 & 115 & 25 & 8 \\
\hline GC PRÉ & 8 & 24 & 1,23 & 24 & 23 & 114 & 24 & 8 \\
\hline GC PRÉ & 8 & 23 & 1,24 & 23 & 20 & 118 & 20 & 8 \\
\hline GC PRÉ & 8 & 25 & 1,26 & 22 & 23 & 113 & 22 & 8 \\
\hline GC PRÉ & 8 & 27 & 1,27 & 26 & 22 & 112 & 23 & 8 \\
\hline
\end{tabular}


NORMAL PÓS 08 ANOS

\begin{tabular}{|c|c|c|c|c|c|c|c|c|}
\hline SUJEITO & IDADE & Peso & Estat & Potên & Coor & $\mathrm{AAO}$ & FCL & $\mathrm{RX}$ \\
\hline GT PRÉ & 8 & 23 & 1,24 & 19 & 23 & 112 & 28 & 8 \\
\hline GT PRÉ & 8 & 24 & 1,22 & 20 & 27 & 115 & 25 & 8 \\
\hline GT PRÉ & 8 & 26,5 & 1,28 & 18 & 25 & 119 & 24 & 8 \\
\hline GT PRÉ & 8 & 26,5 & 1,25 & 16 & 19 & 115 & 21 & 8 \\
\hline GT PRÉ & 8 & 28 & 1,29 & 19 & 21 & 114 & 27 & 8 \\
\hline GT PRÉ & 8 & 25 & 1,24 & 20 & 22 & 115 & 25 & 8 \\
\hline GT PRÉ & 8 & 23 & 1,25 & 20 & 22 & 114 & 24 & 8 \\
\hline GT PRÉ & 8 & 26 & 1,23 & 21 & 23 & 115 & 25 & 8 \\
\hline GM PRÉ & 8 & 27 & 1,31 & 29 & 24 & 117 & 32 & 8 \\
\hline GM PRÉ & 8 & 24 & 1,28 & 33 & 28 & 118 & 33 & 8 \\
\hline GM PRÉ & 8 & 24,5 & 1,26 & 29 & 27 & 124 & 30 & 8 \\
\hline GM PRÉ & 8 & 23 & 1,24 & 27 & 29 & 120 & 32 & 8 \\
\hline GM PRÉ & 8 & 27 & 1,23 & 28 & 30 & 121 & 32 & 8 \\
\hline GM PRÉ & 8 & 26,5 & 1,25 & 27 & 30 & 123 & 29 & 8 \\
\hline GM PRÉ & 8 & 28 & 1,24 & 30 & 31 & 124 & 32 & 8 \\
\hline GM PRÉ & 8 & 25 & 1,24 & 32 & 31 & 118 & 31 & 8 \\
\hline GM PRÉ & 8 & 26,5 & 1,25 & 31 & 29 & 120 & 36 & 8 \\
\hline GM PRÉ & 8 & 26 & 1,26 & 30 & 31 & 123 & 30 & 8 \\
\hline GM PRÉ & 8 & 25 & 1,27 & 28 & 30 & 125 & 28 & 8 \\
\hline GM PRÉ & 8 & 30 & 1,26 & 29 & 32 & 124 & 30 & 8 \\
\hline GM PRÉ & 8 & 28 & 1,28 & 29 & 29 & 123 & 33 & 8 \\
\hline GM PRÉ & 8 & 27 & 1,25 & 30 & 31 & 128 & 31 & 8 \\
\hline GC PRÉ & 8 & 22 & 1,22 & 19 & 27 & 116 & 32 & 8 \\
\hline GC PRÉ & 8 & 31,5 & 1,30 & 23 & 23 & 116 & 28 & 8 \\
\hline GC PRÉ & 8 & 29 & 1,27 & 21 & 24 & 114 & 29 & 8 \\
\hline GC PRÉ & 8 & 25 & 1,26 & 24 & 24 & 112 & 22 & 8 \\
\hline GC PRÉ & 8 & 25 & 1,25 & 23 & 26 & 118 & 23 & 8 \\
\hline GC PRÉ & 8 & 28 & 1,27 & 24 & 26 & 118 & 24 & 8 \\
\hline GC PRÉ & 8 & 25 & 1,24 & 25 & 25 & 116 & 27 & 8 \\
\hline GC PRÉ & 8 & 24 & 12,5 & 24 & 22 & 120 & 26 & 8 \\
\hline GC PRÉ & 8 & 26 & 1,26 & 23 & 24 & 114 & 23 & 8 \\
\hline GC PRÉ & 8 & 28 & 1,27 & 27 & 24 & 114 & 23 & 8 \\
\hline GC PRÉ & 8 & 28 & 1,28 & 26 & 25 & 113 & 24 & 8 \\
\hline GC PRÉ & 8 & 27 & 1,29 & 28 & 26 & 110 & 25 & 8 \\
\hline GC PRÉ & 8 & 25 & 1,28 & 29 & 24 & 109 & 24 & 8 \\
\hline GC PRÉ & 8 & 23 & 1,24 & 28 & 23 & 110 & 22 & 8 \\
\hline GC PRÉ & 8 & 24 & 1,30 & 32 & 30 & 111 & 25 & 8 \\
\hline
\end{tabular}


PRECOCE PRÉ 8 ANOS

\begin{tabular}{|c|c|c|c|c|c|c|c|c|}
\hline SUJEITO & IDADE & Peso & Estat & Potên & Coor & AAO & FCL & RX \\
\hline GT PRÉ & 8 & 25,5 & 1,24 & 18 & 25 & 116 & 27 & 9 \\
\hline GT PRÉ & 8 & 23 & 1,25 & 17 & 22 & 113 & 24 & 9 \\
\hline GT PRÉ & 8 & 26 & 1,23 & 19 & 23 & 115 & 22 & 9 \\
\hline GT PRÉ & 8 & 24,5 & 1,24 & 15 & 21 & 116 & 23 & 9 \\
\hline GT PRÉ & 8 & 23 & 1,26 & 16 & 24 & 117 & 25 & 9 \\
\hline GT PRÉ & 8 & 22 & 1,27 & 18 & 23 & 114 & 20 & 9 \\
\hline GT PRÉ & 8 & 25 & 1,23 & 17 & 26 & 113 & 21 & 10 \\
\hline GM PRÉ & 8 & 26 & 1,22 & 19 & 25 & 110 & 24 & 9 \\
\hline GM PRÉ & 8 & 24 & 1,21 & 16 & 23 & 112 & 27 & 10 \\
\hline GM PRÉ & 8 & 25,5 & 1,25 & 19 & 25 & 111 & 21 & 10 \\
\hline GM PRÉ & 8 & 23 & 1,23 & 17 & 26 & 120 & 20 & 9 \\
\hline GM PRÉ & 8 & 25 & 1,26 & 18 & 24 & 117 & 22 & 9 \\
\hline GC PRÉ & 8 & 26 & 1,27 & 19 & 25 & 118 & 26 & 9 \\
\hline GC PRÉ & 8 & 27 & 1,21 & 21 & 21 & 117 & 24 & 10 \\
\hline
\end{tabular}

PRECOCE PÓS 8 ANOS

\begin{tabular}{|c|c|c|c|c|c|c|c|c|}
\hline SUJEITO & IDADE & Peso & Estat & Potên & Coor & AAO & FCL & RX \\
\hline GT PRÉ & 8 & 26 & 1,26 & 20 & 26 & 117 & 28 & 7 \\
\hline GT PRÉ & 8 & 24 & 1,27 & 19 & 24 & 115 & 26 & 7 \\
\hline GT PRÉ & 8 & 28 & 1,25 & 20 & 25 & 117 & 24 & 7 \\
\hline GT PRÉ & 8 & 26 & 1,26 & 17 & 23 & 118 & 25 & 7 \\
\hline GT PRÉ & 8 & 24 & 1,28 & 18 & 27 & 119 & 27 & 7 \\
\hline GT PRÉ & 8 & 27 & 1,25 & 19 & 28 & 115 & 23 & 7 \\
\hline GT PRÉ & 8 & 23 & 1,29 & 20 & 27 & 116 & 23 & 7 \\
\hline GM PRÉ & 8 & 28 & 1,23 & 25 & 31 & 121 & 30 & 7 \\
\hline GM PRÉ & 8 & 25 & 1,22 & 23 & 30 & 120 & 35 & 7 \\
\hline GM PRÉ & 8 & 26 & 1,27 & 26 & 33 & 118 & 30 & 7 \\
\hline GM PRÉ & 8 & 24 & 1,25 & 26 & 34 & 128 & 28 & 7 \\
\hline GM PRÉ & 8 & 27 & 1,27 & 25 & 32 & 124 & 30 & 7 \\
\hline GC PRÉ & 8 & 27 & 1,28 & 27 & 33 & 126 & 32 & 7 \\
\hline GC PRÉ & 8 & 28 & 1,22 & 29 & 29 & 127 & 30 & 7 \\
\hline
\end{tabular}


TARDIO PRÉ - 9 ANOS

\begin{tabular}{|c|c|c|c|c|c|c|c|c|}
\hline SUJEITO & IDADE & Peso & Estat & Potên & Coor & AAO & FCL & RX \\
\hline GT PRÉ & 9 & 23 & 1,26 & 23 & 25 & 118 & 26 & 8 \\
\hline GT PRÉ & 9 & 23 & 1,27 & 24 & 27 & 119 & 27 & 8 \\
\hline GT PRÉ & 9 & 24,5 & 1,30 & 22 & 26 & 120 & 28 & 8 \\
\hline GT PRÉ & 9 & 25 & 1,25 & 20 & 27 & 122 & 27 & 8 \\
\hline GT PRÉ & 9 & 25 & 1,27 & 23 & 28 & 117 & 26 & 8 \\
\hline GT PRÉ & 9 & 24,5 & 1,30 & 20 & 25 & 120 & 25 & 8 \\
\hline GT PRÉ & 9 & 23 & 1,28 & 24 & 26 & 119 & 24 & 8 \\
\hline GC PRÉ & 9 & 24 & 1,27 & 23 & 27 & 121 & 23 & 7 \\
\hline GM PRÉ & 9 & 25,5 & 1,30 & 23 & 26 & 120 & 27 & 7 \\
\hline GM PRÉ & 9 & 26 & 1,32 & 24 & 25 & 122 & 26 & 8 \\
\hline GM PRÉ & 9 & 26 & 1,36 & 22 & 28 & 121 & 25 & 8 \\
\hline GM PRÉ & 9 & 25,5 & 1,32 & 21 & 29 & 120 & 24 & 8 \\
\hline GM PRÉ & 9 & 26,5 & 1,40 & 20 & 30 & 119 & 25 & 8 \\
\hline GC PRÉ & 9 & 24 & 1,32 & 23 & 26 & 120 & 26 & 8 \\
\hline
\end{tabular}

TARDIO PÓS - 9 ANOS

\begin{tabular}{|c|c|c|c|c|c|c|c|c|}
\hline SUJEITO & IDADE & Peso & Estat & Potên & Coor & AAO & FCL & RX \\
\hline GT PRÉ & 8 & 23 & 1,20 & 17 & 23 & 117 & 25 & 7 \\
\hline GT PRÉ & 8 & 27 & 1,30 & 17 & 23 & 116 & 26 & 7 \\
\hline GT PRÉ & 8 & 25 & 1,24 & 18 & 22 & 115 & 24 & 7 \\
\hline GT PRÉ & 8 & 24 & 1,31 & 20 & 25 & 114 & 26 & 7 \\
\hline GT PRÉ & 8 & 28 & 1,35 & 21 & 25 & 113 & 27 & 7 \\
\hline GT PRÉ & 8 & 26 & 1,30 & 20 & 23 & 118 & 26 & 6 \\
\hline GM PRÉ & 8 & 30 & 1,39 & 26 & 29 & 123 & 30 & 6 \\
\hline GM PRÉ & 8 & 29 & 1,40 & 28 & 30 & 124 & 32 & 7 \\
\hline GC PRÉ & 8 & 27 & 1,25 & 22 & 26 & 128 & 26 & 7 \\
\hline GC PRÉ & 8 & 27 & 1,26 & 24 & 27 & 127 & 28 & 6 \\
\hline
\end{tabular}


NORMAL PRÉ - 9 ANOS

\begin{tabular}{|c|c|c|c|c|c|c|c|c|}
\hline SUJEITO & IDADE & Peso & Estat & Potên & Coor & AAO & FCL & RX \\
\hline GT PRÉ & 9 & 30 & 1,29 & 17 & 20 & 115 & 27 & 9 \\
\hline GT PRÉ & 9 & 33 & 1,32 & 18 & 25 & 118 & 29 & 9 \\
\hline GT PRÉ & 9 & 35 & 1,30 & 17 & 24 & 113 & 28 & 9 \\
\hline GT PRÉ & 9 & 30,5 & 1,35 & 18 & 23 & 117 & 26 & 9 \\
\hline GT PRÉ & 9 & 33 & 1,43 & 17 & 25 & 116 & 29 & 9 \\
\hline GT PRÉ & 9 & 35 & 1,44 & 17 & 24 & 114 & 27 & 9 \\
\hline GT PRÉ & 9 & 32 & 1,46 & 15 & 22 & 113 & 27 & 9 \\
\hline GT PRÉ & 9 & 32,5 & 1,44 & 18 & 23 & 117 & 27 & 9 \\
\hline GM PRÉ & 9 & 30 & 1,46 & 20 & 28 & 116 & 27 & 9 \\
\hline GM PRÉ & 9 & 31 & 1,50 & 19 & 27 & 118 & 28 & 9 \\
\hline GM PRÉ & 9 & 35 & 1,49 & 23 & 29 & 117 & 28 & 9 \\
\hline GM PRÉ & 9 & 33 & 1,52 & 25 & 28 & 116 & 26 & 9 \\
\hline GM PRÉ & 9 & 32,5 & 1,53 & 26 & 27 & 118 & 27 & 9 \\
\hline GM PRÉ & 9 & 31 & 1,55 & 28 & 28 & 116 & 29 & 9 \\
\hline GM PRÉ & 9 & 31,5 & 1,53 & 29 & 26 & 118 & 30 & 9 \\
\hline GM PRÉ & 9 & 33,5 & 1,55 & 27 & 25 & 117 & 32 & 9 \\
\hline GC PRÉ & 9 & 32 & 1,30 & 18 & 26 & 113 & 30 & 9 \\
\hline GC PRÉ & 9 & 34 & 1,30 & 19 & 27 & 114 & 31 & 9 \\
\hline GC PRÉ & 9 & 35 & 1,42 & 20 & 25 & 115 & 34 & 9 \\
\hline GC PRÉ & 9 & 30 & 1,40 & 21 & 23 & 116 & 32 & 9 \\
\hline GC PRÉ & 9 & 31 & 1,39 & 21 & 22 & 116 & 26 & 9 \\
\hline GC PRÉ & 9 & 32 & 1,43 & 20 & 27 & 115 & 29 & 9 \\
\hline GC PRÉ & 9 & 33 & 1,40 & 19 & 26 & 114 & 25 & 9 \\
\hline GC PRÉ & 9 & 31,5 & 1,52 & 18 & 25 & 115 & 27 & 9 \\
\hline GC PRÉ & 9 & 31,5 & 1,41 & 17 & 23 & 117 & 26 & 9 \\
\hline GC PRÉ & 9 & 32 & 1,38 & 17 & 22 & 114 & 28 & 9 \\
\hline GC PRÉ & 9 & 34 & 1,29 & 18 & 20 & 113 & 29 & 9 \\
\hline GC PRÉ & 9 & 33 & 1,35 & 19 & 21 & 115 & 30 & 9 \\
\hline
\end{tabular}


NORMAL PÓS - 9 ANOS

\begin{tabular}{|c|c|c|c|c|c|c|c|c|}
\hline SUJEITO & IDADE & Peso & Estat & Potên & Coor & AAO & FCL & RX \\
\hline GT PRÉ & 8 & 30 & 1,30 & 19 & 22 & 117 & 27 & 8 \\
\hline GT PRÉ & 8 & 33 & 1,32 & 17 & 24 & 115 & 28 & 8 \\
\hline GT PRÉ & 8 & 35 & 1,40 & 20 & 25 & 116 & 26 & 8 \\
\hline GT PRÉ & 8 & 32 & 1,35 & 23 & 20 & 118 & 29 & 8 \\
\hline GT PRÉ & 8 & 29 & 1,38 & 24 & 21 & 119 & 30 & 8 \\
\hline GT PRÉ & 8 & 30 & 1,45 & 19 & 23 & 120 & 31 & 8 \\
\hline GT PRÉ & 8 & 31 & 1,43 & 21 & 23 & 117 & 27 & 8 \\
\hline GT PRÉ & 8 & 32 & 1,28 & 23 & 22 & 118 & 28 & 8 \\
\hline GT PRÉ & 8 & 31 & 1,29 & 22 & 20 & 115 & 27 & 8 \\
\hline GT PRÉ & 8 & 30 & 1,30 & 24 & 21 & 118 & 28 & 8 \\
\hline GM PRÉ & 8 & 35 & 1,50 & 25 & 26 & 120 & 30 & 8 \\
\hline GM PRÉ & 8 & 36 & 1,40 & 27 & 27 & 119 & 32 & 8 \\
\hline GM PRÉ & 8 & 34 & 1,42 & 29 & 25 & 121 & 33 & 8 \\
\hline GM PRÉ & 8 & 33,5 & 1,39 & 30 & 26 & 120 & 34 & 8 \\
\hline GM PRÉ & 8 & 35 & 1,40 & 32 & 25 & 122 & 36 & 8 \\
\hline GM PRÉ & 8 & 36 & 1,45 & 33 & 24 & 123 & 37 & 8 \\
\hline GM PRÉ & 8 & 37 & 1,47 & 34 & 26 & 124 & 38 & 8 \\
\hline GM PRÉ & 8 & 34 & 1,48 & 32 & 24 & 125 & 40 & 8 \\
\hline GM PRÉ & 8 & 35 & 1,48 & 31 & 25 & 128 & 39 & 8 \\
\hline GM PRÉ & 8 & 36 & 1,42 & 30 & 26 & 130 & 39 & 8 \\
\hline GC PRÉ & 8 & 29 & 1,30 & 21 & 24 & 116 & 26 & 8 \\
\hline GC PRÉ & 8 & 30 & 1,29 & 22 & 25 & 117 & 27 & 8 \\
\hline GC PRÉ & 8 & 28 & 1,27 & 23 & 23 & 115 & 26 & 8 \\
\hline GC PRÉ & 8 & 29 & 1,28 & 21 & 26 & 116 & 25 & 8 \\
\hline GC PRÉ & 8 & 31 & 1,26 & 23 & 24 & 115 & 26 & 8 \\
\hline GC PRÉ & 8 & 30 & 1,27 & 23 & 22 & 116 & 26 & 8 \\
\hline GC PRÉ & 8 & 29 & 1,30 & 22 & 23 & 117 & 27 & 8 \\
\hline GC PRÉ & 8 & 28 & 1,30 & 24 & 24 & 115 & 27 & 8 \\
\hline GC PRÉ & 8 & 30 & 1,28 & 25 & 23 & 116 & 28 & 8 \\
\hline GC PRÉ & 8 & 30 & 1,29 & 23 & 21 & 116 & 27 & 8 \\
\hline GC PRÉ & 8 & 30 & 1,30 & 22 & 22 & 118 & 27 & 8 \\
\hline GC PRÉ & 8 & 31 & 1,27 & 21 & 23 & 117 & 27 & 8 \\
\hline GC PRÉ & 8 & 29 & 1,30 & 20 & 23 & 116 & 26 & 8 \\
\hline
\end{tabular}


PRECOCE PRÉ - 9 ANOS

\begin{tabular}{|c|c|c|c|c|c|c|c|c|}
\hline SUJEITO & IDADE & Peso & Estat & Potên & Coor & AAO & FCL & RX \\
\hline GT PRÉ & 9 & 26 & 1,27 & 20 & 26 & 118 & 28 & 10 \\
\hline GT PRÉ & 9 & 26,5 & 1,26 & 19 & 26 & 117 & 25 & 10 \\
\hline GT PRÉ & 9 & 27 & 1,25 & 21 & 25 & 116 & 23 & 10 \\
\hline GT PRÉ & 9 & 25,5 & 1,23 & 22 & 28 & 115 & 2 & 10 \\
\hline GT PRÉ & 9 & 26 & 1,45 & 18 & 29 & 116 & 26 & 10 \\
\hline GM PRÉ & 9 & 28 & 1,43 & 19 & 25 & 117 & 22 & 10 \\
\hline GM PRÉ & 9 & 27 & 1,30 & 20 & 24 & 115 & 23 & 11 \\
\hline GM PRÉ & 9 & 26 & 1,29 & 22 & 23 & 116 & 27 & 10 \\
\hline GM PRÉ & 9 & 28 & 1,35 & 21 & 27 & 115 & 23 & 11 \\
\hline GM PRÉ & 9 & 26 & 1,50 & 23 & 22 & 116 & 25 & 10 \\
\hline GM PRÉ & 9 & 27 & 1,41 & 22 & 26 & 118 & 24 & 10 \\
\hline GM PRÉ & 9 & 26 & 1,42 & 23 & 28 & 119 & 22 & 10 \\
\hline GM PRÉ & 9 & 28 & 1,50 & 21 & 27 & 115 & 22 & 10 \\
\hline GC PRÉ & 9 & 25 & 1,48 & 20 & 26 & 115 & 27 & 11 \\
\hline GC PRÉ & 9 & 26,5 & 1,47 & 19 & 24 & 118 & 26 & 10 \\
\hline GC PRÉ & 9 & 26,5 & 1,30 & 22 & 25 & 116 & 25 & 10 \\
\hline GC PRÉ & 9 & 27 & 1,35 & 23 & 24 & 115 & 24 & 11 \\
\hline GC PRÉ & 9 & 27 & 1,35 & 23 & 25 & 117 & 23 & 11 \\
\hline GC PRÉ & 9 & 27 & 1,40 & 22 & 22 & 118 & 22 & 11 \\
\hline
\end{tabular}

PRECOCE PÓS - 9 ANOS

\begin{tabular}{|c|c|c|c|c|c|c|c|c|}
\hline SUJEITÓ & IDADE & Peso & Estat & Potên & Coor & AAO & FCL & RX \\
\hline GT PRÉ & 8 & 28 & 1,35 & 24 & 30 & 117 & 29 & 9 \\
\hline GT PRÉ & 8 & 25 & 1,55 & 26 & 29 & 118 & 29 & 9 \\
\hline GT PRÉ & 8 & 29 & 1,67 & 28 & 27 & 119 & 30 & 9 \\
\hline GT PRÉ & 8 & 30 & 1,50 & 27 & 26 & 117 & 27 & 9 \\
\hline GM PRÉ & 8 & 27 & 1,55 & 25 & 25 & 120 & 28 & 9 \\
\hline GM PRÉ & 8 & 26 & 1,56 & 24 & 24 & 119 & 26 & 9 \\
\hline GT PRÉ & 8 & 29 & 1,60 & 26 & 27 & 124 & 27 & 9 \\
\hline GM PRÉ & 8 & 33 & 1,65 & 27 & 26 & 125 & 28 & 9 \\
\hline GM PRÉ & 8 & 35 & 1,60 & 27 & 25 & 123 & 26 & 9 \\
\hline GM PRÉ & 8 & 36 & 1,65 & 28 & 24 & 122 & 27 & 9 \\
\hline GM PRÉ & 8 & 38 & 1,60 & 27 & 27 & 121 & 28 & 9 \\
\hline GM PRÉ & 8 & 38 & 1,60 & 28 & 27 & 120 & 27 & 9 \\
\hline GC PRÉ & 8 & 27 & 1,50 & 27 & 26 & 122 & 28 & 9 \\
\hline GC PRÉ & 8 & 28 & 1,55 & 25 & 25 & 121 & 29 & 9 \\
\hline GC PRÉ & 8 & 29 & 1,45 & 24 & 24 & 120 & 30 & 9 \\
\hline GC PRÉ & 8 & 30 & 1,45 & 25 & 26 & 119 & 28 & 9 \\
\hline GC PRÉ & 8 & 27 & 1,47 & 26 & 24 & 121 & 27 & 9 \\
\hline
\end{tabular}

